\title{
12h-clock control of central dogma information flow by XBP1s
}

Yinghong $\operatorname{Pan}^{1,2}$, Heather Ballance ${ }^{3}$, Yisrael Schnytzer ${ }^{5,6}, \mathrm{Xi}$ Chen $^{4}$, Oren Levy ${ }^{5}$, Cristian Coarfa ${ }^{4}$, and Bokai $\mathrm{Zhu}^{3,7+\dagger}$

${ }^{1}$ Department of Biology and Biochemistry, University of Houston, Houston, TX 77004, USA

${ }^{2}$ Present address: UPMC Genome Center, Pittsburgh, PA 15232, USA

${ }^{3}$ Aging Institute of UPMC, University of Pittsburgh School of Medicine, Pittsburgh, PA, 15219, USA

${ }^{4}$ Department of Molecular and Cellular Biology, Baylor College of Medicine, Houston, TX 77030, USA

5 The Mina \& Everard Goodman Faculty of Life Sciences, Bar-llan University, 52900 Ramat-Gan, Israel

${ }^{6}$ Present address: Marine Biological Laboratory, Woods Hole, MA, 02543, USA

7 Division of Endocrinology and Metabolism, Department of Medicine, University of Pittsburgh School of Medicine, Pittsburgh, PA, 15219, USA

${ }^{+\dagger}$ Corresponding author: bzhu@pitt.edu 


\section{ASTRACT:}

Our group recently discovered a cell-autonomous mammalian $12 \mathrm{~h}$-clock regulating physiological unfolded protein response. Xbp1s ablation impairs 12h-transcript oscillations in vitro, and we now show liver-specific deletion of XBP1s globally impaired murine $12 \mathrm{~h}$-transcriptome, but not the circadian rhythms in vivo. XBP1s-dependent $12 \mathrm{~h}$ transcriptome is enriched for transcription, mRNA processing, ribosome biogenesis, translation, and protein endoplasmic reticulum (ER)-Golgi processing/sorting in a temporal order consistent with the progressive molecular processing sequence described by the central dogma information flow (CEDIF). The 12h-rhythms of CEDIF are cell-autonomous and evolutionarily conserved in circatidal marine animals. Mechanistically, we found the motif stringency of promoter XBP1s binding sites, but not necessarily XBP1s expression, dictates its ability to drive 12h-rhythms of transcription and further identified GABP as putative novel transcriptional regulator of $12 \mathrm{~h}$-clock. We hypothesize the 12h-rhythms of CEDIF allows rush hours' gene expression and processing, with the particular genes processed at each rush hour regulated by circadian and/or tissue specific pathways. 


\section{INTRODUCTION:}

All life on earth is governed by biological rhythms that are defined as self-sustained oscillations cycling with a fixed period. Biological clocks enable organisms to keep track of the time of day and to adjust their physiology to recurring daily changes in the external environment, including nutrient and microenvironment status. Not surprisingly, lifestyle behaviors (e.g. shift work) that chronically de-regulate biological clocks are strongly associated with increased risk for a plethora of diseases, including but not limited to metabolic syndromes, cancer, sleep disorders, autoimmune diseases, brain disorders and cardiovascular diseases (Logan and McClung, 2019; Masri and SassoneCorsi, 2018; Morris et al., 2016; Paganelli et al., 2018; Roenneberg and Merrow, 2016; Zhou et al., 2016).

Our understandings of biological rhythms in mammals have expanded beyond the well-characterized circadian rhythms ( $\sim 24 \mathrm{~h}$ oscillation) in recent years through the discovery of the existence of $12 \mathrm{~h}$ rhythms in mice (Hughes et al., 2009; Zhu et al., 2018). In a seminal 2009 study, using microarray to profile high resolution temporal mouse hepatic transcriptome, the authors originally identified approximately 200 genes cycling with a dominant $12 \mathrm{~h}$ period, which are enriched in unfolded protein response (UPR) and endoplasmic reticulum (ER) stress pathway (Hughes et al., 2009). Since then, a handful of studies followed up on this initial discovery and proposed different hypothesis on the how the 12h rhythms are established (Cretenet et al., 2010; Hughes et al., 2012; Westermark and Herzel, 2013; Zhu et al., 2018). Early studies favor the hypothesis that the mammalian $12 \mathrm{~h}$ rhythms are not cell-autonomous and instead are established by the combined effects of circadian clock and fasting-feeding cues. This 
conclusion was largely based upon the findings showing the lack of cell-autonomous 12h rhythms of gene expression in forskolin-synchronized NIH3T3 cells and altered 12h rhythms of gene expression under certain feeding and circadian clock perturbation conditions (Cretenet et al., 2010; Hughes et al., 2009; Hughes et al., 2012). Alternatively, it was suggested that two circadian transcription activators or repressors appearing in anti-phase is theoretically capable of establishing $12 \mathrm{~h}$ rhythms of gene expression in a cell-autonomous manner (Westermark and Herzel, 2013). Contrary to these hypotheses, our group proposed a third scenario, whereby the mammalian $12 \mathrm{~h}$ rhythms are not only cell-autonomous, but also are established by a dedicated ' $12 \mathrm{~h}$ clock' separate from the circadian clock and function to coordinate cellular stress with metabolism (Antoulas et al., 2018; Zhu et al., 2018; Zhu et al., 2017).

Evidences supporting the existence of a cell-autonomous mammalian 12h-clock include 1) the presence of intact hepatic $12 \mathrm{~h}$ rhythms of $\mathrm{ER}$ and metabolism-related gene expression in BMAL1 knock-out and $C l o c k^{\Delta 19}$ mutant mice in vivo under freerunning conditions (Zhu et al., 2018; Zhu et al., 2017); 2) the detection of cellautonomous $12 \mathrm{~h}$ rhythms of gene expression in mouse embryonic fibroblasts (MEFs) (Zhu et al., 2018; Zhu et al., 2017); 3) 12h rhythms of gene expression and metabolism can be established in vitro after synchronization by tunicamycin or glucose depletion in a Bmal1-independent manner (Zhu et al., 2018; Zhu et al., 2017); 4) 12h rhythms of gene expression are highly conserved evolutionarily: they are found in species as divergent as crustacean, sea anemone, $C$. elegans, zebrafish and mammals including mouse and baboon (Zhu et al., 2018; Zhu et al., 2017) and 5) 12h-cycling genes arose much earlier during evolution than circadian genes (averaged evolution age of 1,143 
million years for $12 \mathrm{~h}$-cycling genes compared to 973 million years for circadian genes), implying a more ancient and distinct origin of $12 \mathrm{~h}$-clock from the circadian clock (Castellana et al., 2018).

Due to the strong enrichment of ER stress and UPR pathways in hepatic transcriptome exhibiting $12 \mathrm{~h}$ rhythms, we initially hypothesized that the mammalian $12 \mathrm{~h}-$ clock may be regulated transcriptionally by the UPR transcription factor XBP1s (Zhu et al., 2017). In agreement with this hypothesis, we previously found that siRNA-mediated knockdown of Xbp1 in MEFs severely impaired cell-autonomous $12 \mathrm{~h}$ oscillations of several genes including Eif2ak3 and Sec23b (Zhu et al., 2018; Zhu et al., 2017). While these data suggest a role of XBP1s in regulating $12 \mathrm{~h}$ rhythms of gene expression in vitro, whether XBP1s is a master transcriptional regulator of mammalian hepatic 12hclock in vivo remains unknown. In the current study, we discovered that hepatic specific deletion of $X B P 1 s$ severely impaired global hepatic $12 \mathrm{~h}$-transcriptome, without affecting the circadian clock nor fasting-feeding behavior in mice. XBP1s-dependent 12htranscriptome is enriched for transcription, mRNA processing, ribosome biogenesis, translation, and protein processing/sorting in the ER-Golgi in a temporal order consistent with the progressive molecular processing sequence described by the central dogma information flow (CEDIF) and preferentially peaks during dawn and dusk in a day. In addition, $12 \mathrm{~h}$ rhythms of CEDIF is coupled to $12 \mathrm{~h}$-rhythms of nucleotide and amino/nucleotide sugar metabolism. Importantly, the $12 \mathrm{~h}$ rhythms of CEDIF is cellautonomous and observed in serum-synchronized liver MMH-D3 cells in vitro; and evolutionarily conserved in marine animals possessing dominant circatidal clock. Mechanistically, we found the motif stringency of XBP1s binding sites, but not 
necessarily its expression, dictates its ability to drive 12h-rhythms of mRNA transcription. We further identified GA-binding protein (GABP) as a potential novel transcriptional regulator of mammalian $12 \mathrm{~h}$-clock acting downstream or in parallel with XBP1s. Based upon this evidence, we propose a vehicle-cargo hypothesis denoting the distinct functions of $12 \mathrm{~h}$ versus circadian clock: whereas the $12 \mathrm{~h}$ clock allows for elevated rush hours' gene expression and processing by controlling the global traffic capacity of the central dogma information flow (thus the vehicle), the circadian clock and/or other tissue specific pathways dictate the particular genes processed at each rush hour (thus the cargo).

\section{RESULTS:}

\section{Liver-specific deletion of XBP1 does not alter rhythmic locomotor activity nor fasting-feeding cycles in mice}

To delete XBP1 specifically in the liver, we crossed XBP1 ${ }^{\text {Flox }}$ mice $\left(\mathrm{Xbp} 1^{f / f t}\right.$ mice with loxP sites flanking exon 2 of the Xbp1 gene) (Lee et al., 2008) with Albumin-CRE transgenic mice as previously described (Olivares and Henkel, 2015). Liver-specific deletion of XBP1s was confirmed by both qPCR and western blot analysis (Figures 1AD). Consistent with previous reports (Cretenet et al., 2010; Zhu et al., 2017), robust $12 \mathrm{~h}$ rhythms of total Xbp1 as well as spliced form of Xbp1 (Xbp1s) mRNA level were observed in XBP1 ${ }^{F l o x}$, but not in XBP1 liver specific knockout $\left(\mathrm{XBP} 1^{\mathrm{LKO}}\right.$ ) mice, indicating XBP1s autoregulates its own $12 \mathrm{~h}$ rhythm of expression (Figures $1 \mathrm{~A}-\mathrm{C}$ ). We further observed a $\sim 3 \mathrm{~h}$ phase delay between the acrophases of Xbp1s (0.3h) and total Xbp1 (3.4h) (Figure 1C). 
To rule out the potential effects of liver specific ablation of XBP1s on mouse locomotor activity and/or feeding behavior, which could confound the interpretation of the transcriptome data, we subjected both $\mathrm{XBP} 1^{\mathrm{Flox}}$ and $\mathrm{XBP} 1^{L K O}$ mice to home cage and CLAMS, respectively. As shown in Figures S1A-E, liver-specific deletion of XBP1 does not alter rhythmic locomotor activity nor fasting-feeding cycles in mice.

\section{Liver-specific deletion of XBP1 does not affect the core circadian clock in mice}

To identify XBP1s-dependent oscillating transcriptome, we performed RNA-Seq analysis in the liver of $\mathrm{XBP} 1^{\text {Flox }}$ and $\mathrm{XBP} 1^{L K O}$ mice at $2 \mathrm{~h}$ interval for a total of 48 hours under constant darkness in duplicates (Table S1 and see Materials and Methods for details). All superimposed oscillations in either $\mathrm{XBP} 1^{\mathrm{Flox}}$ or $\mathrm{XBP} 1^{L K O}$ mice were identified by the newly developed eigenvalue/pencil method (Antoulas et al., 2018; Zhu et al., 2017), which unlike canonical oscillation-identification methods such as JTK_CYCLE and ARSER, does not require a pre-assignment of period range and thus allow unbiased identification of all superimposed oscillations (Antoulas et al., 2018; Zhu et al., 2017). Consistent with past findings (Zhu et al., 2017), the vast majority of oscillations identified were circadian rhythms and oscillations that cycle at the second ( 12h) and third harmonics ( $8 \mathrm{~h})$ of the circadian rhythm [due to the $2 \mathrm{~h}$ sampling frequency of the current study, only up to third harmonics can be identified with high confidence (Antoulas et al., 2018)] (Figure 1E and Table S2). To determine the false discovery rate (FDR) of the identified rhythmic transcripts, we used a permutation-based method that randomly shuffles the time label of gene expression data and subjects each of the permutation dataset to eigenvalue/pencil method as previously described (Rey et al., 2018). As expected, permutation datasets are devoid of distinct populations of 
oscillations cycling at different harmonics of the circadian rhythm (Figures S2A-B). In this way, we identified a total of 2,615 24h circadian genes with FDR of 0.05, 5,299 12h-cycling genes with FDR of 0.24 and 5,608 8h-cycling genes with FDR of 0.31 respectively (Table S3, S4 and see Materials and Methods for details) in XBP1 ${ }^{\text {Flox }}$ mice. Agreeing with past findings (Zhu et al., 2017), while the phases of circadian rhythms are evenly distributed throughout the day (Figure S3B), the phases of $\sim 12 \mathrm{~h}$ rhythms are enriched at dawn (CT0-2) and dusk (CT12-14), which is more evident for dominant oscillations (Figures $\mathrm{S} 3 \mathrm{H})$.

Of all circadian genes identified in $\mathrm{XBP} 1^{\text {Flox }}$ mice, $\sim 70 \%$ were unaffected by hepatic XBP1s ablation, which includes all known core circadian clock genes such as Arnt/1 (Bmal1), Clock, Npas2, Per1, Per2, Cry1, Cry2, Nr1d1, Nr1d2, Nfil3, Dbp and Tef (Figures 1F,G S2C). On average, comparable average gene expression and phase distribution of circadian oscillations are found between $X B P 1^{\text {Flox }}$ and $X B P 1^{L K O}$ mice (Figures S3A-C). Circadian genes not affected by hepatic XBP1s ablation are enriched in circadian rhythm and metabolic pathways (Figures S3D, E), which are the dominant biological pathways under hepatic circadian clock control (Eckel-Mahan and SassoneCorsi, 2013; Stashi et al., 2014). We further identified 798 genes, whose superimposed circadian rhythms are abolished in $\mathrm{XBP} 1^{L K O}$ mice (Figure $1 \mathrm{~F}$ ). These genes are enriched in biological pathways including RNA degradation and PI3K-AKT signaling, processes not known be under strong circadian clock control (Figure S3F, G). Further, circadian rhythms of these genes oscillate with a much smaller amplitude and are often subordinate oscillations (Figures 1F, S3G). We conjecture the circadian rhythms of these genes are likely not driven by the circadian clock and are altered as an indirect 
consequence of XBP1s ablation. Taken together, our data indicate that the liver-specific deletion of XBP1 does not affect the core circadian clock in mice.

\section{Liver-specific deletion of XBP1 globally impairs $12 \mathrm{~h}$ transcriptome, which is enriched in pathways regulating central dogma information flow}

In sharp contrast to largely intact circadian rhythms in $\mathrm{XBP} 1^{L K O}$ mice, ablation of XBP1 in the liver significantly impairs the global $12 \mathrm{~h}$ transcriptome profile (Figures $1 \mathrm{H}$, S2D). Specifically, we identified 3,311 genes (62.5\%), 1,289 genes (24.4\%) and 691 genes (13.1\%), whose superimposed $12 \mathrm{~h}$ rhythms were abolished, dampened or increased in the absence of XBP1, respectively (Figure $1 \mathrm{H})$. Subsequent Gene ontology (GO) analysis on those 4,600 (86.9\%) genes whose $12 \mathrm{~h}$ rhythms were either abolished or dampened in $\mathrm{XBP}^{L K O}$ mice revealed top enriched KEGG pathways of protein processing in the ER, RNA transport, splicesome, mRNA surveillance, protein export and ribosome biogenesis (Figures 2A, B, Table S5). In addition, we also found $12 \mathrm{~h}$ genes enriched in Golgi apparatus by using a different GO category (Figure 2B, Table S5). These enriched biological pathways are reminiscent of the progressive molecular processing sequence described by the central dogma information flow (CEDIF), namely, mRNA processing in the nucleus, ribosome biogenesis/translation in the nucleus/cytosol, protein processing and sorting in the ER/Golgi apparatus in a temporal order (Figure 2C). Importantly, we found both anabolism and catabolism pathways are enriched, suggesting an overall XBP1s-dependent 12h-rhythm of RNA and protein processing rate.

Based upon the GO analysis, we divided the XBP1s-dependent 12h-cycling CEDIF into eleven steps and carefully annotated the genes and assigned them into one of the 
eleven steps (Figure 2C). In total, we identified 114 genes involved in RNA metabolism (Figure 2C and Table S6). These genes encompass the steps of pre-mRNA cleavage and polyadenylation, pre-mRNA splicing, RNA export and mRNA degradation and nonsense-mediated mRNA decay, with prominent examples including cleavage stimulatory factor (Cstf) and cleavage and polyadenylation specificity factor (Cpsf) family members involved in pre-mRNA cleavage and polyadenylation (Mandel et al., 2008), numerous mRNA splicing factors including Sf3a1-3 and Prpf family members, small nuclear ribonucleoproteins that are part of splicesome (Maniatis and Reed, 1987) (Snrpa, Snrpd1, Snrpe), RNA export factors $N x f 1$ and $N x t 1$, multipotent gene expression regulator CCR4-NOT complex family member (Collart, 2016) (Cnot3, Cnot4, Cnot6) and exosome complex components mediating RNA degradation (Zinder and Lima, 2017) (Exosc1, Exosc3) (Figure 2C). Overall, we found the mean expression of these $12 \mathrm{~h}$ cycling RNA metabolism genes were elevated in $\mathrm{XBP} 1^{L K O}$ mice (Figure $2 \mathrm{~B}$ ).

The most dominant GO pathways whose $12 \mathrm{~h}$ rhythms are dependent on XBP1s are protein metabolism, which include a total of 170 genes (Figure $2 \mathrm{C}$ and Table S6). These pathways include ER-associated protein degradation (Edem1 and Edem3), translation initiation (eukaryotic initiation factor members), protein translocation across the ER membrane (the ER translocon Sec61 proteins), protein folding in the ER (HSP40 family members), protein glycosylation in the ER (multiple ALG members) and protein transport from ER to the Golgi (COPII subunits Sec13, Sec22 and Sec23). For these genes, the average expression was reduced in $\mathrm{XBP} 1^{L K O}$ mice (Figure $\left.2 \mathrm{~B}\right)$.

The last category includes 110 genes involved in maintaining the integrity of the structure and function of the Golgi apparatus, where additional protein and lipid 
transport and protein N-linked glycosylation also take place (Figure 2C and Table S6). Examples include golgins family members (Golga3-5) playing key roles in the stacking of Golgi cisternae (Barr and Short, 2003), and Golgi transport protein (Golt1a and Golt1b) involved in fusion of ER-derived transport vesicles with the Golgi complex (Conchon et al., 1999). For these genes, the average expression was similar between $\mathrm{XBP} 1^{\text {Flox }}$ and $\mathrm{XBP} 1^{L K O}$ mice (Figure $\left.2 \mathrm{~B}\right)$.

To determine whether nuance exists in the $12 \mathrm{~h}$ transcriptome profile of genes involved in different steps of CEDIF, we performed t-distributed Stochastic Neighbor Embedding (t-SNE) analysis on the superimposed $12 \mathrm{~h}$ transcriptome of XBP1 ${ }^{\text {Flox }}$ mice revealed by the eigenvalue/pencil method (Figure 3A). t-SNE has been extensively used in the analysis of single-cell RNA-Seq data to reveal local structure in highdimensional data and to cluster different single cells based upon their gene signature through dimension reduction (Yang et al., 2018). Here we reason that if such nuance exists, these subtle differences must be encoded by the shape of a waveform, specifically, by the different combinations of amplitude, phase, decay rate, and period information of the superimposed $12 \mathrm{~h}$ rhythms; and therefore, are likely to be revealed through the spatial clustering of genes belonging to different steps of CEDIF based upon their $12 \mathrm{~h}$ transcriptome profile. As expected, t-SNE analysis revealed that the clustering of CEDIF genes exhibits a spatial trajectory consistent with the direction of central dogma information flow (Figures 3B-C, S4A-C). This is reflected both by a gradual spatial separation of genes involved in mRNA processing, ribosome biogenesis/translation, and protein processing in the ER/Golgi (Figures 3B, S4A-B), and by a much finer spatial separation of genes involved in the different sub steps of protein 
metabolism (Figures 3C, S4C). Lastly, we found one contributing factor to the spatial gene clustering is the progressive phase delay of genes involved in mRNA processing, protein processing in the ER, and protein sorting in the Golgi, changing from CTO to CT3 and from CT12 to CT15. This progressive phase delay is consistent with the direction of central dogma information flow (Figure 3D). In sum, these data indicate a delicately-orchestrated $12 \mathrm{~h}$ rhythms of CEDIF by XBP1s.

\section{Coordinated $12 \mathrm{~h}$ rhythms of nucleotide and nucleotide/amino sugar metabolism and CEDIF}

In addition to biological pathways involved in CEDIF, we also observed statistically significant enrichment of multiple metabolic pathways in XBP1s-dependent $12 \mathrm{~h}$ genes (Figure 4A). Two notable pathways are nucleotide metabolism (purine and pyrimidine metabolism), and amino sugar and nucleotide sugar/N-glycan biosynthesis, which provide metabolite precursors for protein N-linked glycosylation in the ER and Golgi (Figures 4A-C). In particular, nine of the eleven genes encoding metabolic enzymes for de novo purine synthesis, and five of the six genes encoding enzymes for de novo pyrimidine synthesis exhibit XBP1s-dependent $12 \mathrm{~h}$ oscillation, which include ratelimiting enzymes PPAT and CAD, for purine and pyrimidine biosynthesis, respectively (Figure 4C). In addition, several genes encoding enzymes for purine salvage pathways including XDH and GDA also reveal XBP1s-dependent 12h oscillation (Figure 4C). Intriguingly, we also uncovered twelve genes encoding subunits of RNA polymerase I, II and III exhibiting XBP1s-dependent 12h rhythms (Figure 4C). To determine whether $12 \mathrm{~h}$ rhythms of hepatic metabolic enzyme expression are associated with $12 \mathrm{~h}$ hepatic metabolite oscillations, we performed post hoc analysis of a previously published high 
resolution (at $1 \mathrm{~h}$ interval for a total of 48 hours) murine hepatic metabolome dataset using the eigenvalue/pencil method (Krishnaiah et al., 2017), and found 12h oscillations of various nucleoside and nucleotide and the N-linked glycosylation precursor UDP-NAcetyl-Amino sugar (Figure 4D and Table S7).

We hypothesize that the $12 \mathrm{~h}$ rhythmic expression of genes regulating nucleotide and amino sugar/nucleotide sugar metabolism are commensurate with those regulating mRNA and protein processing, respectively (Figure 4F). To test this hypothesis, we again performed t-SNE analysis on the superimposed $12 \mathrm{~h}$ transcriptome of these four pathways. As shown in Figures 4E and S4D, we observed that genes involved in nucleotide metabolism and mRNA processing occupy largely overlapping t-SNE space, while genes involved in amino sugar/nucleotide sugar/N-glycan biosynthesis and protein processing in the ER/Golgi also reveal similar spatial clustering. Together, we discovered a coordinated $12 \mathrm{~h}$ rhythms of nucleotide and nucleotide/amino sugar metabolism and CEDIF in mouse liver (Figure 4F).

\section{Cell-autonomous $12 \mathrm{~h}$ rhythms of CEDIF and metabolism gene expression in hepatocyte and MEF}

We wondered whether the $12 \mathrm{~h}$ rhythms of CEDIF and metabolism gene expression observed in vivo are also cell-autonomous, namely, whether they can also be observed in cell culture systems deprived of systemic cues. We addressed this question first by performing a post hoc analysis of time series transcriptome of serum-synchronized murine liver MMH-D3 cell (Atwood et al., 2011). Upon examining the raw data, we observed noticeable baseline changes in most reported mRNA oscillations. Therefore, we subjected the raw data to polynomial detrend before the identification of all 
superimposed oscillations using the eigenvalue/pencil analysis (See Materials and Methods for details). Similar to what is observed in vivo, the majority of oscillations identified in MMH-D3 cells were circadian rhythms (which cycle at a slightly shorter period of 21.6h) and oscillations that cycle at the second ( 10.8h) and third harmonics ( 7.3h) of the circadian rhythm, although more oscillations cycling with periods in between were observed in vitro compared to in vivo (Figures S5A, B, Table S8). Genes with circadian oscillations were enriched in biological pathways of circadian rhythm and HIF-1 signaling and include core circadian clock genes such as Bmal1, Clock, Nr1d1, Nr1d2 and Per1 (Figures S5C-E, Table S8), consist with past findings (Adamovich et al., 2017; Atwood et al., 2011; Peek et al., 2017; Wu et al., 2017).

Enriched biological pathways associated with $\sim 12 \mathrm{~h}$ genes (9.5h to 12.5h) in MMH-D3 cells reveal large convergence with those found in mouse liver in vivo, including all CEDIF pathways: mRNA processing (splicesome and mRNA surveillance pathways), translation and protein metabolism (ribosome, ubiquitin-mediated proteolysis, protein processing in the ER, SNARE interactions in vesicular transport, protein export) and Golgi apparatus (Figures 5A,B and Table S9). In total, 228 12h-cycling CEDIF genes were commonly found in mouse liver in vivo and $\mathrm{MMH}-\mathrm{D} 3$ cells in vitro (Figures $5 \mathrm{C}, \mathrm{D}$ and Table S10) and representative genes were shown in Figures 5G and S5G, which also include the $12 \mathrm{~h}$ oscillation of total Xbp1 mRNA expression. After converting the time post serum shock into CT time, we further observed a similar bimodal phase distribution of those 12h-cycling CEDIF genes at dawn and dusk (Figure 5E). For the other 273 12h-cycling CEDIF genes only found in MMH-D3 cells in vitro, they often represent different members of the same gene family as found in vivo (Figures $5 \mathrm{C}$ and 
$\mathrm{S} 5 \mathrm{H}) . \mathrm{t}-\mathrm{SNE}$ analysis on the $12 \mathrm{~h}$ transcriptome of MMH-D3 CEDIF genes reveal spatial separation of mRNA processing genes with those regulating protein processing (Figures $5 \mathrm{~F}$ and $\mathrm{S} 5 \mathrm{~F})$, in line with in vivo findings.

To determine whether XBP1s also transcriptionally regulates $12 \mathrm{~h}$ rhythms of CEDIF gene expression independently from the circadian clock in vitro, we knocked down Xbp1 or Bmal1 using siRNA and performed $\mathrm{qPCR}$ in dexamethasone or tunicamycinsynchronized MEFs as previously described (Zhu et al., 2017). In agreement with the unaffected core circadian clock in XBP1 ${ }^{L K O}$ mice liver, knocking down Xbp1 has no effects on dexamethasone-synchronized circadian oscillations of Per2 and Reverba (Nr1d1) expression, whose rhythms are nonetheless significantly impaired by Bmal1 knock down as expected (Figure S5I). In tunicamycin-synchronized MEFs, robust $12 \mathrm{~h}$ rhythms of both total and spliced Xbp1 expression were observed, with a similar $\sim 3.5 \mathrm{~h}$ phase difference found between the two as in vivo (Figures $5 \mathrm{H}$ and $1 \mathrm{C}$ ). We further observed Xbp1s-dependent $12 \mathrm{~h}$ rhythmic expression of genes involved in different steps of CEDIF (Sf3a1 in pre-mRNA splicing, Srp72 in protein translocation across ER membrane, Ero1/b in protein folding in the ER, Tmed7 in protein transport in the cisGolgi network), as well purine de novo synthesis gene Paics. These $12 \mathrm{~h}$ rhythms are not affected by Bmal1 knock down (Figures $5 \mathrm{H}$ and S5J). These evidence strongly support the existence of cell-autonomous $12 \mathrm{~h}$ rhythms of CEDIF and metabolism gene expression.

\section{GABP as putative novel transcription regulators of mammalian $12 \mathrm{~h}$ rhythm}

$\mathrm{XBP1s}$ is known to act as a basic region leucine zipper (bZIP) transcription factor activating gene expression by binding to gene regulatory regions harboring consensus 
DNA sequence GCCACGT under ER stress condition (Chen et al., 2014; He et al., 2010; Kanemoto et al., 2005). Since hepatic XBP1s expression exhibits a $12 \mathrm{~h}$ rhythm under physiological conditions without exogenous ER stress at both the mRNA and protein level (Figures 1A-C) (Cretenet et al., 2010; Zhu et al., 2017), we performed hepatic XBP1s ChIP-seq (at a 4 h interval for a total of 48 hours) to globally profile its cistrome under constant darkness condition and identified a total of 3,129 high confidence binding sites (See Materials and Methods for details) (Figure 6A and Table S11). Consistent with its oscillating expression, XBP1s cistrome cycles with a $12 \mathrm{~h}$ period, with peak binding observed at CT0, CT12, CT24 and CT36 (Figures 6A, C, S6D, $\mathrm{F})$.

Motif analysis on 1000bp DNA region surrounding XBP1s peak center did not reveal enriched motifs associated with core circadian clock transcription factors, which is supported by very limited overlap of XBP1s cistrome with those of BMAL1, CLOCK, CRY1, CRY2, NPAS2, PER1, PER2, REV-ERBa, REV-ERBß and RORa (Figure S6A). Instead, leucine zipper containing transcription factor binding sites, including XBP1, ATF6 and CREB3/CREB3L were strongly enriched as expected (Figure 6B). Both ATF6 and CREB3/CREB3L1/CREB3L2 are known to activate gene expression involved in unfolded protein response (Li et al., 2000; Liang et al., 2006; Tomoishi et al., 2017; Vellanki et al., 2013) and ATF6 and CREB3L2 also exhibit $12 \mathrm{~h}$ rhythm of gene expression (Figure S6B) (Zhu et al., 2017). These data suggest that ATF6 and CREB3L2 may cooperate with XBP1s in dictating $12 \mathrm{~h}$ rhythms of gene expression. In addition to leucine zipper transcription factors, we unexpectedly found enriched motifs of ETS transcription factors including GAPB and ELF1 at XBP1s cistrome (Figure 6B). 
While the ETS transcription factors are known to play important roles in tissue development and cancer progression (Sharrocks, 2001; Sizemore et al., 2017), to the best of our knowledge, their potential involvement in the regulation of CEDIF and crosstalk with XBP1s remain unreported. To determine whether the ETS DNA binding motif mainly localizes mutually exclusive with XBP1 motif or adjacent to the XBP1 motif in cis, we re-performed the motif analysis using an 800bp DNA region surrounding the XBP1s peak center, and no longer found the enrichment of these motifs (Figure 6B). This result indicates that GABP and/or ELF1 binding sites mostly occur adjacent to that of XBP1s in cis on the same molecule of DNA. GABP transcriptionally regulates gene expression predominantly by forming a heterotetrameric complex composed of two a and two $\beta$ subunits encoded by the Gabpa and Gabpb1/b2 genes, respectively (Chinenov et al., 2000). By examining a previously published hepatic circadian proteome database (Wang et al., 2018), we found a robust $12 \mathrm{~h}$ oscillation of nuclear GABPA level (GABPB not reported) (Figure S6C-i). In addition, robust $12 \mathrm{~h}$ oscillations of nuclear GABPA/GABPB2 (GABPB1 not reported) bound to an artificial DNA fragment harboring GABP consensus sequence were also reported in the same study (Figure S6C-i) (Wang et al., 2018). Both hepatic Gabpa and Gabpb1 mRNA exhibit XBP1sdepenent 12h oscillations (Figures S6C-ii, 7D), and 12h chromatin recruitment of XBP1s to Gabpb1 gene promoter containing consensus CCACGTCA sequence was also found (Figure S6C-iii). While future efforts are needed to firmly establish the causal roles of GABP in transcriptionally regulating the mammalian $12 \mathrm{~h}$ rhythms of gene expression, these data, nevertheless, imply the putative concerted actions of GABP with XBP1s in regulating the mammalian $12 \mathrm{~h}$-clock (Figure $8 \mathrm{~A}$ ). 
The motif stringency of XBP1s promoter binding sites dictates XBP1s' ability to drive $12 \mathrm{~h}$-rhythms of transcription of CEDIF genes

Hepatic XBP1s cistrome is predominantly enriched around proximal promoter, compared to enhancer, intragenic and intergenic regions (Figures 6C-E, S6D-F), which is consistent with previously reported XBP1s cistrome distribution in human triple negative breast cancers (Chen et al., 2014). Very intriguingly, we found highly enriched XBP1s binding sites at bidirectional promoter regions (Figures S6E, F). Gene pairs regulated by XBP1s-targeted bidirectional promoters exhibit similar XBP1s-dependent $12 \mathrm{~h}$ oscillation of expression (Figure S6F). XBP1s transcriptional regulation of bidirectional promoters may reflect a cost-effective way of mammalian $12 \mathrm{~h}$-clock control.

We focused our subsequent analysis on proximal promoter XBP1s sites as they can be unambiguously assigned to each gene and thus permit identification of genes exhibiting both XBP1s-dependent 12h-cyling transcriptome and 12h XBP1s cistrome. A limited overlap of these genes was observed, although it reaches statistical significance indicating a dependent relationship between two "omics" (Figure 6F). The 3,431 XBP1sdependent 12h-cycling genes without XBP1s binding were still enriched in CEDIF and metabolic pathways (Figure S6G). Motif analysis on the promoters of these genes confirmed the lack of XBP1s consensus binding motif but instead revealed strong enrichment of GABP and ELF1 binding sequences (Figure $\mathrm{S} 6 \mathrm{H}$ ), suggesting these genes are likely transcriptionally regulated by GABP downstream of XBP1s (Figure 8A).

We were surprised to find 679 genes with XBP1s binding near promoters but without $12 \mathrm{~h}$ transcriptome and eager to identify the potential mechanisms that distinguish these 
679 genes (cistrome positive) from the 532 genes (double positive) with both $12 \mathrm{~h}$ XBP1s cistrome and transcriptome (Figure 6F). GO analysis revealed that while the 532 double positive genes are strongly enriched in CEDIF pathways as expected, the 679 cistrome positive genes completely lack GO terms associated with CEDIF but instead are modestly enriched with various metabolic pathways mainly under circadian clock regulation (Figure 6G). Motif analysis on the promoters of double positive genes reveal expected XBP1s consensus motif CCACGTCA (Figure 6H). Very intriguingly, the top enriched motif for the cistrome positive gene promoters is identified as a de novo motif with the sequence $\mathrm{CAC}(\mathrm{G} / \mathrm{C})(\mathrm{T} / \mathrm{C})(\mathrm{C} / \mathrm{G})$, which resembles a degenerate XBP1s motif with the 5' $\mathrm{C}$ and 3' A missing and reduced frequency of the central CACGTC sequences (Figure $6 \mathrm{H}$ ). XBP1s binding intensity and amplitude to the degenerate motif are weaker compared to consensus XBP1s sequence (Figure 6I). Accordingly, XBP1s binding to the double positive, but not the cistrome positive gene promoters is strongly associated with $12 \mathrm{~h}$ rhythm of nascent mRNA transcription initiation, as assayed by calculating the area under the curve of pre-pausing portion of Gro-Seq signal (Fang et al., 2014) (Figures 6J-L, S6I, K). Overall, for the 532 double positive genes, we observed a positive correlation among the amplitude of nascent pre-mRNA transcription oscillation (assayed by Gro-Seq), the amplitude of mature mRNA oscillation (assayed by RNA-Seq) and the XBP1s binding motif stringency score (assayed by ChIP-Seq and the higher the score, the more similar the XBP1s binding motif is to the consensus sequence) in XBP1 ${ }^{\text {Flox }}$ mice (Figures 6L-Q, S6J).

Taken together, we hereby demonstrated that the motif stringency of XBP1s binding sites, but not necessarily its expression, dictates its ability to drive $12 \mathrm{~h}$ rhythms of 
mRNA transcription: 12h XBP1s chromatin recruitment to gene promoters harboring consensus XBP1s DNA binding motif CCACGTCA drives $12 \mathrm{~h}$ rhythms of transcription initiation of genes involved in CEDIF and nucleotide/amino sugar metabolism, while weaker binding to promoters with degenerate motifs does not (Figure 8A). Due to the elevated basal level of gene expression among half of the 679 cistrome positive genes in $\mathrm{XBP}^{L K O}$ mice (Figures S6K-N), we hypothesize that XBP1s binding to degenerate motif can repress lipid metabolic gene expression possibly through a tethering mechanism by interfering with gene activation by adjacent transcription activators (Herrema et al., 2016).

\section{The $12 \mathrm{~h}$ rhythms of CEDIF and nucleotide metabolism gene expression are evolutionarily conserved in marine animals possessing dominant circatidal clock}

We originally hypothesized that the mammalian $12 \mathrm{~h}$ clock evolved from the circatidal clock of coastal and estuarine animals that modulate their behavior in tune to the $\sim 12.4$ hour ebb and flow of the tides (Zhu et al., 2018; Zhu et al., 2017), which were also established independently from the circadian clock (III et al., 2008; Naylor, 1996; Takekata et al., 2012; Takekata et al., 2014; Zhang et al., 2013). To seek further support for our hypothesis, we analyzed two recently published time series RNA-Seq dataset of two marine animals harboring circatidal clock, aposymbiotic sea anemone Aiptasia diaphaha (Sorek et al., 2018) and the limpet Cellana rota (Schnytzer et al., 2018). In both cases, we found large overlap of $12 \mathrm{~h}$-cycling transcritptome between mouse and these two species (Figures 7A-C, S7A-C, Table S12). Computationally constructing predicted interactive network using the overlapping $12 \mathrm{~h}$-cycling genes in both species via STRING (Szklarczyk et al., 2015) or by traditional GO analysis 
revealed sub-hubs involved in different steps of CEDIF and nucleotide metabolism (Figures 7B and S7B, Table S13). We further observed 12h oscillations of Gabpa in both Aiptasia diaphaha and Cellana rota and Gabpb2 in Aiptasia diaphaha (Figures 7D and S7D). 12h oscillation of Xbp1 in Cellana rota was previously reported (Zhu et al., 2018). These data combined with the recent independent report of earlier evolutionary origin of $12 \mathrm{~h}$-cycling genes than circadian genes (Castellana et al., 2018) provides strong support for our hypothesis that the mammalian $12 \mathrm{~h}$ clock evolved from the circatidal clock.

\section{DISCUSSION:}

In this section, we will mainly discuss two aspects of the mammalian $12 \mathrm{~h}$-clock, its transcriptional regulation and physiological functions.

\section{The working model of the transcriptional regulation of mammalian $12 \mathrm{~h}$-clock by XBP1s}

Our study establishes XBP1s as a master transcriptional regulator of the mammalian $12 \mathrm{~h}$-clock. Hepatic ablation of XBP1 results in the impairment of $87 \%$ of hepatic $12 \mathrm{~h}$ cycling transcriptome. XBP1s directly transcriptionally regulates more than 500 genes (with acrophases around CT2 and CT14) via rhythmic binding to promoters containing consensus sequence CCACGTCA. Alternatively, XBP1s transcriptionally regulates $12 \mathrm{~h}$ oscillations of GABP expression, which in turn can bind to gene promoters harboring ETS consensus sequence CCGGAAG and putatively regulates additional $12 \mathrm{~h}$ transcriptome with a wider range of acrophases. GABP can also act in concert with XBP1s in cis on a subset of genes containing adjoining XBP1s and GABP DNA binding 
motif in gene promoters (Figure 8A). XBP1s also regulates its own $12 \mathrm{~h}$ transcription, therefore completing a positive feedforward loop (Figure 8A) (Majumder et al., 2012). At this point, what remains elusive is the mechanism(s) of negative feedback required for sustaining cell-autonomous oscillations of the $12 \mathrm{~h}$-clock. One potential candidate is the unspliced form of XBP1 (Xbp1us), which has been previously shown to negatively regulate UPR by forming a complex with XBP1s and ATF6 in the cytosol and target them for ubiquitin-mediated degradation (Yoshida et al., 2006; Yoshida et al., 2009). Supporting this hypothesis is the observed $12 \mathrm{~h}$ rhythm of Xbp1us mRNA (data not shown), although more evidence is needed in the future. One last note, what is summarized in Figure 8 is the current working model of the transcriptional regulation of mammalian $12 \mathrm{~h}$-clock by XBP1s, it is subject to revision and modification with more available experimental and mathematical modeling data in the future.

\section{The vehicle-cargo hypothesis on the distinct functions of $12 \mathrm{~h}$-clock versus the circadian clock}

A very fascinating finding from our study is the coordinated $12 \mathrm{~h}$ oscillations of genes involved in the entire central dogma information flow, ranging from mRNA transcription, mRNA processing, translation regulation to protein processing and sorting in the ER and Golgi, which include both anabolic and catabolic processes. The vast majority of these genes peak at dawn (CT0- CT3) and dusk (CT12 to CT15), corresponding to the transition periods between fasting/feeding and rest/activity that are associated with elevated metabolic stress (Zhu et al., 2018). In light of these findings, we hereby propose a vehicle-cargo hypothesis that attempts to decipher the distinct functions of 12h-clock versus the circadian clock (Figure 8B). We argue that the 12h-clock 
accommodates rush hours' (at dawn and dusk) elevated gene expression and processing by controlling the $12 \mathrm{~h}$ rhythms of the global traffic capacity (and/or the traffic rate) of the central dogma information flow (thus the vehicle), in tune to the $12 \mathrm{~h}$ cycle of metabolic stress (Zhu et al., 2018) (Figure 8B). The circadian clock and/or other tissue specific pathways, on the other hand, dictate the particular genes/gene products processed at each rush hour (thus the cargo) (Figure 8B). An everyday metaphor would be the fluctuating daily traffic on the highway: the $12 \mathrm{~h}$-clock is comparable to the highway that increases its operating capacity during the morning and evening rush hours (by opening the HOV lane, for example), while the $24 \mathrm{~h}$ circadian clock dictates the specific cars that go on the highway during morning and evening (Figure 8B). Future efforts should be directed toward characterizing the temporal profile of $12 \mathrm{~h}$-clockdependent mRNA and protein being processed in the nucleus and ER/Golgi, respectively.

\section{MATERIALS AND METHODS:}

\section{Cell Lines}

Mouse embryonic fibroblast (MEF) was prepared as previously described (Stashi et al., 2014).

\section{Animals}

$\mathrm{XBP} 1^{\text {Flox }}$ mice was previously described (Lee et al., 2008). XBP $1^{L K O}$ mice were generated by crossing Albumin-CRE mice with XBP1 ${ }^{\text {Flox }}$ mice. All mice are in C57BL/6 background, male and between 3 and 4 months of age. Mice were first entrained under LD12:12 conditions for 2 weeks before transferred to constant darkness for $24 \mathrm{hrs}$. Mice 
were then sacrificed at a $2 \mathrm{~h}$ interval for a total of $48 \mathrm{hrs}$. Mice were fed ad libitum during the entire experiment. The Baylor College of Medicine and University of Pittsburgh Institutional Animal Care and Utilization Committee approved all experiments.

\section{Food Intake Monitoring}

Comprehensive Lab Animal Monitoring System (CLAMS) Calorimetry (Columbus Instruments) was used for real-time measuring of food intake. XBP1 ${ }^{\text {Flox }}(n=4)$ and $\mathrm{XBP}^{\text {LKO }}(\mathrm{n}=4)$ mice were acclimated to the chambers for at least one week and ad libitum food intake was monitored for 72 hours under LD12:12 followed by 96 hours of constant darkness.

\section{Locomotor Activity Monitoring}

The Home Cage Activity System (Omnitech Electronics, Inc) was used for real-time measuring of spontaneous locomotor activity in a home-cage environment. XBP1 ${ }^{\text {Flox }}$ $(n=4)$ and $\operatorname{XBP}_{1}^{L K O}(n=4)$ mice were acclimated to the home cage for at least one week and fed ad libitum. Spontaneous locomotor activity was measured under either LD12h:12h condition or constant darkness conditions.

\section{siRNA Transient Transfections}

MEFs were transfected with $10 \mu \mathrm{M}$ of different siRNAs for $24 \sim 48$ hours with Lipofectamine RNAiMAX reagents (Life technologies) per the manufacturer's instructions. Source of siRNA are as follows: siGENOME Non-Targeting siRNA pool (Dharmacon, D-001206-1305), siGENOME SMARTpool ARNTL (Dharmacon, L040483-01-0005), siGENOME SMARTpool XBP1 (Dharmacon, L-040825-00-0005). 


\section{Synchronization of MEFs}

MEFs were isolated from male SRC-2 $2^{f / f t}$ mice and immortalized by SV40 T antigen as previously described (Stashi et al., 2014). For tunicamycin treatment, MEFs were cultured in DMEM (4.5g/L glucose) supplemented with 10\% FBS and treated with $25 \mathrm{ng} / \mathrm{ml}$ of tunicamycin for $2 \mathrm{~h}$, and then washed with 1 X PBS before cultured in the same medium. For dexamethasone treatment, MEFs were cultured in DMEM $(4.5 \mathrm{~g} / \mathrm{L}$ glucose) supplemented with 10\% FBS and treated with 100nM Dex for 30mins, and then washed with 1X PBS before cultured in the same medium. For all cell culture experiments, cells were cultured at $37^{\circ} \mathrm{C}$ with $5 \% \mathrm{CO} 2$.

\section{Immunoblot}

Immunoblot analyses were performed as described previously (Zhu et al., 2015). Briefly, proteins separated by 4 20\% gradient SDS-PAGE gels (Biorad) were transferred to nitrocellulose membranes, blocked in TBST buffer supplemented with $5 \%$ bovine serum albumin (BSA) and incubated overnight with primary anti-XBP1s antibody (Biolegend Poly6195) at $4^{\circ} \mathrm{C}$. Blots were incubated with an appropriate secondary antibody coupled to horseradish peroxidase at room temperature for 1 hour, and reacted with ECL reagents per the manufacturer's (Thermo) suggestion and detected on X-ray film by autoradiography.

\section{qRT-PCR}

Total mRNA was isolated from murine embryonic fibroblasts (MEFs) with PureLink RNA mini kit (Life Technologies) per the manufacturer's instructions. Reverse transcription was carried out using $5 \mu \mathrm{g}$ of RNA using Superscript III (Life Technologies) per the 
manufacturer's instructions. For gene expression analyses, cDNA samples were diluted $1 / 30$-fold (for all other genes except for 18sRNA) and 1/900-fold (for 18sRNA). qPCR was performed using the Taqman or SYBR green system with sequence-specific primers and/or the Universal Probe Library (Roche). All data were analyzed with $18 \mathrm{~S}$ or $\beta$-actin as the endogenous control. qPCR primer sequences are as follows:

Mouse total Xbp1 forward primer: gggtctgctgagtcc

Mouse total Xbp1 reverse primer: cagactcagaatctgaagagg

Mouse Xbp1s forward primer: ccgcagcaggtgc

Mouse Xbp1s reverse primer: cagactcagaatctgaagagg

Mouse Xbp1us forward primer: actatgtgcacctctgcag

Mouse Xbp1us reverse primer: cagactcagaatctgaagagg

Mouse Arnt/ forward primer: gccccaccgacctactct

Mouse Arnt/ reverse primer: tgtctgtgtccatacttcttgg

Mouse Nr1d1 forward primer: acgaccctggactccaataa

Mouse Nr1d1 reverse primer: ccattggagctgtcactgtaga

Mouse Per2 forward primer: caacacagacgacagcatca

Mouse Per2 reverse primer: tcctggtcctccttcaacac

Mouse Ero1/b forward primer: atgattcgcaggaccacttt

Mouse Ero1/b reverse primer: tcagcagcaggtccacatac

Mouse Paics forward primer: tagcactccagaggctgagg

Mouse Paics reverse primer: ctccacggcaagttgagtc

Mouse Srp72 forward primer: ccaaagcgtgtctaatcctga

Mouse Srp72 reverse primer: ggtcaccaatgcagatacca

Mouse Sf3a1 forward primer: gatgatgaggtttatgcaccag

Mouse Sf3a1 reverse primer: agtacgtcgctcagccaact

Mouse Tmed 7 forward primer: agttggagaagacccaccttt

Mouse Tmed7 reverse primer: agagcttcatgaatggaaacg 
Mouse 18s RNA forward primer: ctcaacacgggaaacctcac

Mouse 18s RNA reverse primer: cgctccaccaactaagaacg

Mouse $\beta$-actin forward primer: aaggccaaccgtgaaaagat

Mouse $\beta$-actin reverse primer: gtggtacgaccagaggcatac

\section{RNA-Seq}

Mouse liver tissues were collected from $\operatorname{XBP}^{\text {Flox }}(n=2)$ and $X B P 1^{L K O}(n=2)$ mice at $2 h$ interval for a total of 48 hours under constant darkness condition. Total RNA was isolated from mouse liver with miRNeasy Mini Kit (Qiagen) per the manufacturer's instructions. Extracted RNA samples underwent quality control assessment using the RNA Pico 6000 chip on Bioanalyzer 2100 (Agilent) and were quantified with Qubit Fluorometer (Thermo Fisher). Strand-specific total mRNA-Seq libraries were prepared using the Universal Plus mRNA-Seq kit (NuGen) per the manufacturer's instructions using 200ng of RNA. The size selection for libraries were performed using SPRlselect beads (Beckman Coulter) and purity of the libraries were analyzed using the High Sensitivity DNA chip on Bioanalyzer 2100 (Agilent). The prepared libraries were pooled and sequenced using NoveSeq 6000 (Illumina), generating 20 million $2 \times 100$ bp paired-end reads per samples. RNA-Seq library preparation and sequencing were performed at University of Houston Seq-N-Edit Core. Reads were mapped to the mouse genome build mm10 using HISAT (Kim et al., 2015), and gene expression was normalized and quantified using StringTie (Pertea et al., 2015) for FPKM values using default parameters in Python.

\section{Identification of Oscillating Transcriptome}


Averaged FPKM values at each time were used for cycling transcripts identification. To identify cycling transcriptome, we first filtered out transcripts that exhibit an average FPKM value below 0.01 and 25,289 transcripts remain. Superimposed oscillations for all 25,289 transcripts were identified using previously described eigenvalue/pencil method (Antoulas et al., 2018; Zhu et al., 2017). Specifically, three oscillations were identified from each gene. Criterion for circadian genes are: period between $22.5 \mathrm{~h}$ to $25.5 \mathrm{~h}$, decay rate between 0.8 and 1.2 and mean expression FPKM larger than 0.1 ; for $\sim 12 \mathrm{~h}$ genes: period between $10.5 \mathrm{~h}$ to $13.5 \mathrm{~h}$, decay rate between 0.8 and 1.2 and mean expression FPKM larger than 0.1; for $\sim 8 \mathrm{~h}$ genes: period between $7 \mathrm{~h}$ to $9 \mathrm{~h}$, decay rate between 0.8 and 1.2 and mean expression FPKM larger than 0.1 . To determine the FDR of identification of rhythmic transcripts, we used a permutation-based method that randomly shuffles the time label of gene expression data and subject each of the permutation dataset to eigenvalue/pencil method applied with the same criterion (Rey et al., 2018). These permutation tests were run 1,000 times, and FDR was estimated by taking the ratio between the mean number of rhythmic profiles identified in the permutated samples (false positive ones) and the number of rhythmic profiles identified in the original data. All the analysis were performed in MatlabR2017A. Heat maps were generated by Gene Cluster 3.0 and TreeView 3.0 alpha 3.0 using log2 meannormalized values.

\section{T-distributed Stochastic Neighbor Embedding ( $t$-SNE) ANALYSIS}

t-SNE analysis was performed on identified pure 12h oscillations using MatlabR2017A. "Exact' algorithm and "city block" distance metric were used.

\section{Chromatin Immunoprecipitation (ChIP)-Seq}


ChIP for XBP1s was performed using anti-XBP1s antibody (Biolegend Poly6195) as previously described (Zhu et al., 2015). Briefly, mouse liver samples were submerged in PBS $+1 \%$ formaldehyde, cut into small $(\sim 1 \mathrm{~mm} 3)$ pieces with a razor blade and incubated at room temperature for 15 minutes. Fixation was stopped by the addition of $0.125 \mathrm{M}$ glycine (final concentration). The tissue pieces were then treated with a TissueTearer and finally spun down and washed twice in PBS. Chromatin was isolated by the addition of lysis buffer, followed by disruption with a Dounce homogenizer. The chromatin was enzymatically digested with MNase. Genomic DNA (Input) was prepared by treating aliquots of chromatin with RNase, Proteinase $\mathrm{K}$ and heated for reversecrosslinking, followed by ethanol precipitation. Pellets were resuspended and the resulting DNA was quantified on a NanoDrop spectrophotometer. An aliquot of chromatin $(30 \mu \mathrm{g})$ was precleared with protein A agarose beads (Invitrogen). Genomic DNA regions of interest were isolated using $4 \mu \mathrm{g}$ of antibody. Complexes were washed, eluted from the beads with SDS buffer, and subjected to RNase and proteinase $\mathrm{K}$ treatment. Crosslinking were reversed by incubation overnight at $65^{\circ} \mathrm{C}$, and ChIP DNA was purified by phenol-chloroform extraction and ethanol precipitation. The DNA libraries were prepared and sequenced at University of Houston Seq-N-Edit Core per standard protocols. DNA libraries were prepared with Ovation® Ultralow V2 DNA-Seq library preparation kit (NuGen) using 1ng input DNA. The size selection for libraries were performed using SPRIselect beads (Beckman Coulter) and purity of the libraries were analyzed using the High Sensitivity DNA chip on Bioanalyzer 2100 (Agilent). The prepared libraries pooled and sequenced using NextSeq 500 (Illumina), generating 15 million 76 bp single-end reads per samples. 


\section{ChIP-Seq analysis}

Duplicates were pooled at each time for subsequent ChIP-Seq analysis. The sequences identified were mapped to the mouse genome (UCSC mm10) using BOWTIE function in Galaxy. Only the sequences uniquely mapped with no more than 2 mismatches were kept and used as valid reads. PCR duplicates were also removed. Peak calling was carried out by MACS (version 1.4.2 20120305) in Galaxy/Cistrome (options --mfold 10, 30 --pvalue 1e-4), on each ChIP-seq file against the ChIP-Seq of XBP1 ${ }^{L K O}$ mice. To account for the different sequencing depths between samples, the signal files generated from MACS were RPKM normalized to sequencing depth (Meyer and Liu, 2014). Due to the robust $12 \mathrm{~h}$ oscillation of XBP1s hepatic nuclear proteins (Cretenet et al., 2010; Zhu et al., 2017), only XBP1s cistrome exhibiting robust $12 \mathrm{~h}$ oscillations (period between $10.5 \mathrm{~h}$ to $13.5 \mathrm{~h}$; decay rate between 0.8 to 1.2 ; phase between $0 \mathrm{~h}$ to $3 \mathrm{~h}$ ) are selected as bona fide XBP1s binding sites.

\section{Gene Ontology Analysis}

DAVID (Huang da et al., 2009) (https://david.ncifcrf.gov) was used to perform Gene Ontology analysis. Briefly, gene names were first converted to DAVID-recognizable IDs using Gene Accession Conversion Tool. The updated gene list was then subject to GO analysis using Mus musculus as background and with Functional Annotation Chart function. KEGG_PATHWAY, were used as GO categories for all GO analysis. Only GO terms with $p$ value smaller than 0.05 were included for further analysis.

\section{Binding Site Annotation and Profiling}

CEAS (Cis-regulatory Element Annotation System) function in Galaxy/Cistrome was applied to calculate the enrichment of the binding sites in the promoter, exon, intron, 
UTR and other genomic regions against the mappable mouse genome using the binomial model.

\section{Motif Analysis}

Motif analysis was performed with Discriminative DNA Motif Discovery (DREAM) tool (version 4.9.1) or the SeqPos motif tool (version 0.590) embedded in Galaxy Cistrome.

\section{Network Analysis}

Construction of interacting network of evolutionarily conserved $12 \mathrm{~h}$ genes were performed by STRING (https://string-db.org/).

\section{Post-hoc Analysis of Serum Synchronized MMH-D3 Transcriptome}

The time series transcriptome of serum-synchronized murine liver MMH-D3 cell was published previously (Atwood et al., 2011). Transcripts with averaged expression larger than 20 were used for subsequent analysis. Upon examining the raw data, we observed noticeable baseline changes in most reported mRNA oscillations. Therefore, we subjected the raw data to polynomial detrend $(n=3)$ [we found higher order of polynomial detrend $(n>3)$ will lead to the disappearance of circadian rhythm in some core circadian genes, therefore we think $n=3$ is the optimal trade-off between over-fitting and underfitting]. The polynomial detrended data were then subject to eigenvalue/pencil analysis to identify superimposed oscillations. Specifically, three oscillations were identified from each gene. Criterion for circadian genes are: period between $20.5 \mathrm{~h}$ to $23.5 \mathrm{~h}$, decay rate between 0.9 and 1.1; for $\sim 12 \mathrm{~h}$ genes: period between $9.5 \mathrm{~h}$ to $12.5 \mathrm{~h}$, decay rate between 0.9 and 1.1. The smaller periods for both circadian and $12 \mathrm{~h}$ genes were selected based upon the distribution of all period uncovered as shown in Figure S5A. 


\section{ACKNOWLEDGEMENTS:}

We want to thank Drs. Brian York, and Maricarmen Delia Planas-Silva for assistance with equipment and experiments. This research was supported by CPRIT grant RP170005 to C.C. and the American Diabetes Association junior faculty development award 1-18-JDF-025 to B.Z.

\section{COMPETING INTEREST:}

We declare no conflicts of interest.

\section{REFERENCES:}

Adamovich, Y., Ladeuix, B., Golik, M., Koeners, M.P., and Asher, G. (2017). Rhythmic Oxygen Levels Reset Circadian Clocks through HIF1alpha. Cell Metab 25, 93-101.

Antoulas, A.C., Zhu, B., Zhang, Q., York, B., O'Malley, B.W., and Dacso, C.C. (2018). A novel mathematical method for disclosing oscillations in gene transcription: A comparative study. PLoS One 13, e0198503.

Atwood, A., DeConde, R., Wang, S.S., Mockler, T.C., Sabir, J.S., Ideker, T., and Kay, S.A. (2011). Cell-autonomous circadian clock of hepatocytes drives rhythms in transcription and polyamine synthesis. Proc Natl Acad Sci U S A 108, 18560-18565.

Barr, F.A., and Short, B. (2003). Golgins in the structure and dynamics of the Golgi apparatus. Current opinion in cell biology 15, 405-413.

Castellana, S., Mazza, T., Capocefalo, D., Genov, N., Biagini, T., Fusilli, C., Scholkmann, F., Relogio, A., Hogenesch, J.B., and Mazzoccoli, G. (2018). Systematic Analysis of Mouse Genome Reveals Distinct Evolutionary and Functional Properties Among Circadian and Ultradian Genes. Front Physiol 9, 1178.

Chen, X., Iliopoulos, D., Zhang, Q., Tang, Q., Greenblatt, M.B., Hatziapostolou, M., Lim, E., Tam, W.L., Ni, M., Chen, Y., et al. (2014). XBP1 promotes triple-negative breast cancer by controlling the HIF1alpha pathway. Nature 508, 103-107.

Chinenov, Y., Henzl, M., and Martin, M.E. (2000). The alpha and beta subunits of the GAbinding protein form a stable heterodimer in solution. Revised model of heterotetrameric complex assembly. J Biol Chem 275, 7749-7756.

Cho, H., Zhao, X., Hatori, M., Yu, R.T., Barish, G.D., Lam, M.T., Chong, L.W., DiTacchio, L., Atkins, A.R., Glass, C.K., et al. (2012). Regulation of circadian behaviour and metabolism by REV-ERB-alpha and REV-ERB-beta. Nature 485, 123-127. 
Collart, M.A. (2016). The Ccr4-Not complex is a key regulator of eukaryotic gene expression. Wiley Interdiscip Rev RNA 7, 438-454.

Conchon, S., Cao, X., Barlowe, C., and Pelham, H.R. (1999). Got1p and Sft2p: membrane proteins involved in traffic to the Golgi complex. The EMBO journal 18, 3934-3946.

Cretenet, G., Le Clech, M., and Gachon, F. (2010). Circadian clock-coordinated $12 \mathrm{Hr}$ period rhythmic activation of the IRE1alpha pathway controls lipid metabolism in mouse liver. Cell Metab 11, 47-57.

Eckel-Mahan, K., and Sassone-Corsi, P. (2013). Metabolism and the circadian clock converge. Physiol Rev 93, 107-135.

Fang, B., Everett, L.J., Jager, J., Briggs, E., Armour, S.M., Feng, D., Roy, A., Gerhart-Hines, Z., Sun, Z., and Lazar, M.A. (2014). Circadian enhancers coordinate multiple phases of rhythmic gene transcription in vivo. Cell 159, 1140-1152.

He, Y., Sun, S., Sha, H., Liu, Z., Yang, L., Xue, Z., Chen, H., and Qi, L. (2010). Emerging roles for XBP1, a sUPeR transcription factor. Gene Expr 15, 13-25.

Herrema, H., Zhou, Y., Zhang, D., Lee, J., Salazar Hernandez, M.A., Shulman, G.I., and Ozcan, U. (2016). XBP1s Is an Anti-lipogenic Protein. J Biol Chem 291, 17394-17404.

Huang da, W., Sherman, B.T., and Lempicki, R.A. (2009). Systematic and integrative analysis of large gene lists using DAVID bioinformatics resources. Nature protocols 4, 44-57.

Hughes, M.E., DiTacchio, L., Hayes, K.R., Vollmers, C., Pulivarthy, S., Baggs, J.E., Panda, S., and Hogenesch, J.B. (2009). Harmonics of circadian gene transcription in mammals. PLoS genetics 5, e1000442.

Hughes, M.E., Hong, H.K., Chong, J.L., Indacochea, A.A., Lee, S.S., Han, M., Takahashi, J.S., and Hogenesch, J.B. (2012). Brain-specific rescue of Clock reveals system-driven transcriptional rhythms in peripheral tissue. PLoS genetics 8, e1002835.

III, W.H.W., Bedford, L., and Chabot, C.C. (2008). Rhythms of Locomotion Expressed by Limulus polyphemus, the American Horseshoe Crab: II. Relationship to Circadian Rhythms of Visual Sensitivity. The Biological Bulletin 215, 46-56.

Kanemoto, S., Kondo, S., Ogata, M., Murakami, T., Urano, F., and Imaizumi, K. (2005). XBP1 activates the transcription of its target genes via an ACGT core sequence under ER stress. Biochemical and biophysical research communications 331, 1146-1153.

Kim, D., Langmead, B., and Salzberg, S.L. (2015). HISAT: a fast spliced aligner with low memory requirements. Nat Methods 12, 357-360.

Koike, N., Yoo, S.H., Huang, H.C., Kumar, V., Lee, C., Kim, T.K., and Takahashi, J.S. (2012). Transcriptional architecture and chromatin landscape of the core circadian clock in mammals. Science 338, 349-354. 
Krishnaiah, S.Y., Wu, G., Altman, B.J., Growe, J., Rhoades, S.D., Coldren, F., Venkataraman, A., Olarerin-George, A.O., Francey, L.J., Mukherjee, S., et al. (2017). Clock Regulation of Metabolites Reveals Coupling between Transcription and Metabolism. Cell Metab 25, 1206.

Lee, A.H., Scapa, E.F., Cohen, D.E., and Glimcher, L.H. (2008). Regulation of hepatic lipogenesis by the transcription factor XBP1. Science 320,1492-1496.

Li, M., Baumeister, P., Roy, B., Phan, T., Foti, D., Luo, S., and Lee, A.S. (2000). ATF6 as a transcription activator of the endoplasmic reticulum stress element: thapsigargin stress-induced changes and synergistic interactions with NF-Y and YY1. Molecular and cellular biology 20 , 5096-5106.

Liang, G., Audas, T.E., Li, Y., Cockram, G.P., Dean, J.D., Martyn, A.C., Kokame, K., and Lu, R. (2006). Luman/CREB3 induces transcription of the endoplasmic reticulum (ER) stress response protein Herp through an ER stress response element. Molecular and cellular biology 26, 79998010.

Logan, R.W., and McClung, C.A. (2019). Rhythms of life: circadian disruption and brain disorders across the lifespan. Nat Rev Neurosci 20, 49-65.

Majumder, M., Huang, C., Snider, M.D., Komar, A.A., Tanaka, J., Kaufman, R.J., Krokowski, D., and Hatzoglou, M. (2012). A novel feedback loop regulates the response to endoplasmic reticulum stress via the cooperation of cytoplasmic splicing and mRNA translation. Molecular and cellular biology 32, 992-1003.

Mandel, C.R., Bai, Y., and Tong, L. (2008). Protein factors in pre-mRNA 3'-end processing. Cell Mol Life Sci 65, 1099-1122.

Maniatis, T., and Reed, R. (1987). The role of small nuclear ribonucleoprotein particles in premRNA splicing. Nature 325, 673-678.

Masri, S., and Sassone-Corsi, P. (2018). The emerging link between cancer, metabolism, and circadian rhythms. Nat Med 24, 1795-1803.

Morris, C.J., Purvis, T.E., Hu, K., and Scheer, F.A. (2016). Circadian misalignment increases cardiovascular disease risk factors in humans. Proc Natl Acad Sci U S A 113, E1402-1411.

Naylor, E. (1996). Crab clockwork: the case for interactive circatidal and circadian oscillators controlling rhythmic locomotor activity of Carcinus maenas. Chronobiol Int 13, 153-161.

Olivares, S., and Henkel, A.S. (2015). Hepatic Xbp1 Gene Deletion Promotes Endoplasmic Reticulum Stress-induced Liver Injury and Apoptosis. J Biol Chem 290, 30142-30151.

Paganelli, R., Petrarca, C., and Di Gioacchino, M. (2018). Biological clocks: their relevance to immune-allergic diseases. Clin Mol Allergy 16, 1.

Peek, C.B., Levine, D.C., Cedernaes, J., Taguchi, A., Kobayashi, Y., Tsai, S.J., Bonar, N.A., McNulty, M.R., Ramsey, K.M., and Bass, J. (2017). Circadian Clock Interaction with HIF1alpha Mediates Oxygenic Metabolism and Anaerobic Glycolysis in Skeletal Muscle. Cell Metab 25, 8692. 
Pertea, M., Pertea, G.M., Antonescu, C.M., Chang, T.C., Mendell, J.T., and Salzberg, S.L. (2015). String Tie enables improved reconstruction of a transcriptome from RNA-seq reads. Nat Biotechnol 33, 290-295.

Rey, G., Milev, N.B., Valekunja, U.K., Ch, R., Ray, S., Silva Dos Santos, M., Nagy, A.D., Antrobus, R., MacRae, J.I., and Reddy, A.B. (2018). Metabolic oscillations on the circadian time scale in Drosophila cells lacking clock genes. Mol Syst Biol 14, e8376.

Roenneberg, T., and Merrow, M. (2016). The Circadian Clock and Human Health. Current biology : CB 26, R432-443.

Schnytzer, Y., Simon-Blecher, N., Li, J., Ben-Asher, H.W., Salmon-Divon, M., Achituv, Y., Hughes, M.E., and Levy, O. (2018). Tidal and diel orchestration of behaviour and gene expression in an intertidal mollusc. Scientific Reports 8, 4917.

Sharrocks, A.D. (2001). The ETS-domain transcription factor family. Nature reviews Molecular cell biology $2,827-837$.

Sizemore, G.M., Pitarresi, J.R., Balakrishnan, S., and Ostrowski, M.C. (2017). The ETS family of oncogenic transcription factors in solid tumours. Nat Rev Cancer 17, 337-351.

Sorek, M., Schnytzer, Y., Ben-Asher, H.W., Caspi, V.C., Chen, C.S., Miller, D.J., and Levy, O. (2018). Setting the pace: host rhythmic behaviour and gene expression patterns in the facultatively symbiotic cnidarian Aiptasia are determined largely by Symbiodinium. Microbiome 6, 83.

Stashi, E., Lanz, R.B., Mao, J., Michailidis, G., Zhu, B., Kettner, N.M., Putluri, N., Reineke, E.L., Reineke, L.C., Dasgupta, S., et al. (2014). SRC-2 is an essential coactivator for orchestrating metabolism and circadian rhythm. Cell reports 6, 633-645.

Szklarczyk, D., Franceschini, A., Wyder, S., Forslund, K., Heller, D., Huerta-Cepas, J., Simonovic, M., Roth, A., Santos, A., Tsafou, K.P., et al. (2015). STRING v10: protein-protein interaction networks, integrated over the tree of life. Nucleic acids research 43, D447-452.

Takekata, H., Matsuura, Y., Goto, S.G., Satoh, A., and Numata, H. (2012). RNAi of the circadian clock gene $<$ em $>$ period $<$ em $>$ disrupts the circadian rhythm but not the circatidal rhythm in the mangrove cricket. Biology Letters 8, 488-491.

Takekata, H., Numata, H., Shiga, S., and Goto, S.G. (2014). Silencing the circadian clock gene Clock using RNAi reveals dissociation of the circatidal clock from the circadian clock in the mangrove cricket. Journal of Insect Physiology 68, 16-22.

Tomoishi, S., Fukushima, S., Shinohara, K., Katada, T., and Saito, K. (2017). CREB3L2mediated expression of Sec23A/Sec24D is involved in hepatic stellate cell activation through ER-Golgi transport. Sci Rep 7, 7992.

Vellanki, R.N., Zhang, L., and Volchuk, A. (2013). OASIS/CREB3L1 is induced by endoplasmic reticulum stress in human glioma cell lines and contributes to the unfolded protein response, extracellular matrix production and cell migration. PLoS One 8, e54060. 
Wang, Y., Song, L., Liu, M., Ge, R., Zhou, Q., Liu, W., Li, R., Qie, J., Zhen, B., Wang, Y., et al. (2018). A proteomics landscape of circadian clock in mouse liver. Nature communications 9 , 1553.

Westermark, P.O., and Herzel, H. (2013). Mechanism for 12 hr rhythm generation by the circadian clock. Cell reports 3, 1228-1238.

Wu, Y., Tang, D., Liu, N., Xiong, W., Huang, H., Li, Y., Ma, Z., Zhao, H., Chen, P., Qi, X., et al. (2017). Reciprocal Regulation between the Circadian Clock and Hypoxia Signaling at the Genome Level in Mammals. Cell Metab 25, 73-85.

Yang, Y., Huh, R., Culpepper, H.W., Lin, Y., Love, M.I., and Li, Y. (2018). SAFE-clustering: Single-cell Aggregated (From Ensemble) Clustering for Single-cell RNA-seq Data. Bioinformatics.

Yoshida, H., Oku, M., Suzuki, M., and Mori, K. (2006). pXBP1(U) encoded in XBP1 pre-mRNA negatively regulates unfolded protein response activator $\mathrm{pXBP} 1(\mathrm{~S})$ in mammalian ER stress response. J Cell Biol 172, 565-575.

Yoshida, H., Uemura, A., and Mori, K. (2009). pXBP1(U), a negative regulator of the unfolded protein response activator pXBP1(S), targets ATF6 but not ATF4 in proteasome-mediated degradation. Cell Struct Funct 34, 1-10.

Zhang, L., Hastings, M.H., Green, E.W., Tauber, E., Sladek, M., Webster, S.G., Kyriacou, C.P., and Wilcockson, D.C. (2013). Dissociation of circadian and circatidal timekeeping in the marine crustacean Eurydice pulchra. Current biology : CB 23, 1863-1873.

Zhou, D., Wang, Y., Chen, L., Jia, L., Yuan, J., Sun, M., Zhang, W., Wang, P., Zuo, J., Xu, Z., et al. (2016). Evolving roles of circadian rhythms in liver homeostasis and pathology. Oncotarget 7 , 8625-8639.

Zhu, B., Dacso, C.C., and O'Malley, B.W. (2018). Unveiling "Musica Universalis" of the Cell: A Brief History of Biological 12-Hour Rhythms. J Endocr Soc 2, 727-752.

Zhu, B., Gates, L.A., Stashi, E., Dasgupta, S., Gonzales, N., Dean, A., Dacso, C.C., York, B., and O'Malley, B.W. (2015). Coactivator-Dependent Oscillation of Chromatin Accessibility Dictates Circadian Gene Amplitude via REV-ERB Loading. Mol Cell 60, 769-783.

Zhu, B., Zhang, Q., Pan, Y., Mace, E.M., York, B., Antoulas, A.C., Dacso, C.C., and O'Malley, B.W. (2017). A Cell-Autonomous Mammalian 12 hr Clock Coordinates Metabolic and Stress Rhythms. Cell Metab 25, 1305-1319 e1309.

Zinder, J.C., and Lima, C.D. (2017). Targeting RNA for processing or destruction by the eukaryotic RNA exosome and its cofactors. Genes Dev 31, 88-100.

FIGURE LEGENDS: 
FIGURE 1. Liver-specific deletion of XBP1s impairs global hepatic 12htranscriptome, but not the circadian rhythm in mice. (A) qPCR analysis of total hepatic Xbp1 mRNA in wild-type $\left(\mathrm{XBP}^{\text {Flox }}\right)$ and XBP1 liver-specific knockout $\left(\mathrm{XBP}^{\text {LKO }}\right.$ mice. (B) Calculated splicing efficiency (ratio of Xbp1s to total Xbp1 mRNA) and total hepatic Xbp1 mRNA in XBP1 ${ }^{\text {Flox }}$ mice. (C) Eigenvalue/pencil analysis of total Xbp1 mRNA level in $X B P 1^{F l o x}$ and $X B P 1^{L K O}$ mice, Xbp1s mRNA level and the splicing efficiency in XBP1 ${ }^{\text {Flox }}$ mice. (D) Western blot analysis of total hepatic XBP1s in XBP1 ${ }^{\text {Flox }}$ and $\mathrm{XBP} 1^{L K O}$ mice. (E) Distribution of periods of all (top) and dominant oscillations (bottom) identified by eigenvalue/pencil method from XBP1 ${ }^{\text {Flox }}$ mice. (F) Heat map of all circadian gene expression (or lack thereof) in $\mathrm{XBP} 1^{F l o x}$ and $\mathrm{XBP} 1^{L K O}$ mice with both raw data and superimposed $24 \mathrm{~h}$ rhythms shown. (G) Heat map of 16 core circadian clock gene expression in $\mathrm{XBP} 1^{F l o x}$ and $\mathrm{XBP} 1^{L K O}$ mice with raw data shown. $(\mathbf{H})$ Heat map of all $\sim 12 \mathrm{~h}$ gene expression (or lack thereof) in $\mathrm{XBP} 1^{F l o x}$ and $\mathrm{XBP} 1^{L K O}$ mice with both raw data and superimposed $\sim 12 \mathrm{~h}$ rhythms shown. Data are graphed as the mean \pm SEM ( $\mathrm{n}$ $=3$ to 5$)$.

FIGURE 2. XBP1s-dependent hepatic $12 \mathrm{~h}$ transcriptome is enriched in regulating central dogma information flow. (A) GO analysis showing enriched KEGG pathways and their corresponding $p$ values for XBP1s-dependent 12h transcriptome. (B) Heat map of $\sim 12 \mathrm{~h}$-cycling gene expression (or lack thereof) involved in mRNA metabolism, protein metabolism and the Golgi apparatus in XBP1 $1^{\text {Flox }}$ and XBP1 $1^{L K O}$ mice with both raw data and superimposed $\sim 12 \mathrm{~h}$ rhythms shown. (C) Diagram illustrating each steps involved in the central dogma information flow from mRNA processing all the way to protein sorting in the Golgi, and RNA-Seq data for representative genes in XBP1 ${ }^{\text {Flox }}$ and 
$\mathrm{XBP} 1^{L K O}$ mice. Additional selected gene names belonging to each step are also shown. Data are graphed as the mean $\pm \operatorname{SEM}(n=2)$.

FIGURE 3. Clustering CEDIF genes based upon their $12 \mathrm{~h}$ transcriptome profile reveals a spatial order consistent with the direction of central dogma information flow. (A) Flow chart illustrating the framework for clustering CEDIF genes based upon their superimposed $12 \mathrm{~h}$ transcriptome profile. (B) Clustering of genes involved in mRNA processing, ribosome biogenesis/translation initiation and protein processing and transport based upon their superimposed $12 \mathrm{~h}$ transcriptome projected onto 3D t-SNE space. (C) Clustering of genes involved in different sub-steps of protein metabolism based upon their superimposed $12 \mathrm{~h}$ transcriptome projected onto 3D t-SNE space. (D) Polar histograms demonstrating phase distributions of genes involved in different steps of central dogma information flow.

FIGURE 4. Coordinated $12 \mathrm{~h}$ rhythms of nucleotide and nucleotide/amino sugar metabolism with $12 \mathrm{~h}$ rhythms of CEDIF (A) GO analysis showing enriched KEGG metabolic pathways and their corresponding $p$ values for XBP1s-dependent $12 \mathrm{~h}$ transcriptome. (B) Heat map of $12 \mathrm{~h}$-cycling gene expression (or lack thereof) involved in nucleotide, amino/nucleotide sugar and N-Glycan metabolism in $\mathrm{XBP}^{\text {Flox }}$ and $\mathrm{XBP} 1^{L K O}$ mice with both raw data and superimposed $\sim 12 \mathrm{~h}$ rhythms shown. (C) The diagram illustrates key metabolic pathways (highlighted by different colors) and corresponding genes that are related to nucleotide and amino/nucleotide sugar metabolism. Genes are numbered from 0 to 29 and those highlighted in red exhibit XBP1s-dependent 12h oscillation. RNA-Seq data for representative genes are shown. (D) Heat map of mouse $12 \mathrm{~h}$ cycling hepatic metabolites related to nucleotide and 
amino/nucleotide sugar metabolism identified by the eigenvalue/pencil method from published metabolomic dataset (Krishnaiah et al., 2017). Both the raw data as well as 12h superimposed oscillations are shown. (E) Clustering of genes involved in different metabolic pathways and CEDIF based upon their superimposed $12 \mathrm{~h}$ transcriptome projected onto 3D t-SNE space. (F) A model demonstrating coordinated $12 \mathrm{~h}$ rhythms of nucleotide and nucleotide/amino sugar metabolism with $12 \mathrm{~h}$ rhythms of CEDIF Data are graphed as the mean $\pm \operatorname{SEM}(n=2)$.

FIGURE 5. The 12h-rhythms of CEDIF gene expression are cell-autonomous. (A) Heat map of all $12 \mathrm{~h}$-cycling gene expression uncovered from serum shocksynchronized murine liver cell line MMH-D3 identified by eigenvalue/pencil analysis (Atwood et al., 2011), with both raw data and superimposed $\sim 12 \mathrm{~h}$ rhythms shown. Both the original time after serum shock, as well as converted time in CT are shown. (B) GO analysis showing enriched KEGG pathways and their corresponding $p$ values for cellautonomous $12 \mathrm{~h}$ transcriptome, with GO terms related to CEDIF highlighted in red. (C) Venn diagram comparison of $12 \mathrm{~h}$ transcriptome involved in CEDIF from mouse liver in vivo and MMH-D3 cells in vitro. (D) Heat map of side-by-side comparison of CEDIFrelated $12 \mathrm{~h}$ gene expression in $\mathrm{MMH}-\mathrm{D} 3$ cells and mouse liver, with both raw data and superimposed $\sim 12 \mathrm{~h}$ rhythms shown. (E) Scatter plot comparing phases of CEDIFrelated $12 \mathrm{~h}$ gene oscillation in MMH-D3 cells and mouse liver. The phases of $12 \mathrm{~h}$ oscillations in MMH-D3 are converted to corresponding time in CT. (F) Clustering of MMH-D3 genes involved in different CEDIF based upon their superimposed $12 \mathrm{~h}$ transcriptome projected onto 3D t-SNE space. (G) Microarray data of representative 12h-cycling genes involved in CEDIF in MMH-D3 cells compiled from (Atwood et al., 
2011). (H) MEFs were transfected with different siRNAs and treated with Tu $(25 \mathrm{ng} / \mathrm{ml})$ for $2 \mathrm{~h}$ and $\mathrm{qPCR}$ was performed at different time points post-Tu shock. Data are graphed as the mean \pm SEM $(n=3)$.

FIGURE 6. The motif stringency of XBP1s promoter binding sites dictates XBP1s' ability to drive 12h-rhythms of transcription of CEDIF genes. (A) Heat maps of all $\mathrm{XBP} 1 \mathrm{~s}$ binding signal at $4 \mathrm{~h}$-interval in $\mathrm{XBP} 1^{\mathrm{Flox}}$ mice as well as in $\mathrm{XBP} 1^{L K O}$ mice surrounding the center of XBP1s binding sites. (B) Top enriched SeqPos motifs common to $12 \mathrm{~h}$-cycling XBP1s cistrome. (C) Snapshot of target genes selected for alignment of XBP1s binding sites at different $\mathrm{CTs}$ in liver tissue of $\mathrm{XBP} 1^{\text {Flox }}$ and $\mathrm{XBP} 1^{L K O}$ mice. (D) Distribution of the distance of all XBP1s binding sites to transcription start site (TSS). (E) Distribution of mouse genome (left) and XBP1s cistrome (right) relative to known target genes. (F) Venn diagram depicting common and unique $12 \mathrm{~h}$ cycling protein-coding transcriptome and TSS-associated XBP1s cistrome. (G) GO analysis showing enriched KEGG pathways and their corresponding $p$ values for 532 genes with both 12h-cycling transcriptome and XBP1s cistrome (left) and 679 genes with XBP1s cistrome but no 12h-cycling transcriptome (right). (H) Top enriched SeqPos motifs common to XBP1s cistromes associated with or without 12h-cycling transcriptome. (I) Calculated amplitude of cycling XBP1s binding signal and peak intensity of XBP1s binding at CT12 for XBP1s cistrome associated with or without 12hcycling transcriptome. (J) A representative diagram depicting a typical Gro-Seq signal from TSS to transcription termination site (TES) of a gene and using area under curve $(A \cup C)$ to calculate both transcription initiation/pausing and transcription elongation rates. (K) $\log _{2}$ mean normalized transcription initiation rates calculated from the Gro- 
Seq data (Fang et al., 2014) for XBP1s target genes with or without associated $12 \mathrm{~h}$ transcriptome. The data is double-plotted for better visualization. (L-Q) 532 genes with both proximal promoter XBP1s binding and $12 \mathrm{~h}$ transcriptome in $\mathrm{XBP}^{\text {Flox }}$ mice. (L) Comparisons of heat maps of XBP1s binding intensity, transcription initiation rates calculated from Gro-Seq (Fang et al., 2014), 12h-cycling gene expression (or lack thereof) in $\mathrm{XBP} 1^{\text {Flox }}$ and $\mathrm{XBP} 1^{L K O}$ mice with both raw data and superimposed $\sim 12 \mathrm{~h}$ rhythms shown, and XBP1s binding motif score. (M) Scatter plot of $\log _{2}$ transform of XBP1s binding motif score versus the relative amplitude of mRNA transcription initiation rates calculated from the Gro-Seq (Fang et al., 2014) for each gene in XBP1 ${ }^{\text {Flox }}$ mice is shown, together with correlation coefficient $r$ and $p$ value that $r$ is significantly different than 0. (N) Scatter plot of $\log _{2}$ transform of XBP1s binding motif score versus the relative amplitude of superimposed $12 \mathrm{~h}$ rhythms for each gene in $\mathrm{XBP} 1^{\text {Flox }}$ mice is shown, together with correlation coefficient $r$ and $p$ value that $r$ is significantly different than 0. (O) Relative amplitude of superimposed $12 \mathrm{~h}$ rhythms for each gene in XBP1 Flox and $\mathrm{XBP} 1^{L K O}$ mice. If a superimposed $12 \mathrm{~h}$ rhythm is not found in $\mathrm{XBP} 1^{L K O}$ mice, then an amplitude of 0 is used. (P) Snapshot of target genes selected for alignment of XBP1s binding sites at different CTs in liver tissue of $\mathrm{XBP} 1^{\text {Flox }}$ and $\mathrm{XBP} 1^{\text {LKO }}$ mice as well as published Gro-Seq data (Fang et al., 2014). Consensus XBP1s binding motifs located at each gene promoter are also shown. (Q) RNA-Seq data for representative genes in $\mathrm{XBP} 1^{\text {Flox }}$ and $\mathrm{XBP} 1^{L K O}$ mice. Data are graphed as the box and whisker plot ( $\min$ to max) in I and mean \pm SEM in $\mathbf{Q}$.

FIGURE 7. The 12h-rhythms of CEDIF gene expression are evolutionarily conserved in the aposymbiotic sea anemone $A$. diaphaha, which possesses a 
dominant circatidal clock. (A) Heat map of side-by-side comparison of evolutionarily conserved $12 \mathrm{~h}$ gene expression in aposymbiotic $A$. diaphaha (Sorek et al., 2018) and mouse liver, with both raw data and superimposed $\sim 12 \mathrm{~h}$ rhythms shown for the mouse liver data. (B) Predicted interactive network construction of these conserved 12h-cycling genes using STRING (Szklarczyk et al., 2015). Genes involved in different biological pathways are colored differently. (C) RNA-Seq data for representative genes in $A$. diaphaha (Sorek et al., 2018) and XBP1 ${ }^{\text {Flox }}$ and XBP1 ${ }^{L K O}$ mice. Data are graphed as the mean \pm SEM $(n=2)$. (D) Gabpa and Gabpb2 expression in aposymbiotic $A$. diaphaha (Sorek et al., 2018) (top) and Gabpa expression in mouse liver from 48h microarray dataset (Hughes et al., 2009) indicated by two different probes.

\section{FIGURE 8. XBP1s transcriptionally regulates $12 \mathrm{~h}$ rhythms of gene expression} involved in central dogma information flow. (A) A simplified model summarizing our current understanding of the transcriptional regulation of mammalian $12 \mathrm{~h}$-clock by XBP1s. 12h rhythmic XBP1s binding to consensus XBP1s binding motif CCACGCTA within proximal promoter regions drives $12 \mathrm{~h}$ rhythms of gene expression that are involved in regulating the traffic capacity of CEDIF. XBP1s further self-regulates its own $12 \mathrm{~h}$ gene expression via this mechanism, thus forming a positive feedforward loop. On the other hand, 12h rhythmic XBP1s binding to degenerate XBP1s binding motif $\operatorname{CAC}(\mathrm{G} / \mathrm{C})(\mathrm{T} / \mathrm{C})(\mathrm{C} / \mathrm{G})$ fail to drive $12 \mathrm{~h}$ rhythms of gene expression that are enriched metabolic pathways. XBP1s further transcriptionally regulates $12 \mathrm{~h}$ oscillation of GABP transcription factors, whose binding motif exhibits equal strong enrichment on the promoters of XBP1s-dependent $12 \mathrm{~h}$ genes. Future studies are needed to establish the casual roles of GABP on the transcriptional regulation of 12h-clock (represented by the 
dashed arrows). (B) The vehicle-cargo hypothesis on the distinct functions of $12 \mathrm{~h}$-clock versus the $24 \mathrm{~h}$ circadian clock. Similar to the increased traffic at "rush" hours at each dawn and dusk in people's daily life, $12 \mathrm{~h}$ rhythms of CEDIF gene expression peaking at dawn (CT0) and dusk (CT12) (indicated by the circular heat map in the middle) suggest the existence of a $12 \mathrm{~h}$ oscillation of "traffic" of central dogma information flow (CEDIF), which consists of progressive molecular processing steps from transcription, mRNA processing, ribosome biogenesis, translation, all the way to protein processing/sorting in the ER and Golgi. At this point, it remains to be determined whether it is the total number of molecules undergo processing (illustrated by the varying arrow sizes) or the metabolic rate of processing (not shown in the figure) (or both) that exhibits a $12 \mathrm{~h}$ oscillation. The vehicle-cargo hypothesis posits: whereas the $12 \mathrm{~h}$-clock regulates the 12h-rhythms of the traffic capacity of the CEDIF (thus the vehicle), the circadian clock (and other temporal and tissue-specific mechanisms) contributes to the regulation of diurnal oscillations of specific cargos that undergo molecular processing.

\section{SUPPLEMENTAL FIGURE LEGENDS}

FIGURE S1. Liver-specific deletion of XBP1s does not alter rhythmic locomotor activity nor fasting-feeding cycles in mice, related to Figure 1. (A, B) Real-time home cage activity monitoring of total distance covered (top), number of movements recorded (middle) and movement time recorded (bottom) in XBP1 ${ }^{\text {Flox }}$ and XBP1 $1^{\text {LKO }}$ mice under $12 \mathrm{~h}$ light/12h dark conditions (A) and constant darkness condition. (B). (C) Averaged measurements within the first and second $12 \mathrm{~h}$ of a day as described in $\mathbf{A}$ and B. (D) Real-time measurement of food intake in $\mathrm{XBP} 1^{\text {Flox }}$ and $\mathrm{XBP} 1^{\mathrm{LKO}}$ mice under both 12h light/12h dark and constant darkness condition measured by CLAMS system. (E) 
Averaged measurements within the first and second $12 \mathrm{~h}$ of a day as described in $\mathbf{D}$. Data are graphed as the mean $\pm \operatorname{SEM}(n=4)$.

FIGURE S2. Liver-specific deletion of XBP1s impairs global hepatic 12htranscriptome, but not the circadian rhythm in mice, related to Figure 1. (A, B) Permutation was performed on the raw data by randomly shuffling the time label. Distribution of periods of all oscillations identified by the eigenvalue/pencil method from five representative permutated dataset from $X B P 1^{F l o x}$ mice $(\mathbf{A})$ and $X B P 1^{L K O}$ mice $(B)$. (C, D) UCSC genome browser snapshot view of RNA-Seq tracks of selective circadian (C) and 12h-cycling (D) gene expression in $X B P 1^{F l o x}$ mice and $X B P 1^{L K O}$ mice.

FIGURE S3. The effects of liver-specific deletion of XBP1s on hepatic circadian gene expression, related to Figure 1. (A) Relative amplitudes of all superimposed $24 \mathrm{~h}$ rhythms from $X B P 1^{F l o x}$ mice and $X B P 1^{L K O}$ mice identified by the eigenvalue/pencil method. (B, C) Polar histograms demonstrating phase distributions of all superimposed $24 \mathrm{~h}$ rhythms from $\mathrm{XBP} 1^{\text {Flox }}(\mathrm{B})$ and $\mathrm{XBP} 1^{L K O}$ (C) mice. (D, E) 1,763 genes with superimposed $24 \mathrm{~h}$ rhythms found in both $\mathrm{XBP} 1^{\text {Flox }}$ and $\mathrm{XBP} 1^{L K O}$ mice. GO analysis showing enriched KEGG pathways and their corresponding $p$ values (D) and RNA-Seq data for representative genes (E) (F, G) 798 genes with superimposed 24 h rhythms only found in XBP1 ${ }^{\text {Flox }}$ mice. GO analysis showing enriched KEGG pathways and their corresponding $p$ values (F) and RNA-Seq data for representative genes (G). (H) Polar histograms demonstrating phase distributions of all (left) and dominant (right) $12 \mathrm{~h}$ rhythms identified from XBP1 ${ }^{\text {Flox }}$ mice.

FIGURE S4. Clustering CEDIF genes based upon their $12 \mathrm{~h}$ transcriptome profile reveals a spatial order consistent with the direction of central dogma information 
flow, related to Figures 3, 4. (A, B) Clustering of genes involved in mRNA processing, ribosome biogenesis/translation initiation and protein processing and transport based upon their superimposed $12 \mathrm{~h}$ transcriptome projected onto 3D (viewed from a different angle compared to Figure 3B) (A) and 2D (B) t-SNE space. (C) Clustering of genes involved in different sub-steps of protein metabolism based upon their superimposed $12 \mathrm{~h}$ transcriptome projected onto $2 \mathrm{D} \mathrm{t}-\mathrm{SNE}$ space. (D) Clustering of genes involved in different metabolic pathways and CEDIF based upon their superimposed $12 \mathrm{~h}$ transcriptome projected onto 2D t-SNE space.

FIGURE S5. The 12h-rhythms of CEDIF gene expression are cell-autonomous, related to Figure 5. (A, B) Distribution of periods of all (A) and dominant oscillations (B) identified by eigenvalue/pencil method from MMH-D3 cells. (C, D) Heat map of all circadian (C) and core circadian clock (D) gene expression identified from MMH-D3 cells with both raw data and superimposed $24 \mathrm{~h}$ rhythms shown. Both the original time after serum shock, as well as converted time in CT are shown. (E) GO analysis showing enriched KEGG pathways and their corresponding $p$ values for all circadian gene identified in C. (F) Clustering of MMH-D3 genes involved in different CEDIF based upon their superimposed $12 \mathrm{~h}$ transcriptome projected onto 2D t-SNE space (G) Microarray data of representative $\sim 12 \mathrm{~h}$-cycling genes involved in CEDIF in MMH-D3 cells that are commonly shared with mouse liver. (H) Microarray data of representative $\sim 12 \mathrm{~h}$-cycling genes involved in CEDIF uniquely found in MMH-D3 cells, but not in mouse liver. (I) MEFs were transfected with different siRNAs and treated with Dexamethasone (100nM) for 30min and qPCR was performed at different time points post Dex shock. (J) MEFs 
were treated with Tu $(25 \mathrm{ng} / \mu \mathrm{l})$ for $2 \mathrm{hr}$ and $\mathrm{qPCR}$ was performed at different time points post Tu shock.

FIGURE S6. The motif stringency of XBP1s promoter binding sites dictates XBP1s' ability to drive 12h-rhythms of transcription of CEDIF genes, related to

Figure 6. (A) Venn diagram depicting common and unique XBP1s cistrome and those of core circadian clock transcription factors compiled from (Cho et al., 2012; Koike et al., 2012; Zhu et al., 2015). (B) RNA-Seq data for Creb3/2 and Elf1 in XBP1 ${ }^{\text {Flox }}$ and $\mathrm{XBP} 1^{L K O}$ mice. (C) $12 \mathrm{~h}$ rhythms of GABP expression regulated by XBP1s. (i) Total nuclear level of GABPA and nuclear level of GABPA and GABPB2 bound to DNA compiled from (Wang et al., 2018). (ii) RNA-Seq data for Gabpa and Gabpb1 in $\mathrm{XBP} 1^{\text {Flox }}$ and $\mathrm{XBP} 1^{L K O}$ mice with calculated periods in $\mathrm{XBP} 1^{\text {Flox }}$ mice shown. (iii) Snapshot of Gabpb1 promoter for alignment of XBP1s binding sites at different CTs in liver tissue of XBP1 $1^{\text {Flox }}$ and XBP1 ${ }^{L K O}$ mice, with XBP1s consensus motif also shown. (D) Snapshot of selected genes for alignment of XBP1s binding sites at different CTs in liver tissue of $\mathrm{XBP} 1^{\mathrm{Flox}}$ and $\mathrm{XBP} 1^{L K O}$ mice. (E) Percentage of XBP1s cistromes located at different positions relative to target genes compared with that of mouse genome. (F) Snapshot of selected genes for alignment of XBP1s binding sites at bidirectional promoters at different CTs in liver tissue of XBP1 ${ }^{\text {Flox }}$ and XBP1 $1^{L K O}$ mice and RNA-Seq data for these genes in XBP1 ${ }^{F l o x}$ and XBP1 ${ }^{L K O}$ mice. (G) GO analysis showing enriched KEGG pathways and their corresponding $p$ values for $3,43112 \mathrm{~h}$ transcriptome without XBP1s binding sites. (H) Top enriched SeqPos motifs common to proximal promoters (600bp around TSS) of 3,431 12h genes without XBP1s binding sites. (I) $\log _{2}$ mean normalized transcription elongation rates calculated from the Gro-Seq data (Fang et al., 
2014) for XBP1s target genes with or without associated $12 \mathrm{~h}$ transcriptome. (J) Snapshot of target genes selected for alignment of XBP1s binding sites at different CTs in liver tissue of $\mathrm{XBP} 1^{\text {Flox }}$ and $\mathrm{XBP} 1^{L K O}$ mice as well as published Gro-Seq data (Fang et al., 2014). Consensus XBP1s binding motifs located at each gene promoter are also shown. (K-N) 679 genes with proximal promoter XBP1s binding but no $12 \mathrm{~h}$ transcriptome in $\mathrm{XBP} 1^{\text {Flox }}$ mice. (K) Comparisons of heat maps of XBP1s binding intensity, transcription initiation rates calculated from Gro-Seq (Fang et al., 2014), gene expression in $\mathrm{XBP} 1^{\text {Flox }}$ and $\mathrm{XBP} 1^{L K O}$ mice, and XBP1s binding motif score. (L) Average expression for each gene in $\mathrm{XBP} 1^{\text {Flox }}$ and $\mathrm{XBP} 1^{L K O}$ mice. (M) Snapshot of target genes selected for alignment of XBP1s binding sites at different CTs in liver tissue of XBP1 ${ }^{\text {Flox }}$ and XBP1 ${ }^{L K O}$ mice as well as published Gro-Seq data (Fang et al., 2014). Degenerate XBP1s binding motifs located at each gene promoter are also shown. (N) RNA-Seq data for representative genes in $\mathrm{XBP} 1^{\text {Flox }}$ and $\mathrm{XBP} 1^{L K O}$ mice. Data are graphed as mean $\pm \operatorname{SEM}(\mathrm{n}=2)$.

FIGURE S7. The 12h-rhythms of CEDIF gene expression are evolutionarily conserved in the limpet $C$. rota, which possesses a dominant circatidal clock, related to Figure 7. (A) Heat map of side-by-side comparison of evolutionarily conserved $12 \mathrm{~h}$ gene expression in C. rota (Schnytzer et al., 2018) and mouse liver, with both raw data and superimposed $\sim 12 \mathrm{~h}$ rhythms shown. The level of tides corresponding to each time was also shown. (B) Predicted interactive network construction of these conserved 12h-cycling genes using STRING (Szklarczyk et al., 2015). Genes involved in different biological pathways are colored differently. (C) RNA-Seq data for representative genes in C. rota (Schnytzer et al., 2018) and $\mathrm{XBP} 1^{\text {Flox }}$ and $\mathrm{XBP} 1^{\text {LKO }}$ 
mice. (D) RNA-Seq data for Gabpa in C. rota. Data are graphed as the mean \pm SEM ( $\mathrm{n}$ $=2)$.

\section{SUPPLEMENTAL TABLES}

Table S1. FPKM quantification of RNA-Seq data in $X B P 1^{F l o x}$ and $X B P 1^{L K O}$ mice, related to Figure 1. Ensemble gene ID, gene symbol, gene biotype and FPKM quantification of both duplicates and mean at each $\mathrm{CT}$ in $\mathrm{XBP} 1^{\mathrm{Flox}}$ and $\mathrm{XBP} 1^{\mathrm{LKO}}$ mice were shown.

Table S2. Eigenvalue/pencil decomposition of all transcriptome with mean larger than 0.01 in $\mathrm{XBP}^{\mathrm{Flox}}$ and $\mathrm{XBP} 1^{L K O}$ mice, related to Figure 1. Period, decay rate, mathematical and biological phase and amplitude for each gene were provided as well as the mean value. Relative amplitude was calculated by normalizing the absolute amplitude to the mean.

Tab 1: Genes in XBP1 ${ }^{\text {Flox }}$ mice

Tab 2: Genes in XBP1 ${ }^{L K O}$ mice

Table S3. Lists of genes with superimposed circadian rhythm in $\mathrm{XBP}^{\text {Flox }}$ and

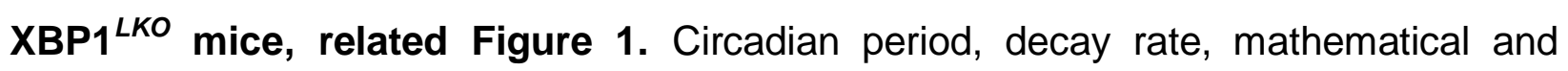
biological phase and amplitude for each gene were provided as well as the mean value. Relative amplitude was calculated by normalizing the absolute amplitude to the mean.

Tab 1: Genes in XBP1 ${ }^{\text {Flox }}$ mice

$\mathrm{Tab}$ 2: Genes in $\mathrm{XBP}^{L K O}$ mice

Table S4. Lists of genes with superimposed $\sim 12 \mathrm{~h}$ rhythm in XBP1 ${ }^{\text {Flox }}$ and XBP1 $1^{\text {LKO }}$ mice, related Figure 1. $\sim 12 \mathrm{~h}$ period, decay rate, mathematical and biological phase 
and amplitude for each gene were provided as well as the mean value. Relative amplitude was calculated by normalizing the absolute amplitude to the mean.

Tab 1: Genes in XBP1 ${ }^{\text {Flox }}$ mice

Tab 2: Genes in XBP1 ${ }^{L K O}$ mice

Table S5. GO terms associated with the 4,600 genes whose $12 \mathrm{~h}$ rhythms were either abolished or dampened in $X B P 1^{L K O}$ compared to $X B P 1^{\text {Flox }}$ mice, related to Figure 1.

Table S6. Lists of genes involved in RNA metabolism, protein metabolism, maintaining Golgi integrity and function, nucleotide metabolism and amino sugar/nucleotide sugar and $\mathrm{N}$-glycan biosynthesis, whose $12 \mathrm{~h}$ rhythms were either abolished or dampened in $X B P 1^{L K O}$ compared to $X B P 1^{\text {Flox }}$ mice, related to Figure 2. 12h period, decay rate, mathematical and biological phase and amplitude for each gene were provided as well as the mean value. Relative amplitude was calculated by normalizing the absolute amplitude to the mean. If a $\sim 12 \mathrm{~h}$ rhythm is not found, it is indicated by $N / A$.

Tab 1: Genes involved in RNA metabolism

Tab 2: Genes involved in protein metabolism

Tab 3: Genes involved in maintaining Golgi integrity and function

Tab 4: Genes involved in nucleotide metabolism

Tab 5: Genes involved in amino sugar/nucleotide sugar and N-glycan biosynthesis

Table S7. Eigenvalue/pencil decomposition of all metabolites reported in (Krishnaiah et al., 2017), related to Figure 4. Period, decay rate, mathematical and biological phase and amplitude for each metabolite were provided as well as the mean 
value. Relative amplitude was calculated by normalizing the absolute amplitude to the mean.

Table S8. Eigenvalue/pencil decomposition of MMH-D3 transcriptome, related to Figure 5. Period, decay rate, biological phase and amplitude for each gene were provided as well as the mean value. Relative amplitude was calculated by normalizing the absolute amplitude to the mean.

Tab 1: all genes

Tab 2: 12h genes

Tab 3: Circadian genes

Table S9. GO terms associated with $~ 12 \mathrm{~h}$-cycling genes in MMH-D3 cells, related to Figure 5.

Table S10. List of $12 \mathrm{~h}$-cycling CEDIF genes uniquely and commonly found in mouse liver in vivo and MMH-D3 cells in vitro, related to Figure 5.

Tab 1: Commonly found $\sim 12 \mathrm{~h}$ genes

Tab 2: Uniquely found $\sim 12 \mathrm{~h}$ genes in vivo

Tab 3: Uniquely found $\sim 12 \mathrm{~h}$ genes in vitro

Table S11. Quantification and eigenvalue/pencil decomposition of XBP1s ChIP.

Seq, related to Figure 6. RPKM quantification and eigenvalue/pencil-identified $12 \mathrm{~h}$ rhythm of XBP1s cistrome.

Tab 1: Promoter-associated XBP1s cistrome

Tab 2: Non promoter-associated XBP1s cistrome 
Tab 3: List of genes bound by promoter-associated XBP1s with or without $12 \mathrm{~h}$ transcriptome

Table S12. List of genes with conserved $12 \mathrm{~h}$ rhythms in both $C$. rota and mouse liver, related to Figure S7. $12 \mathrm{~h}$ period, decay rate, mathematical and biological phase and amplitude for each gene were provided as well as the mean value. Relative amplitude was calculated by normalizing the absolute amplitude to the mean.

Table S13. GO terms associated with conserved $12 \mathrm{~h}$ genes in mouse liver and $C$. rota, related to Figure S7.

Tab 1: Using all mouse genes as background

Tab 2: Using all conserved genes (in mouse and C. rota) as background 
bioRxiv preprint doi: https://doi.org/10.1101/559039; this version posted March 8, 2019. The copyright holder for this preprint (which was not certified by peer review) is the author/funder. All rights reserved. No reuse allowed without permission. 
bioRxiv preprint doi: https://doi.org/10.1101/559039; this version posted March 8, 2019. The copyright holder for this preprint (which was not Figure 1 certified by peer review) is the author/funder. All rights reserved. No reuse allowed without permission.

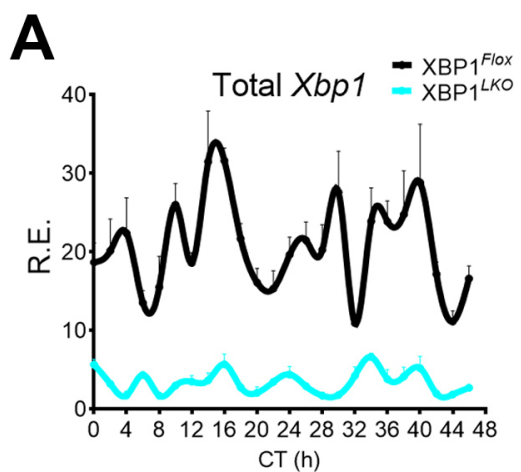

E

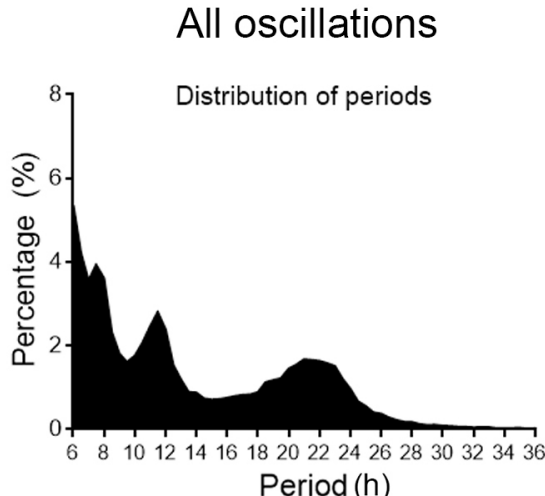

Dominant oscillations

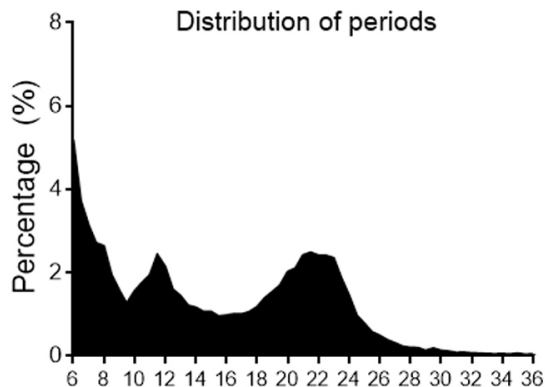

Period (h)

G

СT $0 \frac{\mathrm{XBP}^{\text {Flox }}}{24 \quad 48} \frac{\mathrm{XBP}^{\text {LKO }}}{24 \quad 48}$

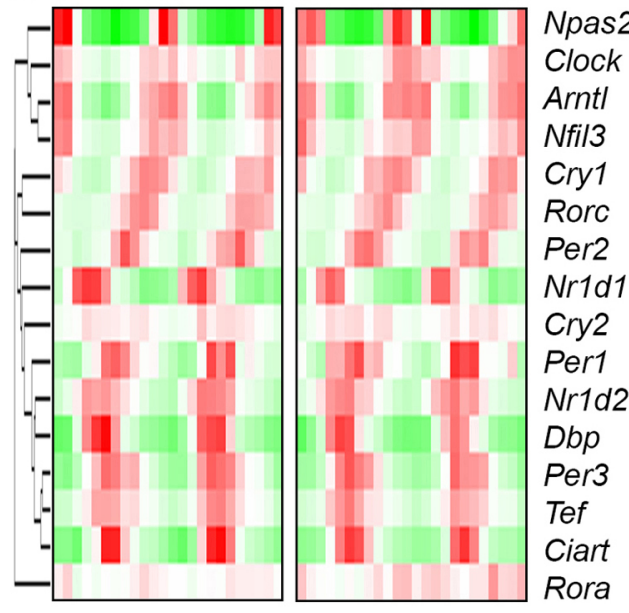

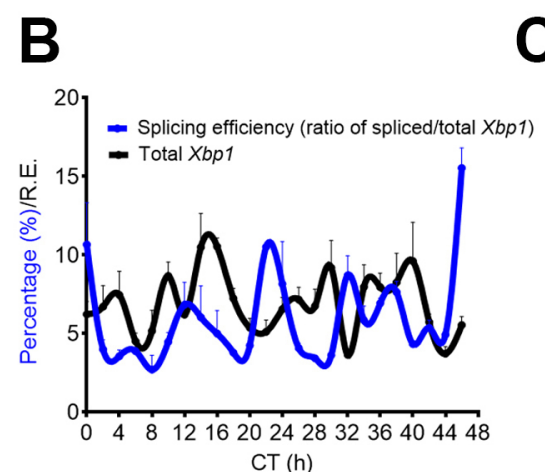
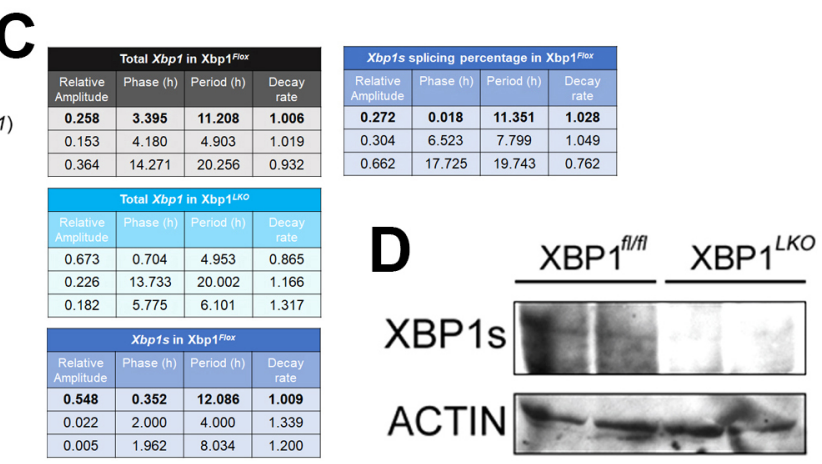

F Raw data

Superimposed $24 \mathrm{~h}$ rhythms

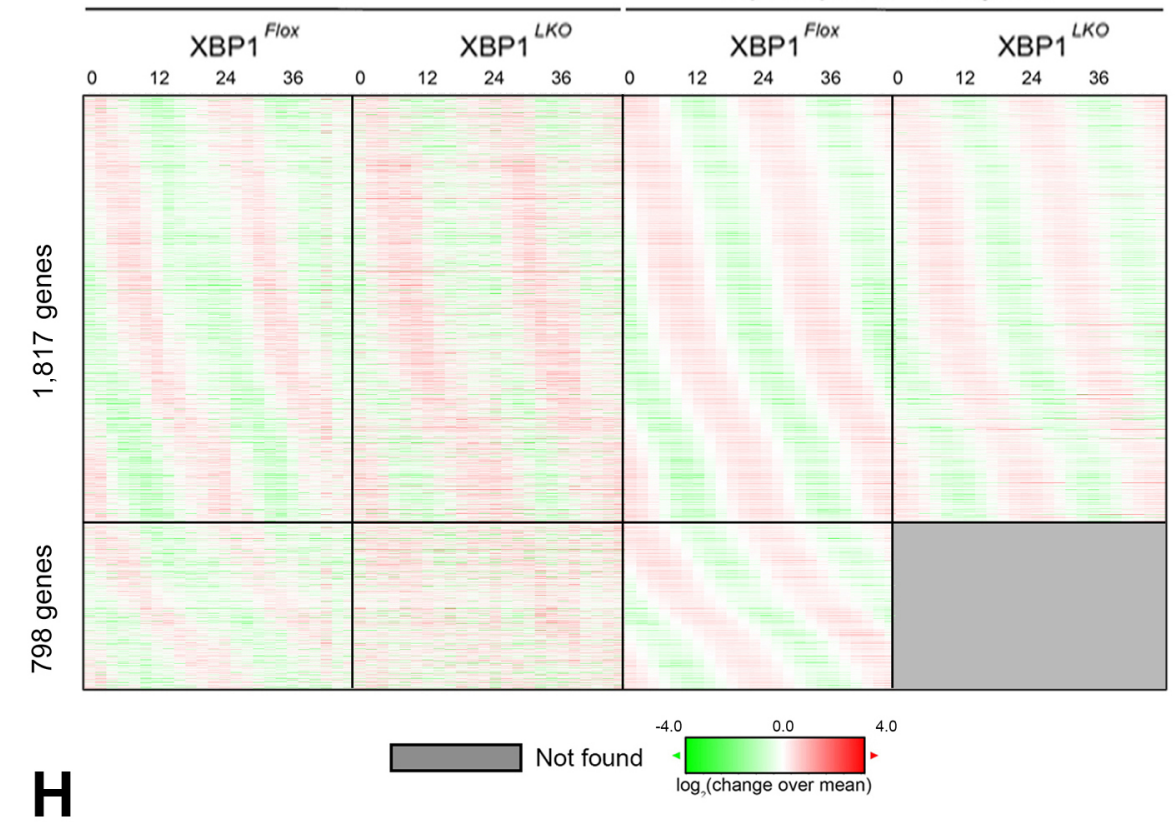

$\frac{\text { Raw data }}{\mathrm{XBP}^{\text {Flox }}} \mathrm{XBP}^{\text {LKO }} \frac{\text { Superimposed } 12 \mathrm{~h} \text { rhythms }}{\mathrm{XBP}^{\text {Flox }}} \frac{\mathrm{XBP}^{\text {LKO }}}{{ }^{\text {LKO }}}$

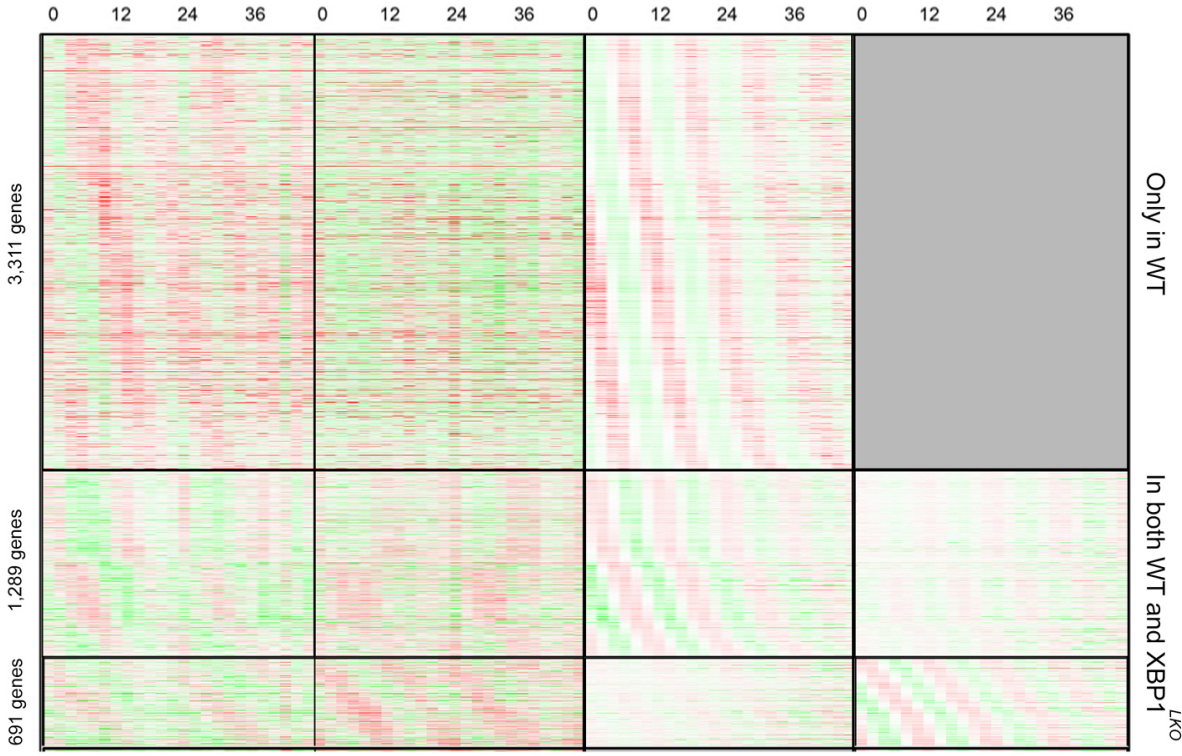

Not found

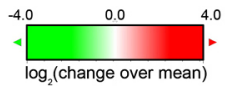


bioRxiv preprint doi: https://doi.org/10.1101/559039; this version posted March 8, 2019. The copyright holder for this preprint (which was not

Figure 2 certified by peer review) is the author/funder. All rights reserved. No reuse allowed without permission.

A

\begin{tabular}{|l|l|}
\hline Term & PValue \\
\hline $\begin{array}{l}\text { Protein processing in endoplasmic } \\
\text { reticulum }\end{array}$ & $1.87 \mathrm{E}-12$ \\
\hline RNA transport & $3.44 \mathrm{E}-10$ \\
\hline Spliceosome & $4.06 \mathrm{E}-07$ \\
\hline mRNA surveillance pathway & $8.20 \mathrm{E}-07$ \\
\hline Protein export & $8.41 \mathrm{E}-05$ \\
\hline Ribosome biogenesis in eukaryotes & $1.22 \mathrm{E}-04$ \\
\hline Viral carcinogenesis & $4.08 \mathrm{E}-04$ \\
\hline Apoptosis & $4.78 \mathrm{E}-04$ \\
\hline Acute myeloid leukemia & $4.80 \mathrm{E}-04$ \\
\hline N-Glycan biosynthesis & $6.17 \mathrm{E}-04$ \\
\hline TNF signaling pathway & $7.30 \mathrm{E}-04$ \\
\hline Purine metabolism & $8.11 \mathrm{E}-04$ \\
\hline
\end{tabular}

B

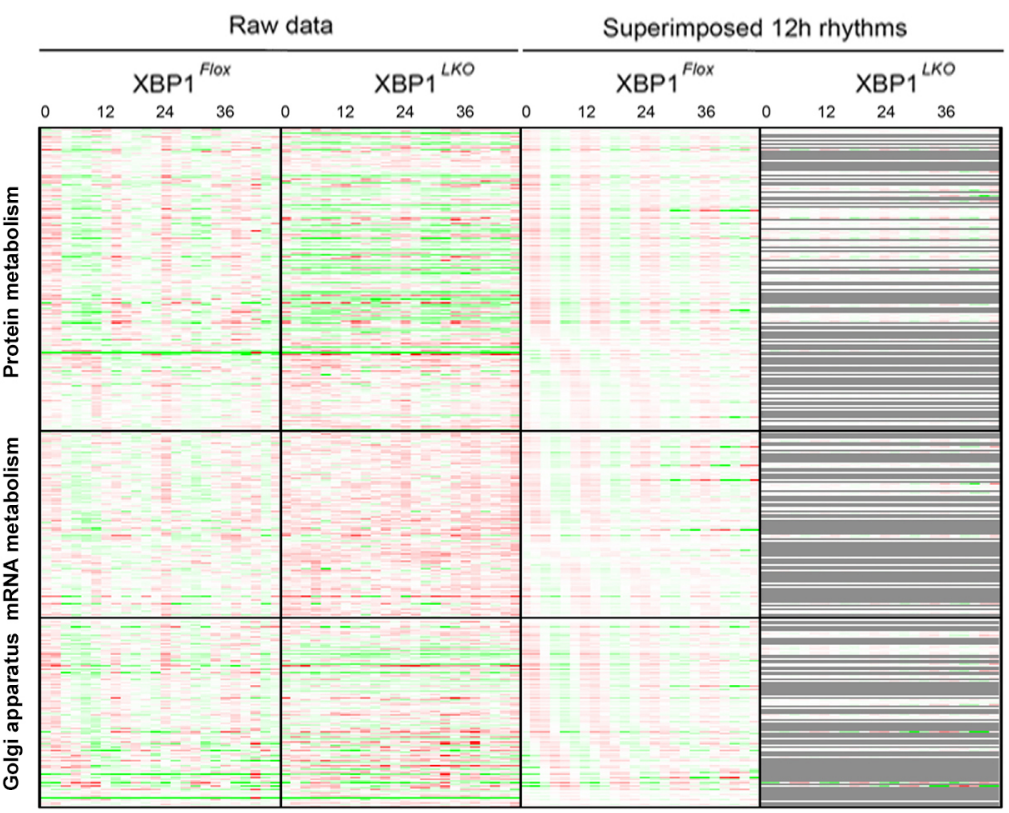

C

(1) Pre-mRNA cleavage and polyadenylation

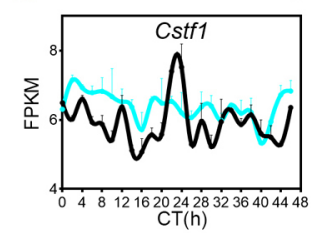

$$
\begin{aligned}
& \text { Cstf3 }=\text { XBP1 }^{\text {Flox }} \\
& \text { Cpsf1 } \\
& \text { Cpsf2 }=\text { XBP1 }^{\text {LKO }} \\
& \text { Cpsf4 } \\
& \text { Clp1 }
\end{aligned}
$$

(2) Pre-mRNA splicing

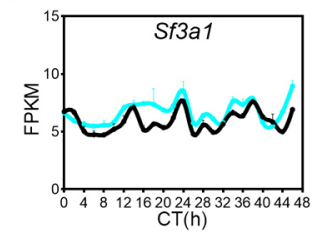

(3) RNA export

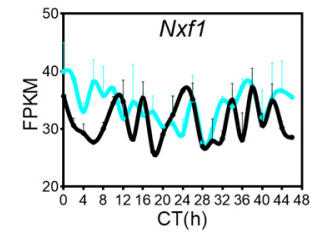

(4) mRNA degradation/nonsense mediated mRNA decay

$\begin{array}{ll}\text { Sf3a2 } & \text { Prpf3 } \\ \text { Sf3a3 } & \text { Prpf31 } \\ \text { Sfsf3 } & \text { Prpf4 } \\ \text { Snrpd1 } & \text { Hnrnpm } \\ \text { Magoh } & \text { Puf60 } \\ \text { Prpf18 } & \text { Prpf38a }\end{array}$

Nxt1 Ncbp1 Pym1 Pom121 Xpo5 Pnn Gemin2 Pabpc4 Gemin4 Rae1 Gemin6 Snupn
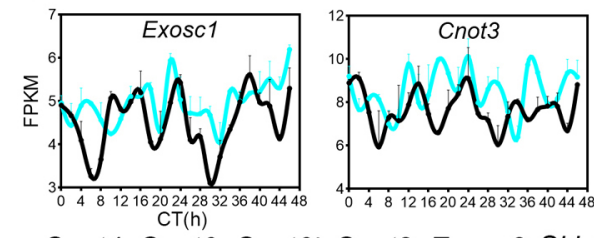

Cnot4, Cnot6, Cnot6l, Cnot8, Exocs3, Skiv2l Exocs6, Exocs8, Smg5, Smg6, Lsm1, Lsm7

(9) ER-associated protein degradation

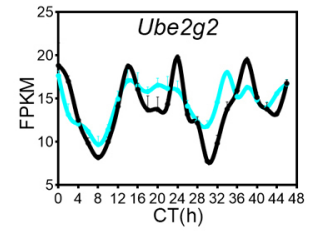

Edem1 Calr

Edem3 Ube2d2a

Fbox6 Ube2j1

UbqIn 4 Usp19

Ube2v1 Syvn1

Ube2f Psmc2
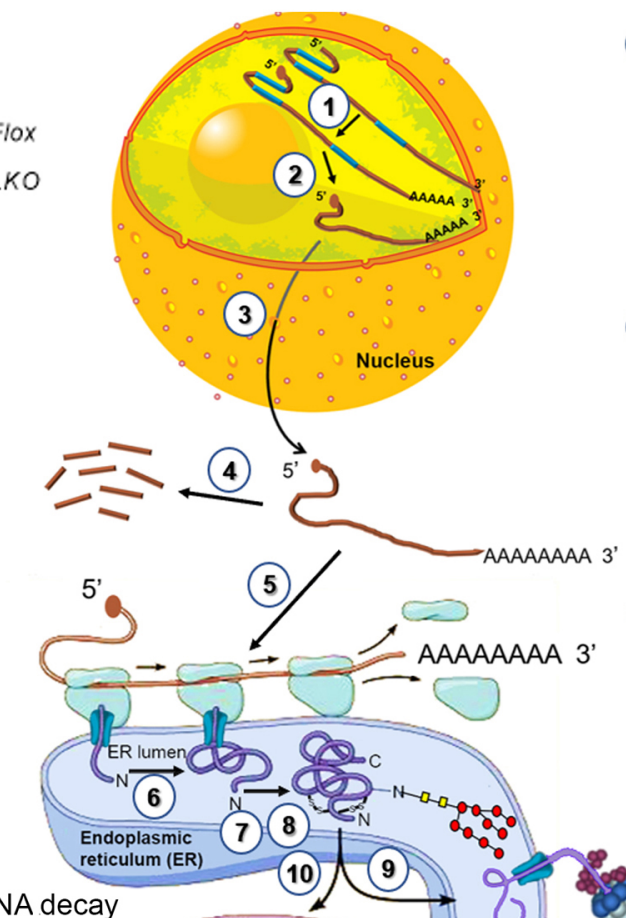

(5) Translation initiation

$\begin{array}{ll}\text { Eif1a } & \text { Eif3e } \\ \text { Eif2s1 } & \text { Eif3g } \\ \text { Eif2s2 } & \text { Eif4a1 } \\ \text { Eif2ak3 } & \text { Eif4a2 } \\ \text { Eif3b } & \text { Eif4ebp1 } \\ \text { Eif3d } & \text { Eif4ebp2 }\end{array}$

(6) Protein translocation across ER membrane

$\begin{array}{ll}\text { Sec61a1 } & \text { Srp19 } \\ \text { Sec61b } & \text { Srp54a } \\ \text { Sec61g } & \text { Ssr1 } \\ \text { Sec11c } & \text { Ssr3 } \\ \text { Spcs2 } & \text { Srpr } \\ \text { Spcs3 } & \text { Srprb }\end{array}$

(7) Protein disulfide formation/protein folding

Dnaja1 Erol1l

Dnaja2 Erol1lb

Dnajb2 Hyou1

Dnjac10 Txndc11

Dnjac3 Txnrd3

Dnajc5 Canx

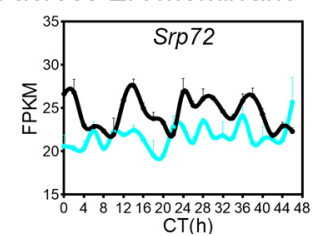

(8) N-linked glycosylation
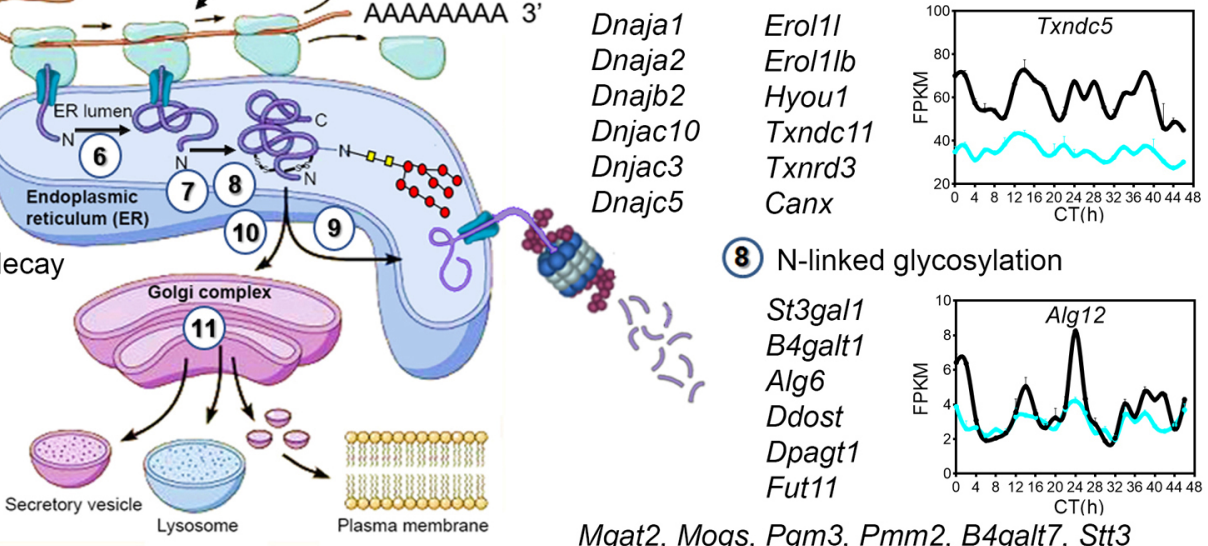

(10) Protein ER-Golgi transport

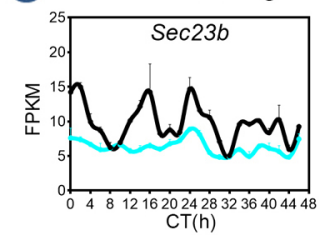

$\begin{array}{ll}\text { Sec13 } & \text { Arf4 } \\ \text { Sec22b } & \text { Arfgap2 } \\ \text { Uso1 } & \text { Arfgap3 } \\ \text { Yipf5 } & \text { Bet1 } \\ \text { Kdelr2 } & \text { Tmed10 } \\ \text { Arf1 } & \text { Tmed2 }\end{array}$

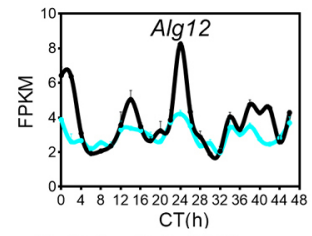

Mgat2, Mogs, Pgm3, Pmm2, B4galt7, Stt3 Uggt1, Syvn1, Alg1, Alg3, Alg9, Galnt7, Galnt10

(11) Protein sorting through Golgi

$\begin{array}{ll}\text { Golga3 } & \text { Gcc1 } \\ \text { Golga4 } & \text { Gorasp2 } \\ \text { Golga5 } & \text { Golt1a } \\ \text { Gbf1 } & \text { Golt1b } \\ \text { Cog8 } & \text { Cog3 } \\ \text { Gopc } & \text { Cobp1 }\end{array}$

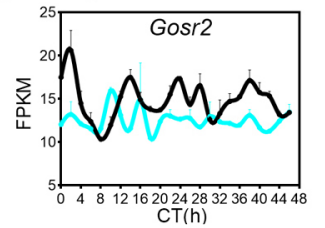


bioRxiv preprint doi: https://doi.org/10.1101/559039; this version posted March 8, 2019. The copyright holder for this preprint (which was not

Figure 3. certified by peer review) is the author/funder. All rights reserved. No reuse allowed without permission.

A
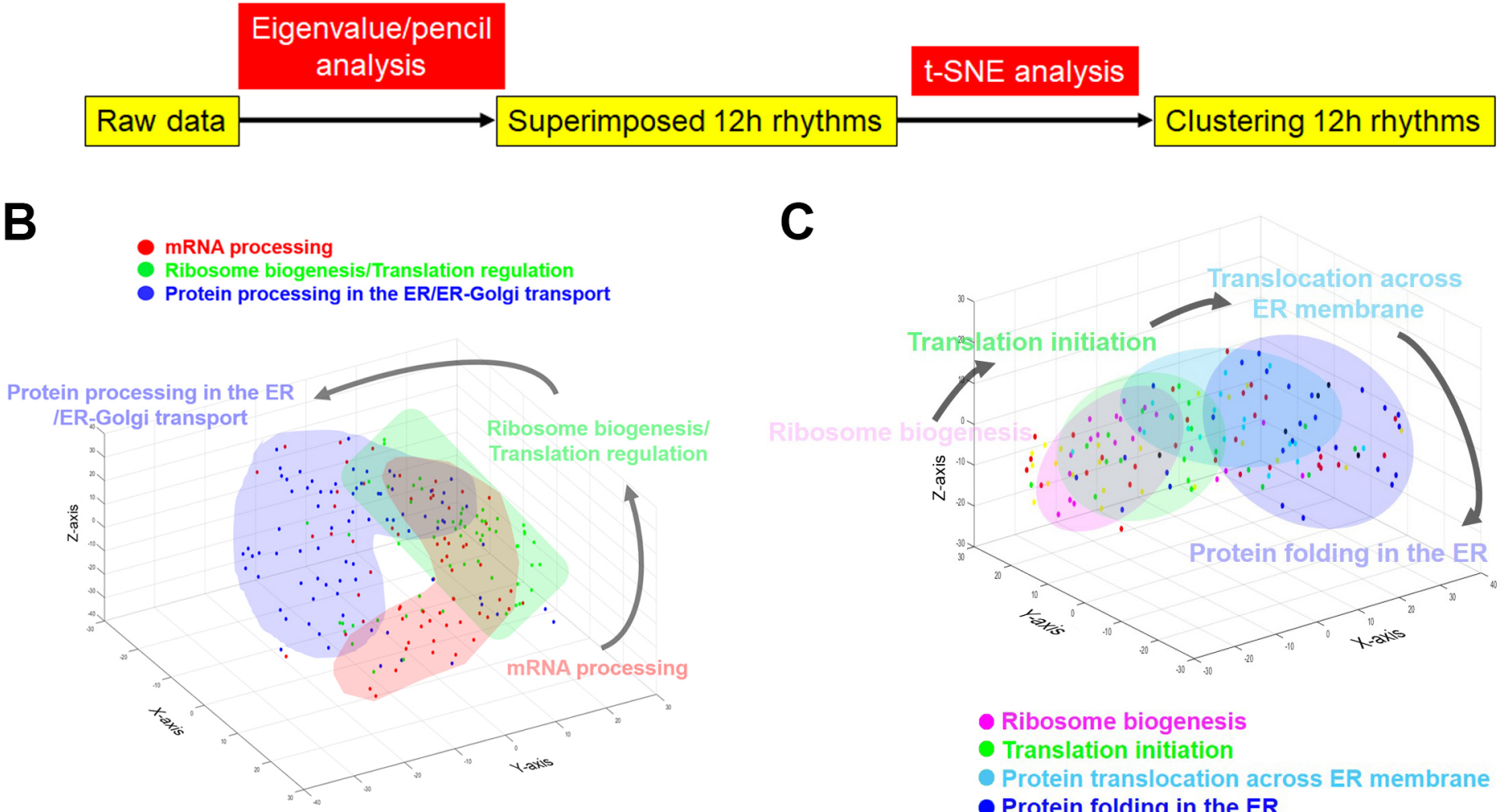

- Ribosome biogenesis

- Translation initiation

- Protein translocation across ER membrane

- Protein folding in the ER

- Protein ER-Golgi transport

- Glycosylation

Proto@lysis/[ERAD

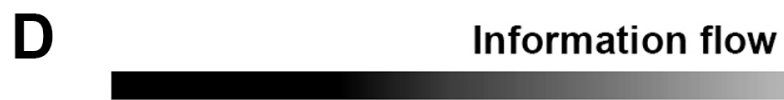

mRNA processing

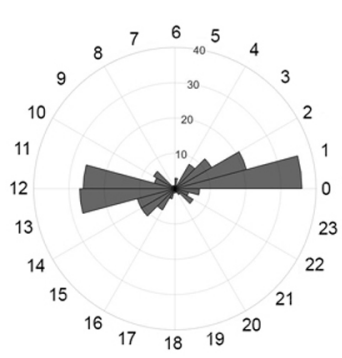

Protein processing

in the ER

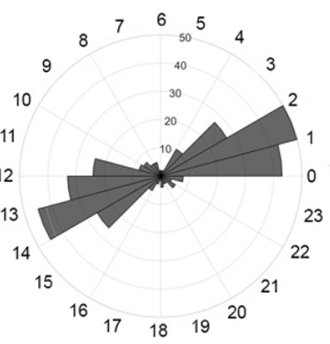

$\mathrm{CT}(\mathrm{h})$
Protein sorting through Golgi

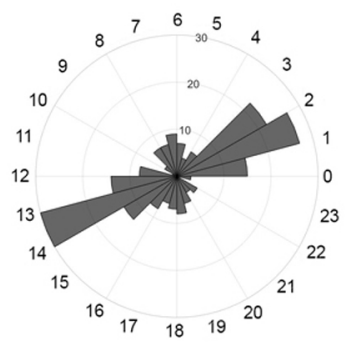


bioRxiv preprint doi: https://doi.org/10.1101/559039; this version posted March 8, 2019. The copyright holder for this preprint (which was not Figure 4. certified by peer review) is the author/funder. All rights reserved. No reuse allowed without permission.

A

\begin{tabular}{|l|r|}
\hline \multicolumn{1}{|c|}{ Term } & \multicolumn{1}{c|}{ PValue } \\
\hline N-Glycan biosynthesis & $6.17 \mathrm{E}-04$ \\
\hline Purine metabolism & $8.11 \mathrm{E}-04$ \\
\hline Pantothenate and CoA biosynthesis & 0.005558062 \\
\hline Pyrimidine metabolism & 0.018374452 \\
\hline Amino sugar and nucleotide sugar metabolism & 0.056793987 \\
\hline Sphingolipid signaling pathway & 0.087995133 \\
\hline Glycerolipid metabolism & 0.096472749 \\
\hline
\end{tabular}

B

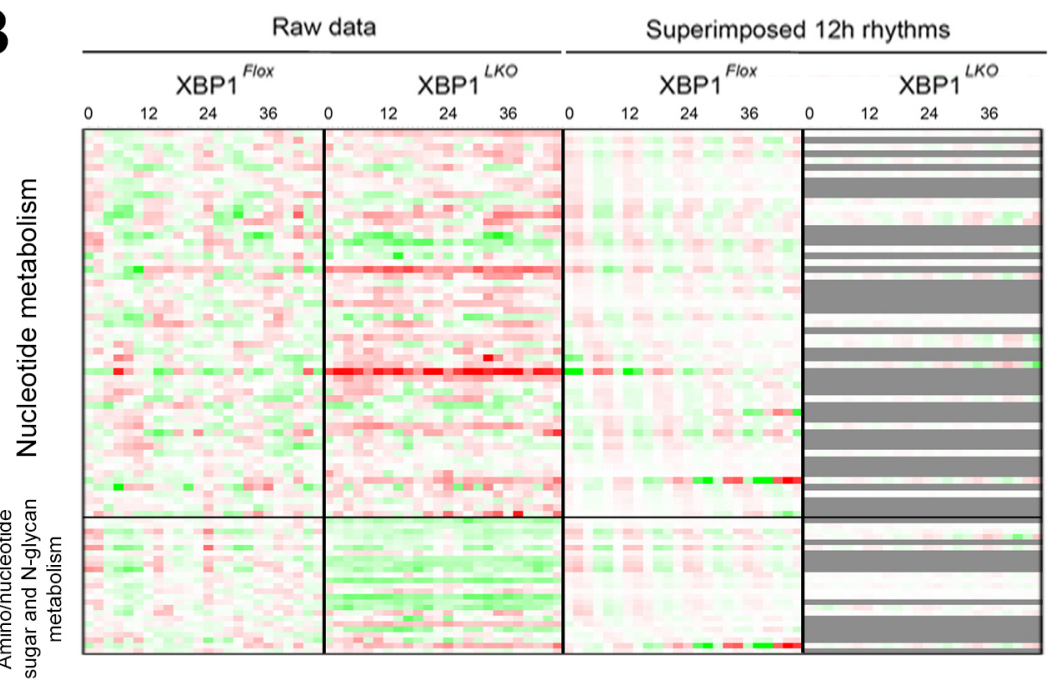

c

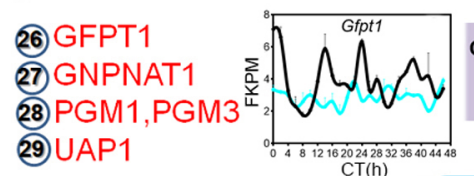

(29) UAP1

(0) PRPS1

(1) PPAT

(2) GART

(3) PFAS

(4) PAICS

(5) ADSL

(6) ATIC

(7) IMPDH1

(8) GMPS

(9) ADSSL1

(ii) APRT

(12) ADA

(13) $\mathrm{NT} 5 \mathrm{C} 2$

(14) ADK

(15) PNP, PNP2

(16) $X D H$

(17) GDA

(18) NT5E

(19) HPRT

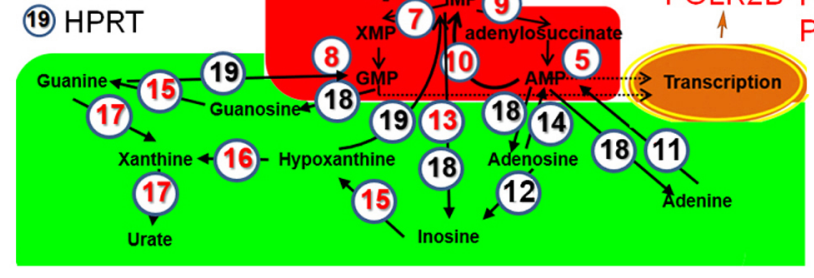

Pentose phosphate pathway Purine de novo synthesis

Purine salvage pathway Transcription by RNA Pol I, II, III Pyrimidine de novo synthesis
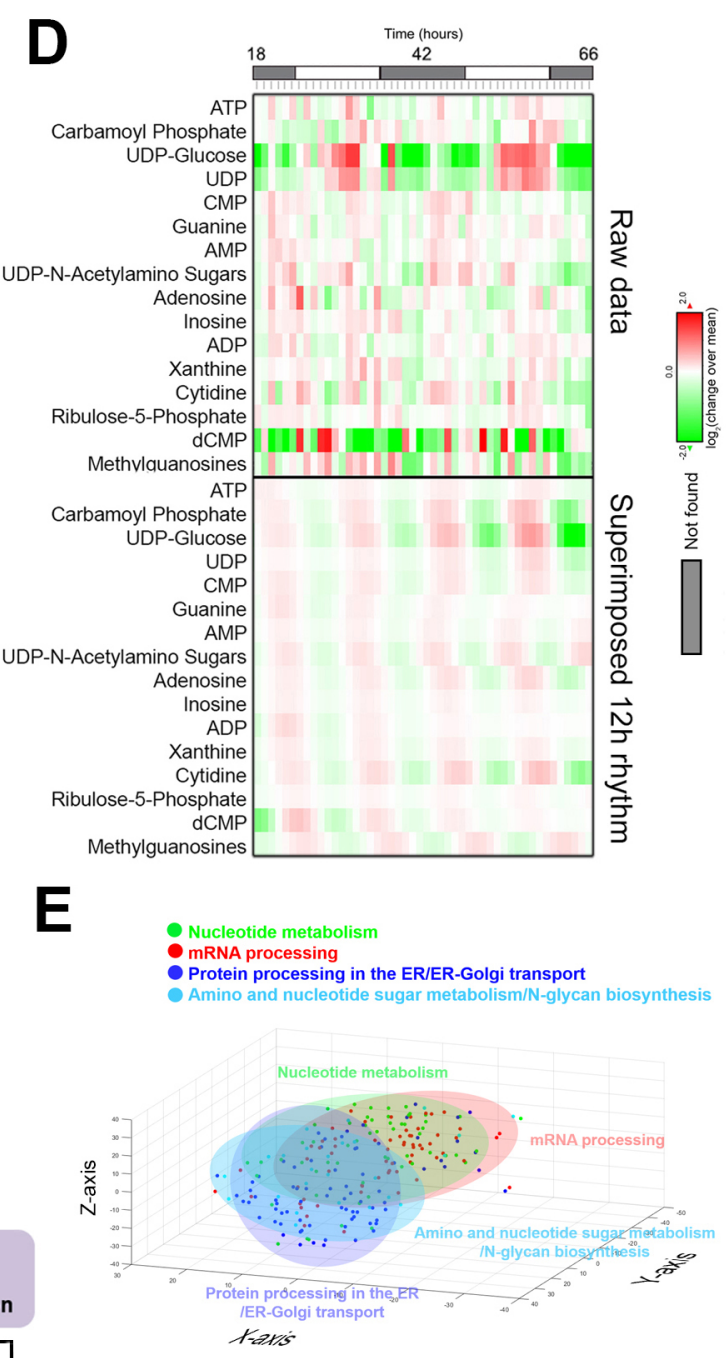

F

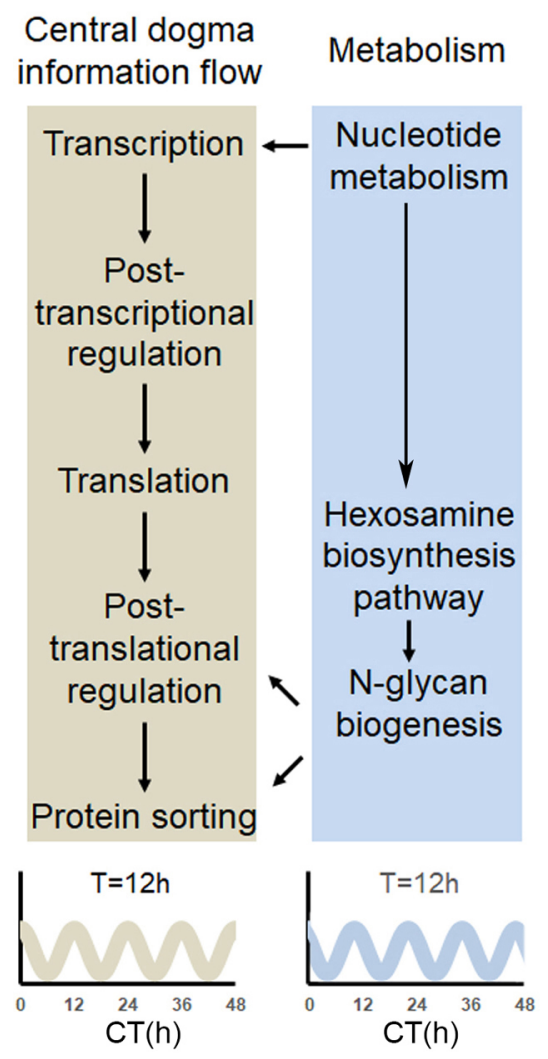


Ei d biokiv 5 eprint doi: https://doi.org/10.1101/559039; this version posted March 8, 2019. The copyright holder for this preprint (which was not FIg certified by peer review) is the author/funder. All rights reserved. No reuse allowed without permission.

A

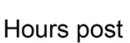

serum shock (h) 12

Corresponding CT(h) 2
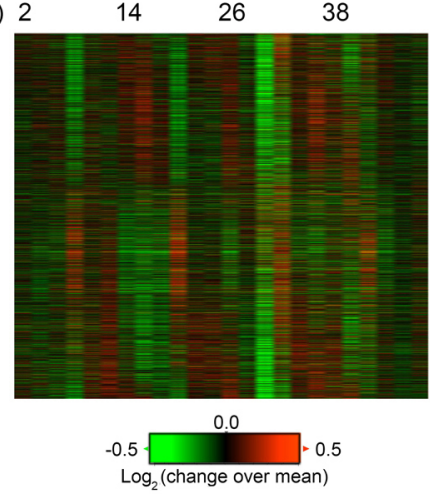

Superimposed $12 \mathrm{~h}$ rhythms

$\begin{array}{llll}12 & 24 & 36 & 48 \\ 2 & 14 & 26 & 38\end{array}$

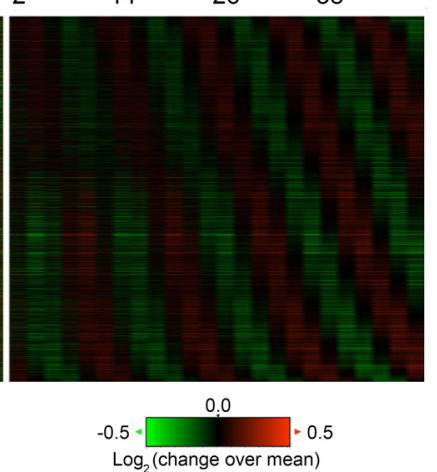

B

\begin{tabular}{|l|c|}
\hline \multicolumn{1}{|c|}{ Term } & PValue \\
\hline Spliceosome & $9.57 \mathrm{E}-10$ \\
\hline Ubiquitin mediated proteolysis & $3.63 \mathrm{E}-07$ \\
\hline Lysosome & $1.03 \mathrm{E}-06$ \\
\hline ErbB signaling pathway & $1.50 \mathrm{E}-06$ \\
\hline MAPK signaling pathway & $3.23 \mathrm{E}-06$ \\
\hline Insulin signaling pathway & $7.60 \mathrm{E}-06$ \\
\hline AMPK signaling pathway & $2.30 \mathrm{E}-05$ \\
\hline HIF-1 signaling pathway & $3.32 \mathrm{E}-05$ \\
\hline Endocytosis & $5.19 \mathrm{E}-05$ \\
\hline Protein processing in endoplasmic reticulum & $6.16 \mathrm{E}-05$ \\
\hline Metabolic pathways & $8.88 \mathrm{E}-05$ \\
\hline SNARE interactions in vesicular transport & $1.03 \mathrm{E}-04$ \\
\hline Ribosome & $1.08 \mathrm{E}-04$ \\
\hline TNF signaling pathway & $1.13 \mathrm{E}-04$ \\
\hline Thyroid hormone signaling pathway & $1.25 \mathrm{E}-04$ \\
\hline mRNA surveillance pathway & $1.49 \mathrm{E}-04$ \\
\hline Acute myeloid leukemia & $1.81 \mathrm{E}-04$ \\
\hline Neurotrophin signaling pathway & $1.85 \mathrm{E}-04$ \\
\hline Protein export & $2.49 \mathrm{E}-04$ \\
\hline
\end{tabular}

C

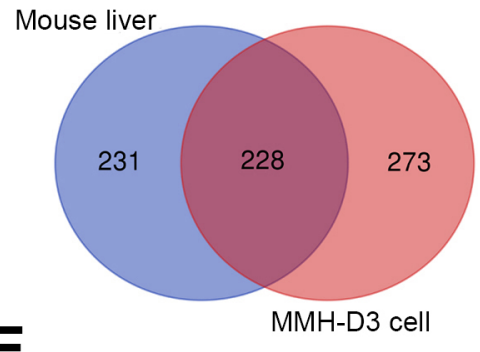

E

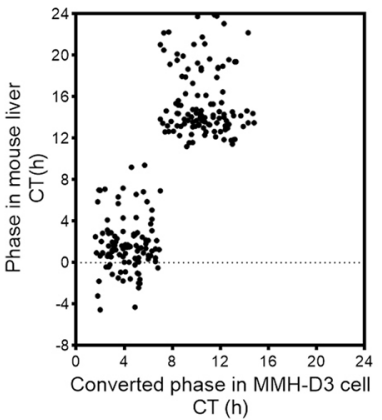

F

H
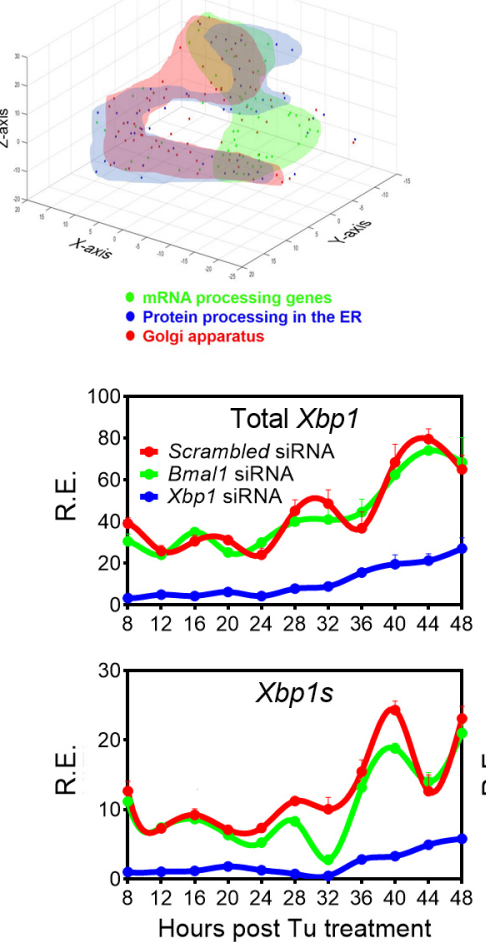

Hours post Tu treatment

D

G

\section{Hours post}

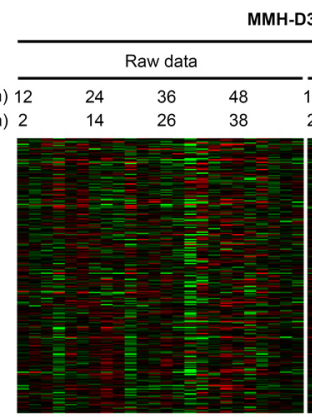

MMH-D3 cells
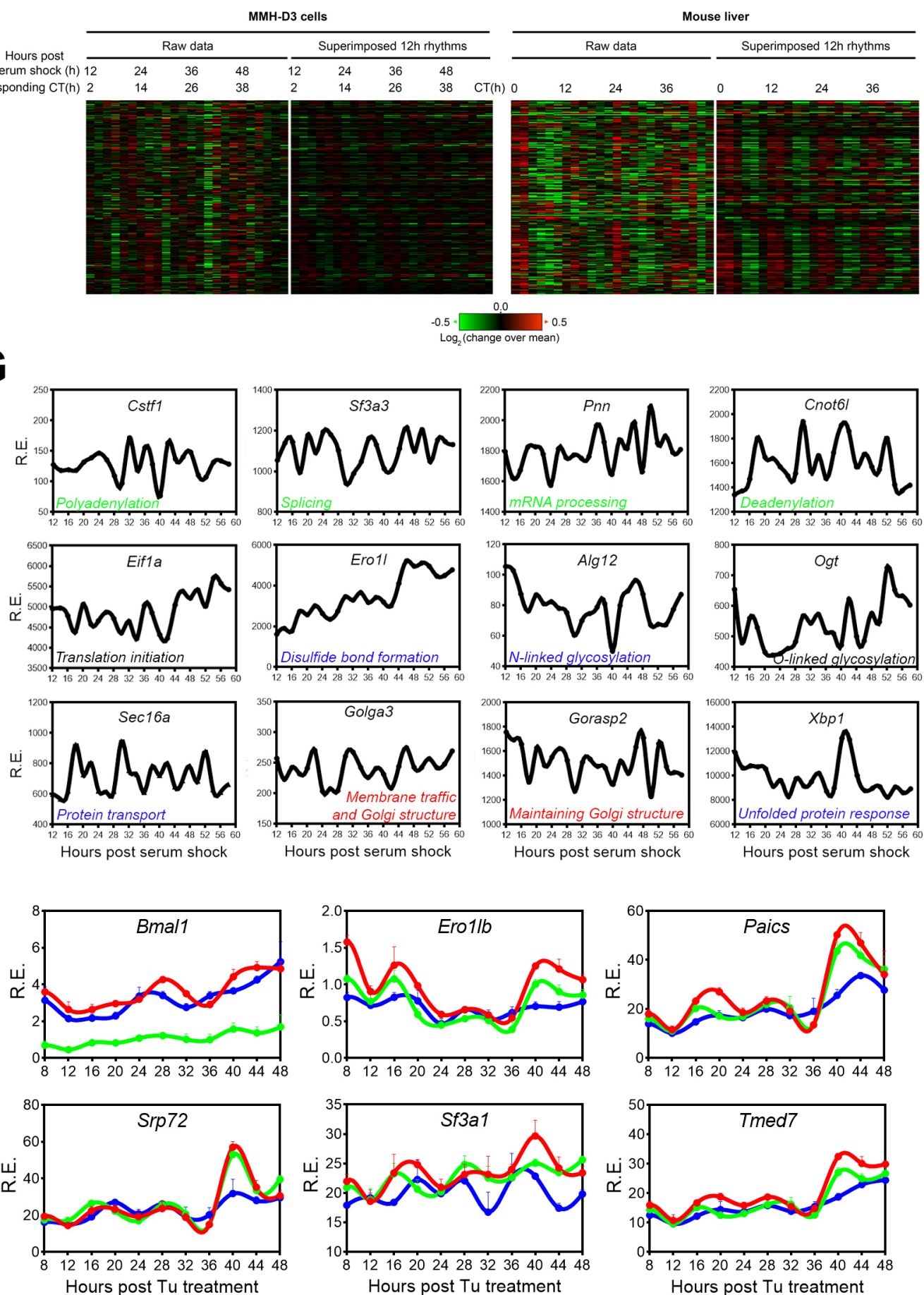
EIq UipRivgreprint doi: https://doi.org/10.1101/559039; this version posted March 8, 2019. The copyright holder for this preprint (which was not FIgUre 6. certified by peer review) is the author/funder. All rights reserved. No reuse allowed without permission.

A

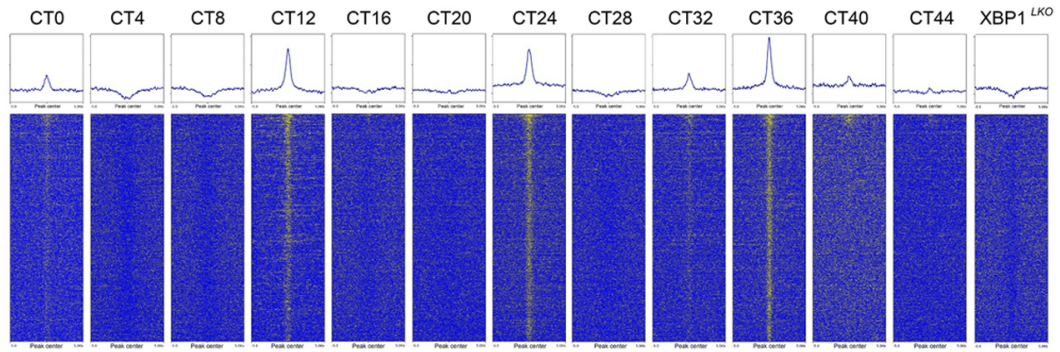

C
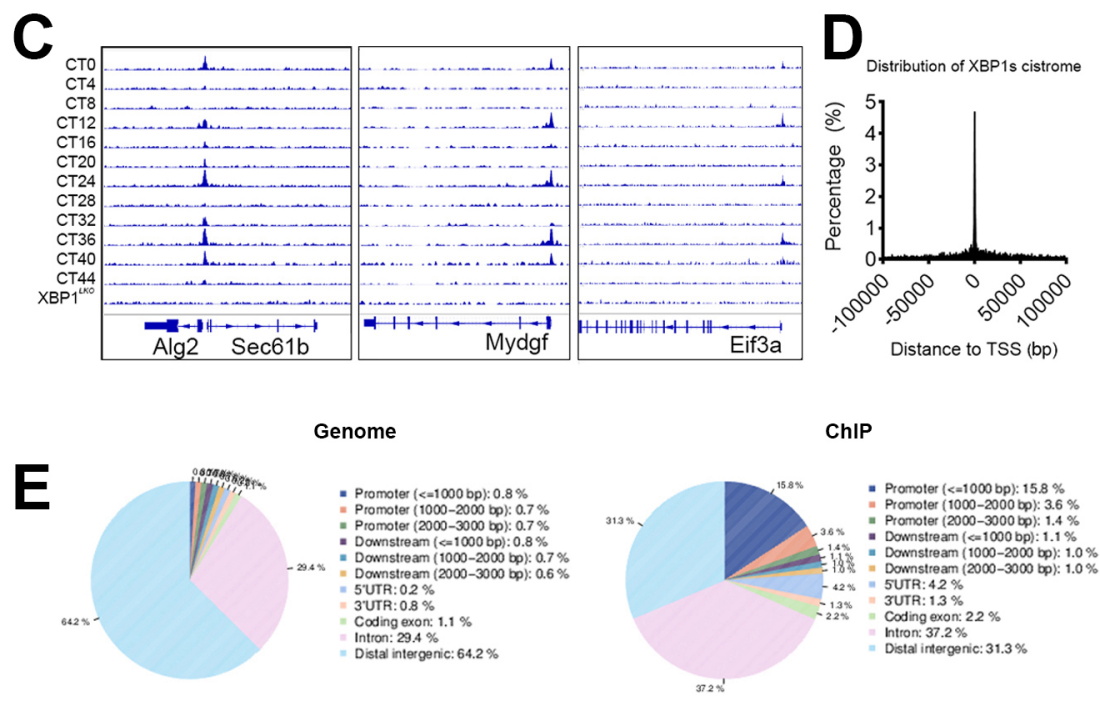

H

\begin{tabular}{|c|c|c|}
\hline Motif & TF & $-10^{*} \log (p$ value $)$ \\
\hline \multicolumn{3}{|c|}{ Associated with $12 \mathrm{~h}$ transcriptome } \\
\hline$I_{1}^{2} \quad C A C G T C A$ & XBP1 & 178.665 \\
\hline \multicolumn{3}{|c|}{ Not associated with $12 \mathrm{~h}$ transcriptome } \\
\hline c CACEIC C & De novo & 232.447 \\
\hline
\end{tabular}

$\mathbf{L}$
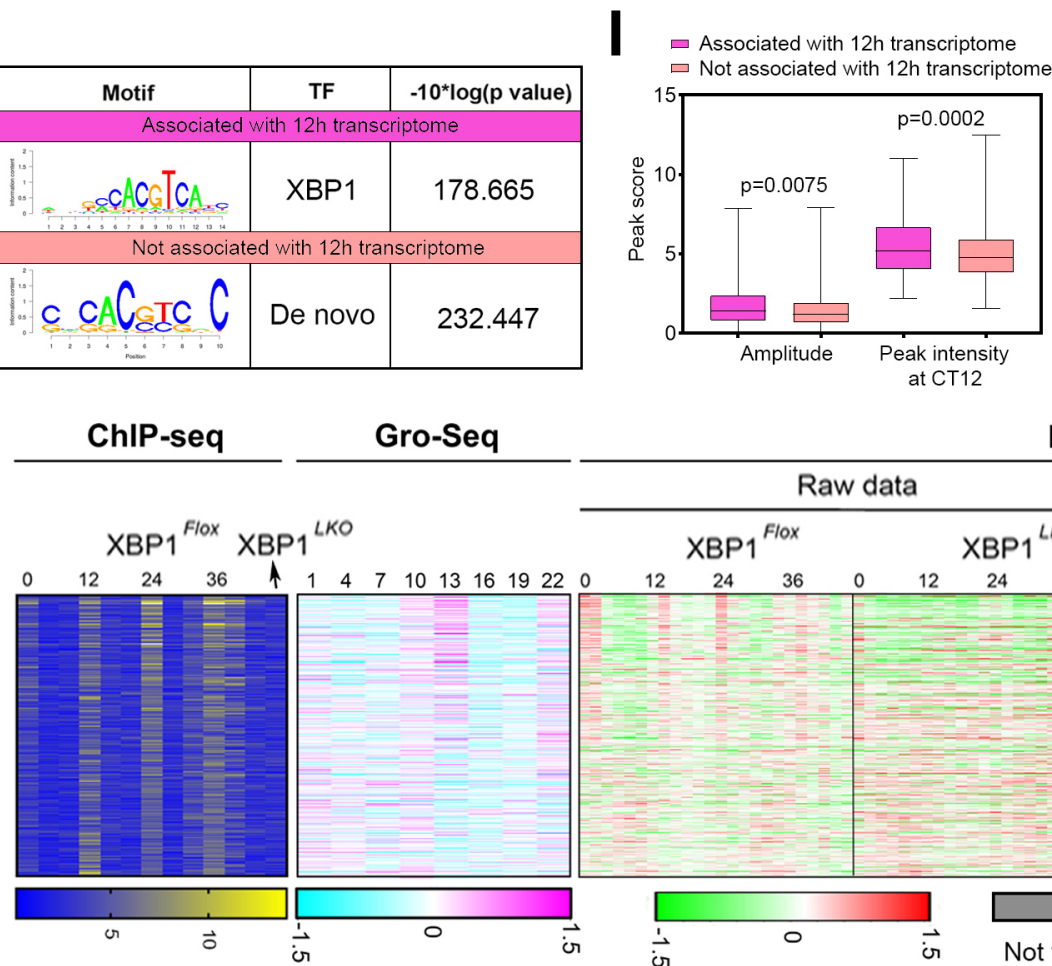
at $\mathrm{CT} 12$
B

\begin{tabular}{|c|c|c|c|c|}
\hline Motif & TF & DNA binidng domain & \multicolumn{2}{|c|}{$-10^{*} \log (p$ value $)$} \\
\hline \multirow{2}{*}[.]{$\quad c A c G T C A$} & & & $1000 \mathrm{bp} \mathrm{scan}$ & $800 \mathrm{bp} \mathrm{scan}$ \\
\hline & XBP1 & Leucine Zipper & 375.555 & 111.049 \\
\hline$\therefore \mathrm{ccAc}$ & ATF6 & Leucine Zipper & 275.288 & 95.249 \\
\hline & $\begin{array}{l}\text { CREB33 } \\
\text { CREBBL }\end{array}$ & Leucine Zipper & 265.076 & 134.129 \\
\hline & GABP & Ets domain & 279.638 & Not found \\
\hline $1: \mathrm{co}$ & ELF1 & Ets domain & 226.085 & Not found \\
\hline
\end{tabular}

$\mathbf{F}$

12h protein-coding transcriptome

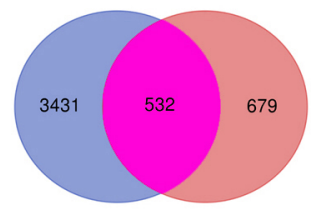

$\mathrm{p}$ value $=5.52 \times 10^{-29}$

12h XBP1s cistrome (TSS-associated)

\section{G}
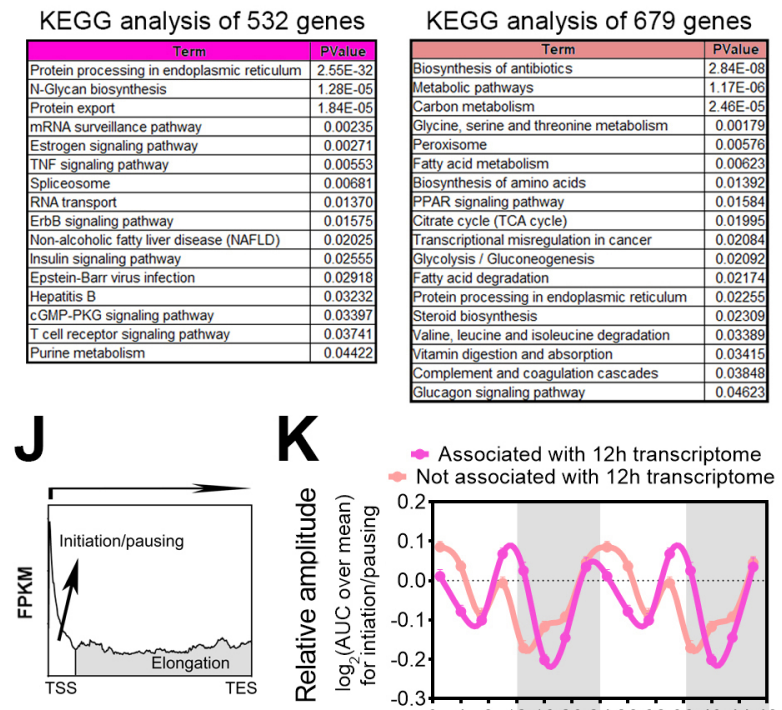

- Associated with $12 \mathrm{~h}$ transcriptome Not associated with $12 \mathrm{~h}$ transcriptome

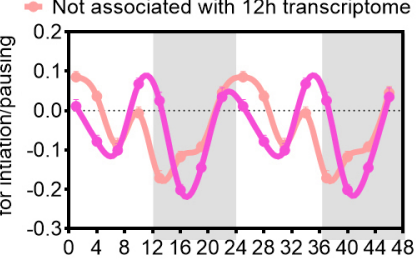
$\mathrm{ZT}(\mathrm{h})$

RNA-Seq

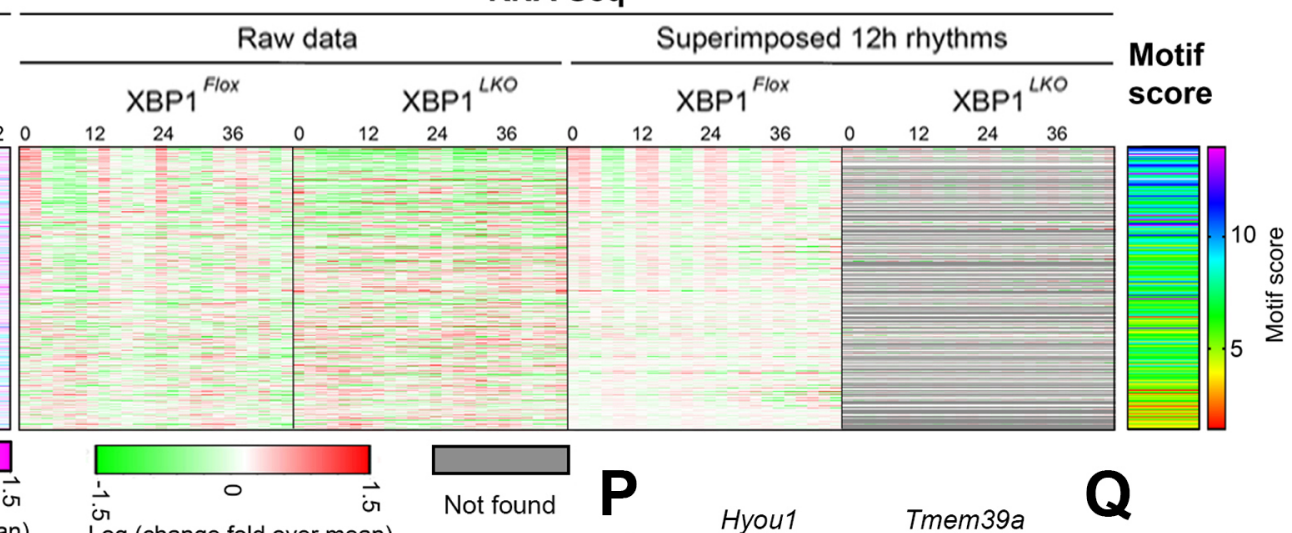

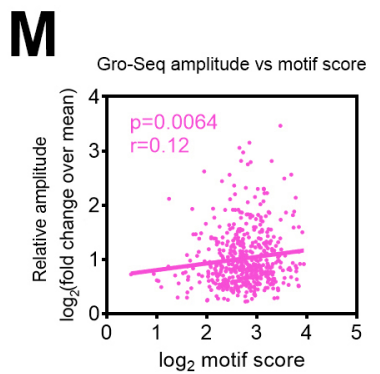

$\mathbf{N}$

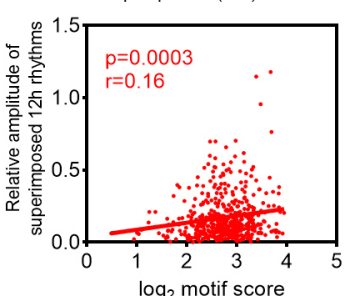

RNA-Seq amplitude WT vs XBP ${ }^{\text {LKO }}$

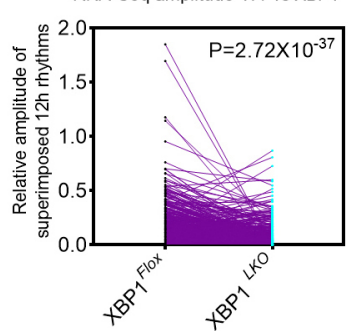

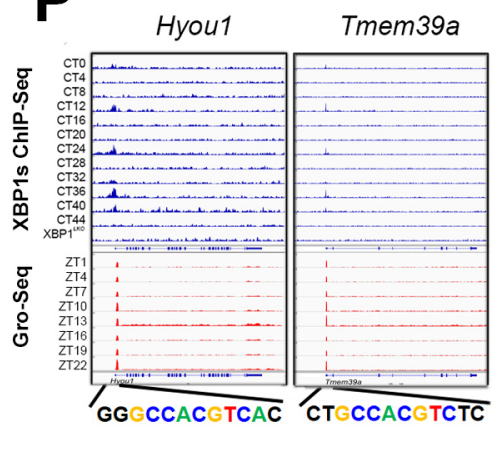
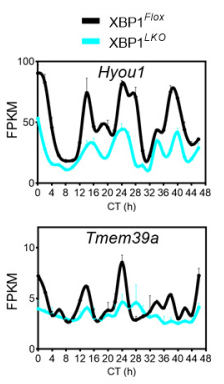
bioRxiv preprint doi: https://doi.org/10.1101/559039; this version posted March 8, 2019. The copyright holder for this preprint (which was not

Figure 7.

A

Aiptasia diaphaha (ZT)

M. musculus (CT)

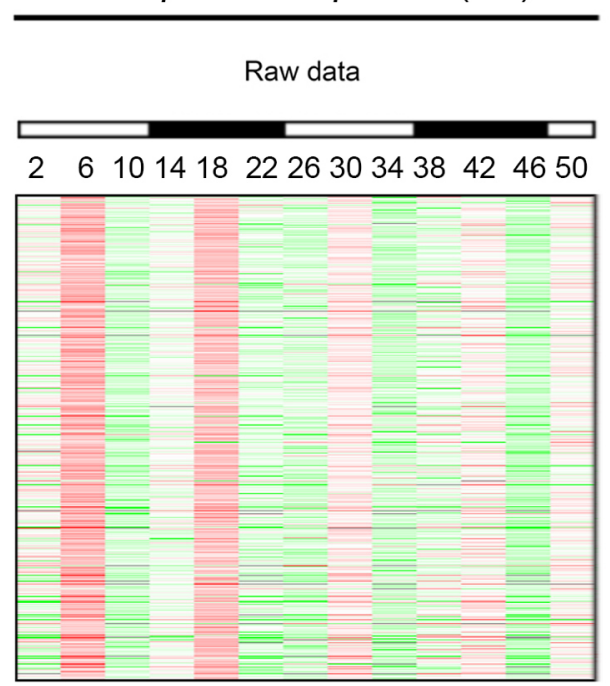

B

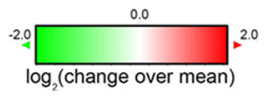

Raw data

Uncovered superimposed $\sim 12 \mathrm{~h}$ rhythms

Constant darkness

Constant darkness
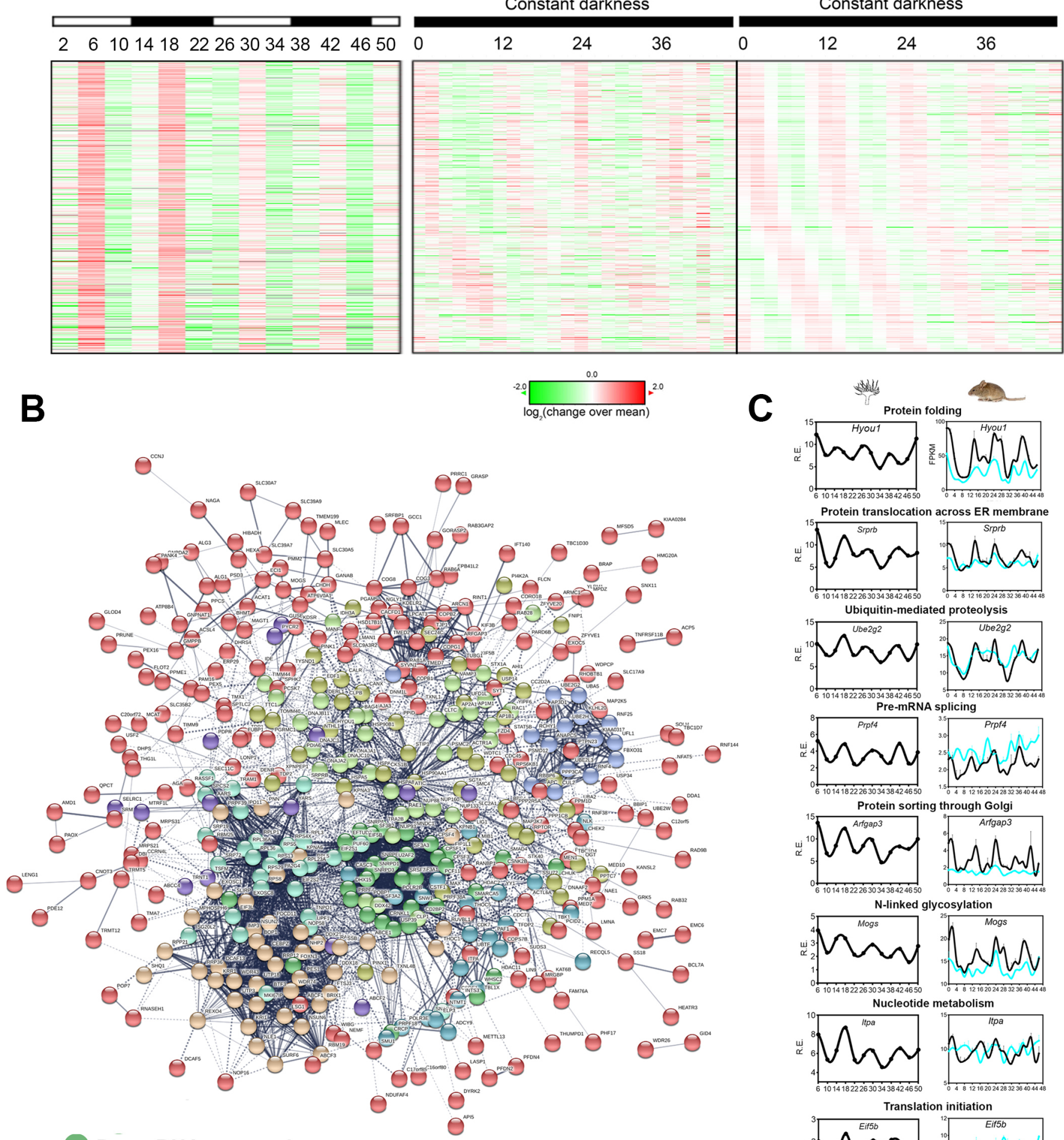

C
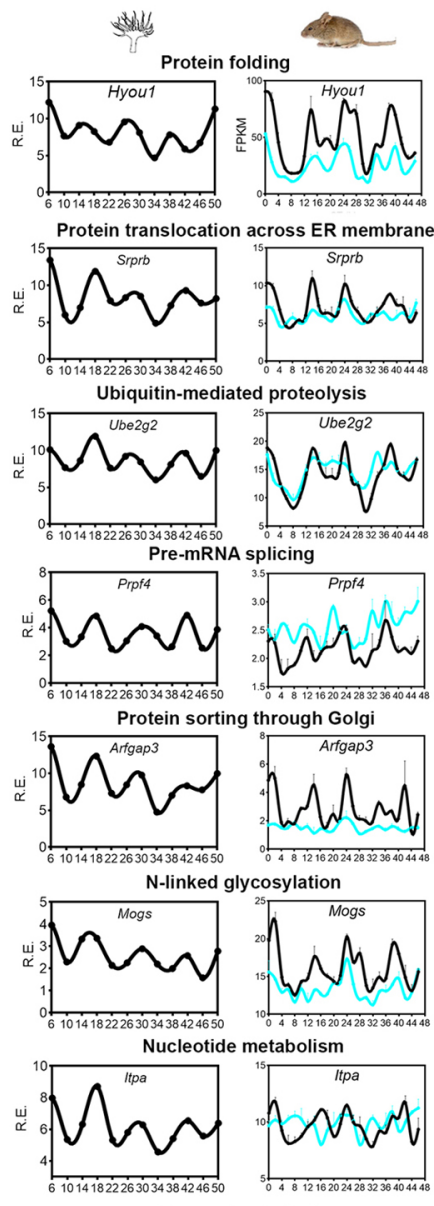

Pre-mRNA processing

\section{Protein folding}

Nucleotide metabolism/Transcription regulation

Amino acid and tRNA metabolsim

Other

Ribosome biogenesis

Ubiquitin-mediated proteolysis

Ribosome/protein translocation across ER membrane

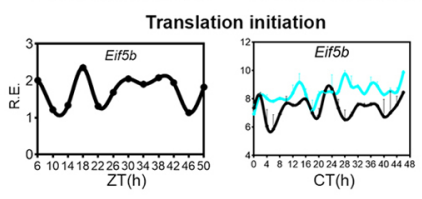

D

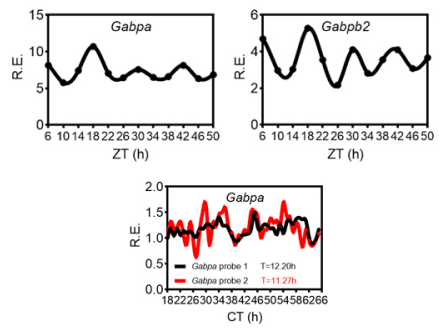


bioRxiv preprint doi: https://doi.org/10.1101/559039; this version posted March 8, 2019. The copyright holder for this preprint (which was not

Figure 8.

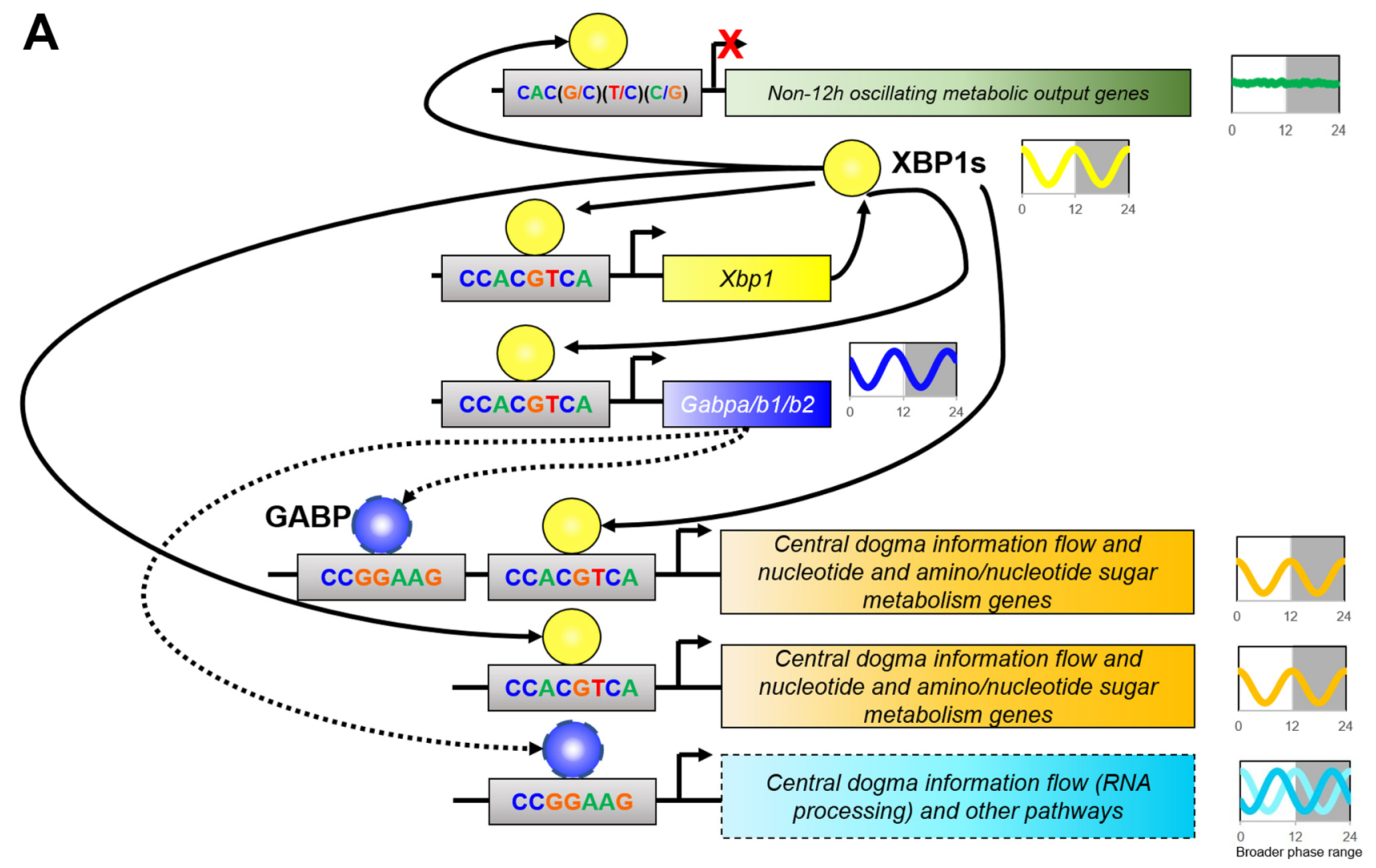

B

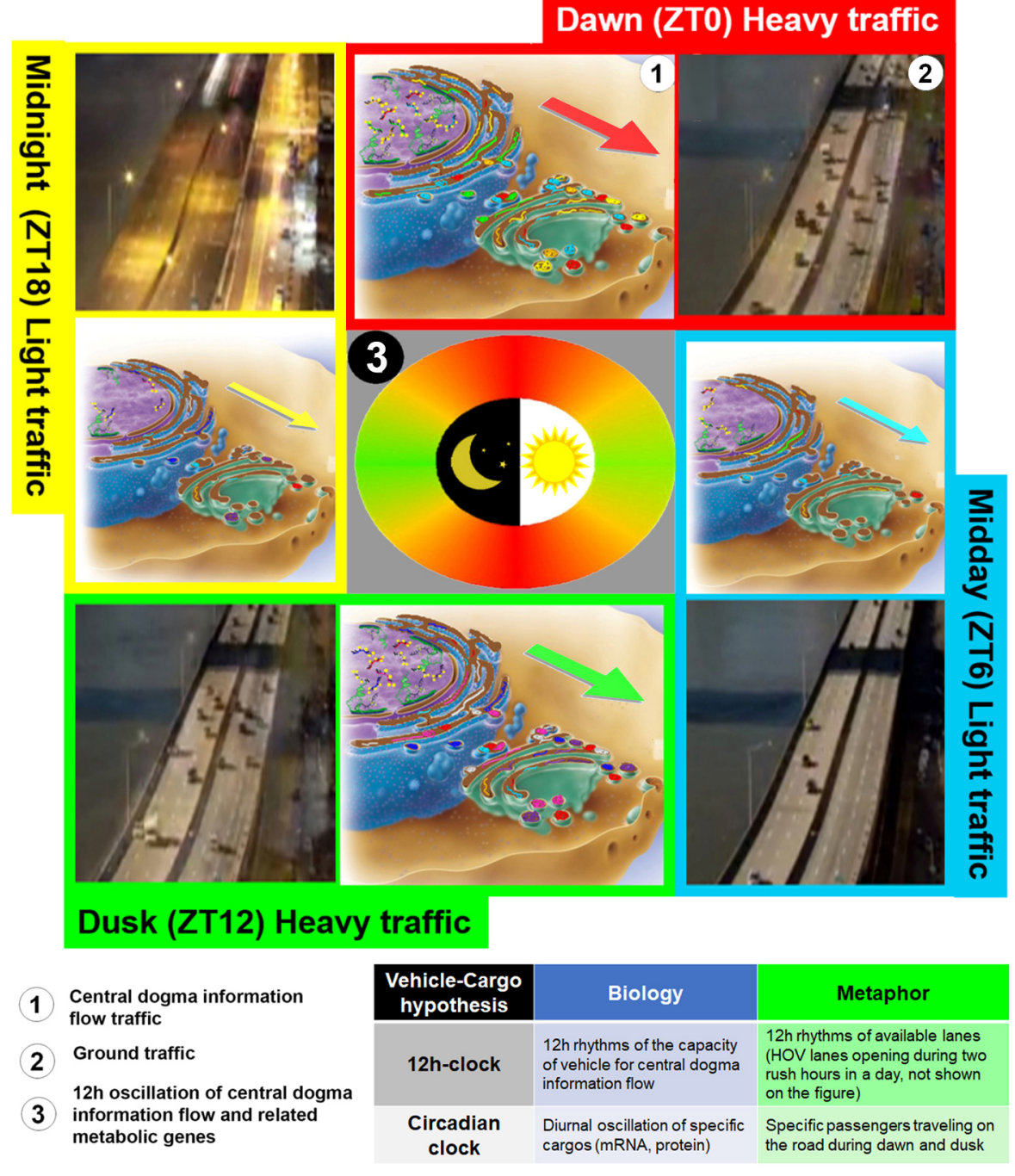




\section{Figure S1.}

A
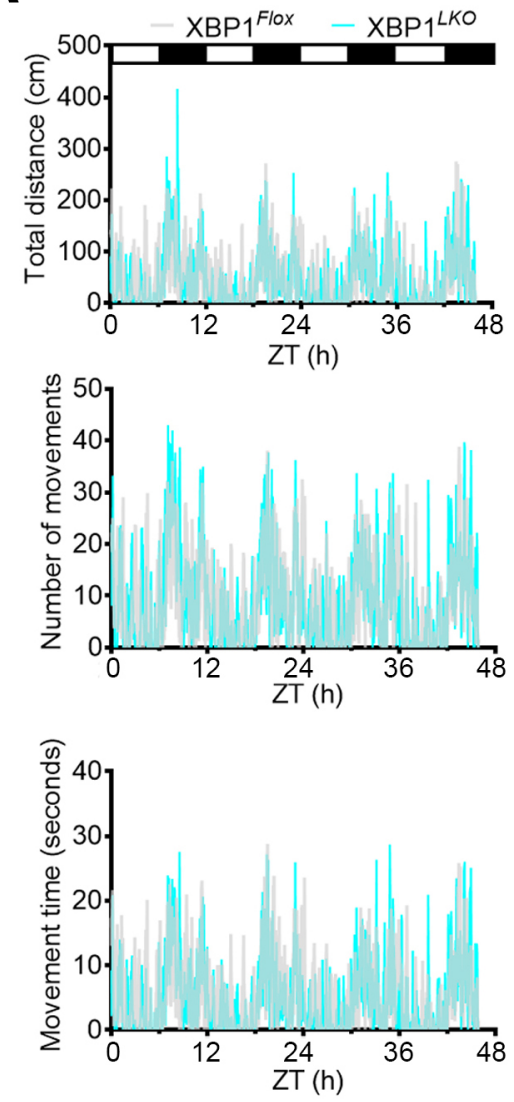

\section{B}
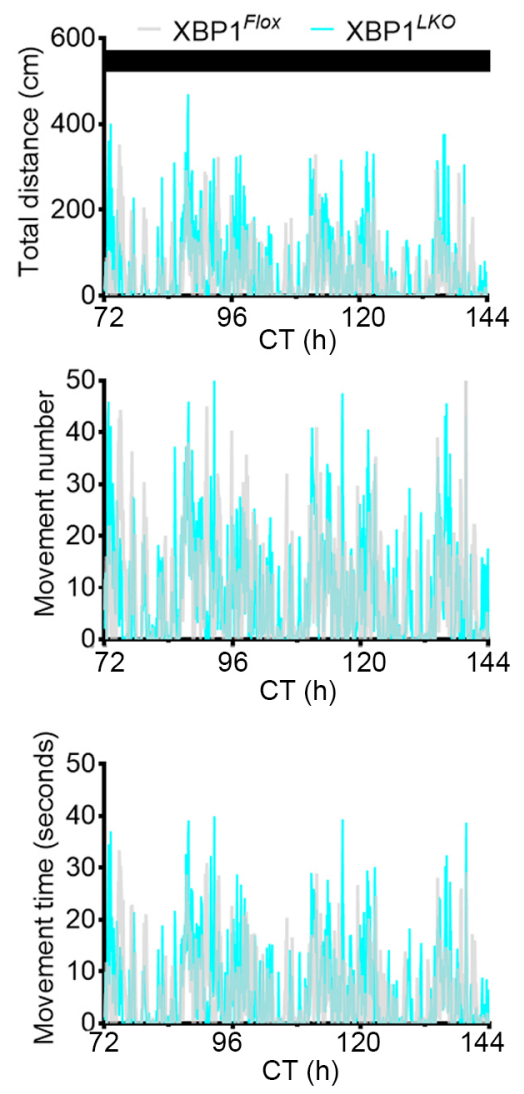

C
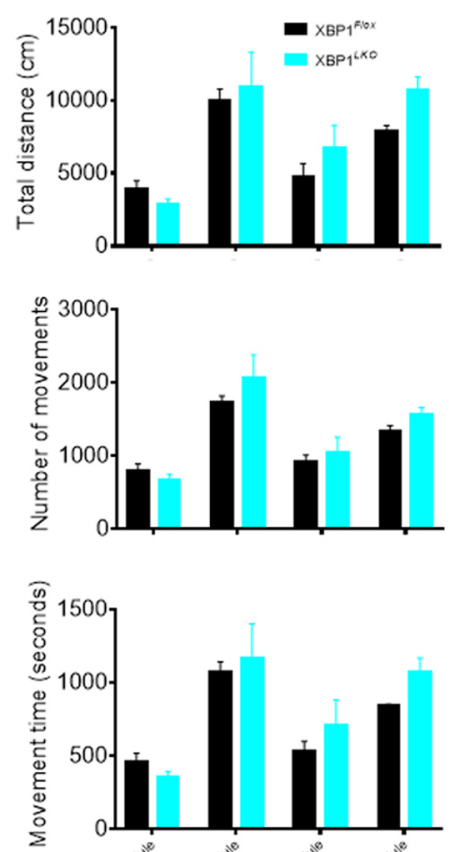

E

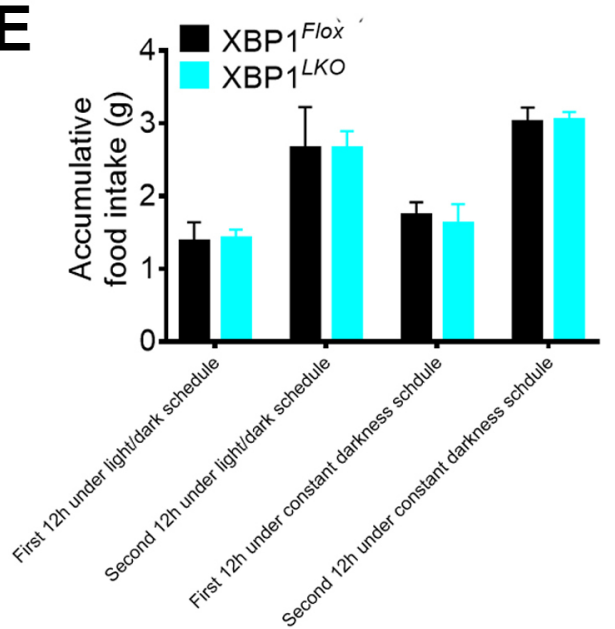




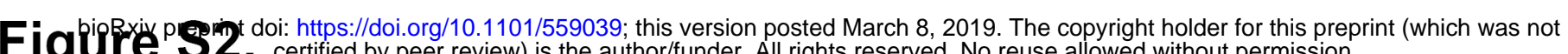
A
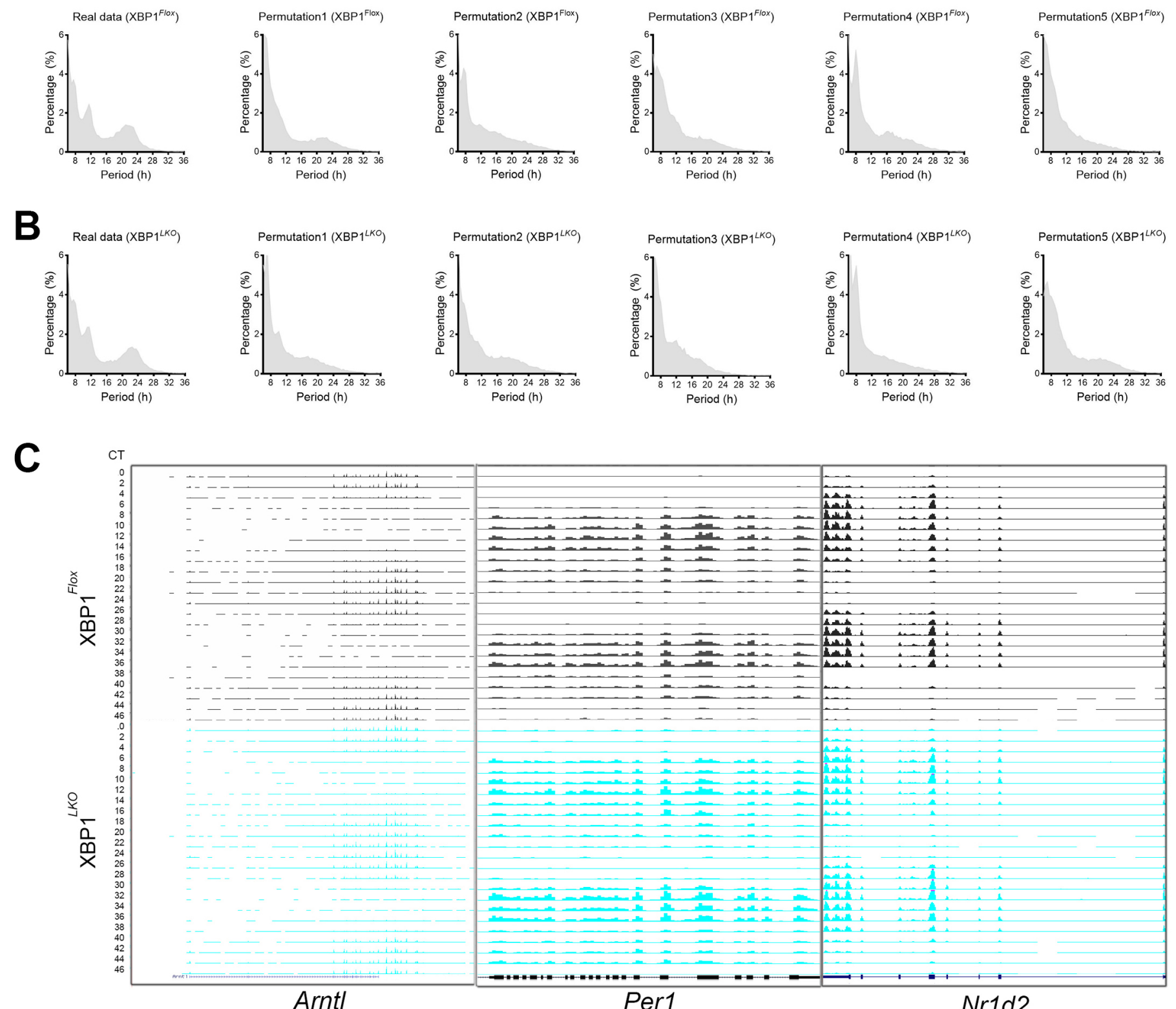

D
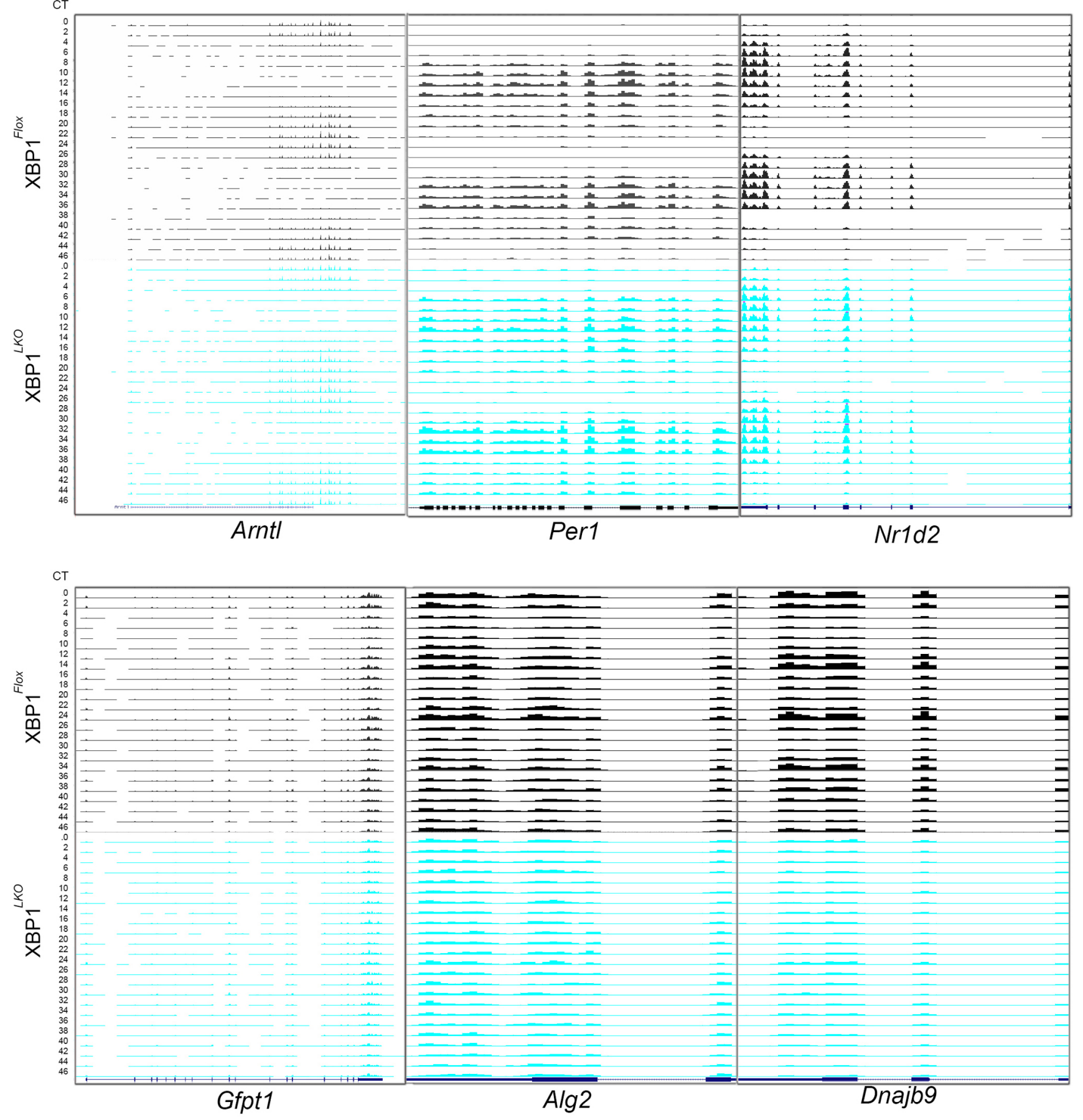
bioRxiv preprint doi: https://doi.org/10.1101/559039; this version posted March 8, 2019. The copyright holder for this preprint (which was not certified by peer review) is the author/funder. All rights reserved. No reuse allowed without permission.

Figure S3.

A

B
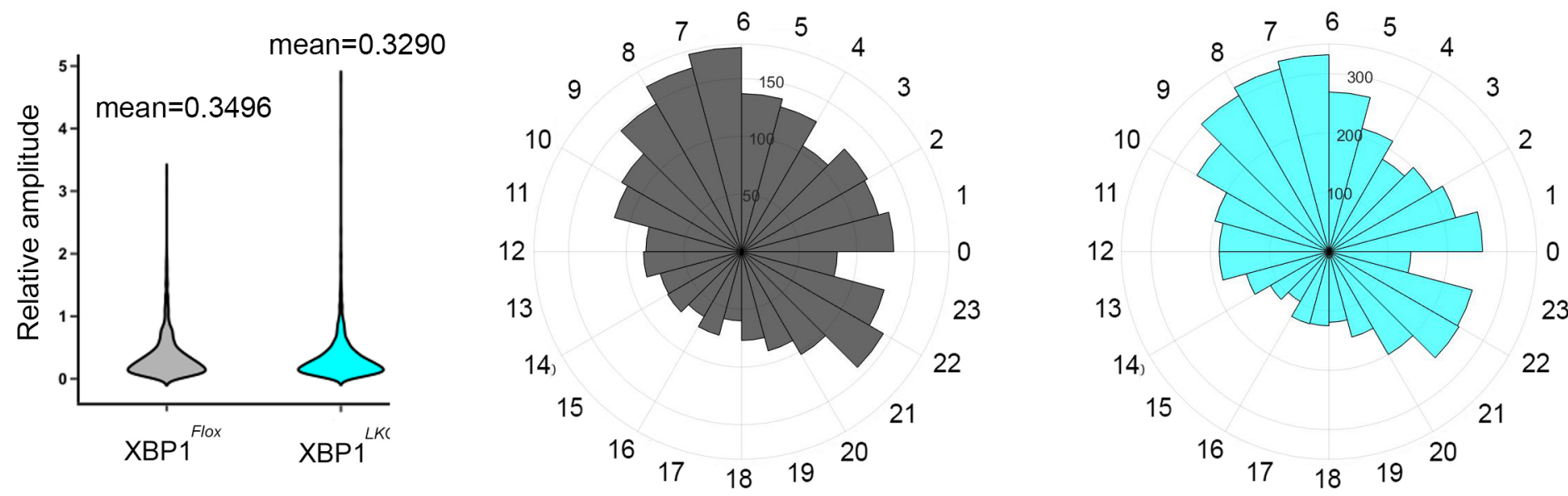

D

\begin{tabular}{|l|r|}
\hline \multicolumn{1}{|c|}{ Term } & \multicolumn{1}{c|}{ PValue } \\
\hline Metabolic pathways & $6.22 \mathrm{E}-07$ \\
\hline ABC transporters & $3.36 \mathrm{E}-04$ \\
\hline Sphingolipid metabolism & $4.99 \mathrm{E}-04$ \\
\hline Insulin resistance & $8.50 \mathrm{E}-04$ \\
\hline Sphingolipid signaling pathway & 0.00139602 \\
\hline Apoptosis & 0.00342719 \\
\hline Insulin signaling pathway & 0.0056416 \\
\hline Circadian rhythm & 0.00572234 \\
\hline
\end{tabular}

F
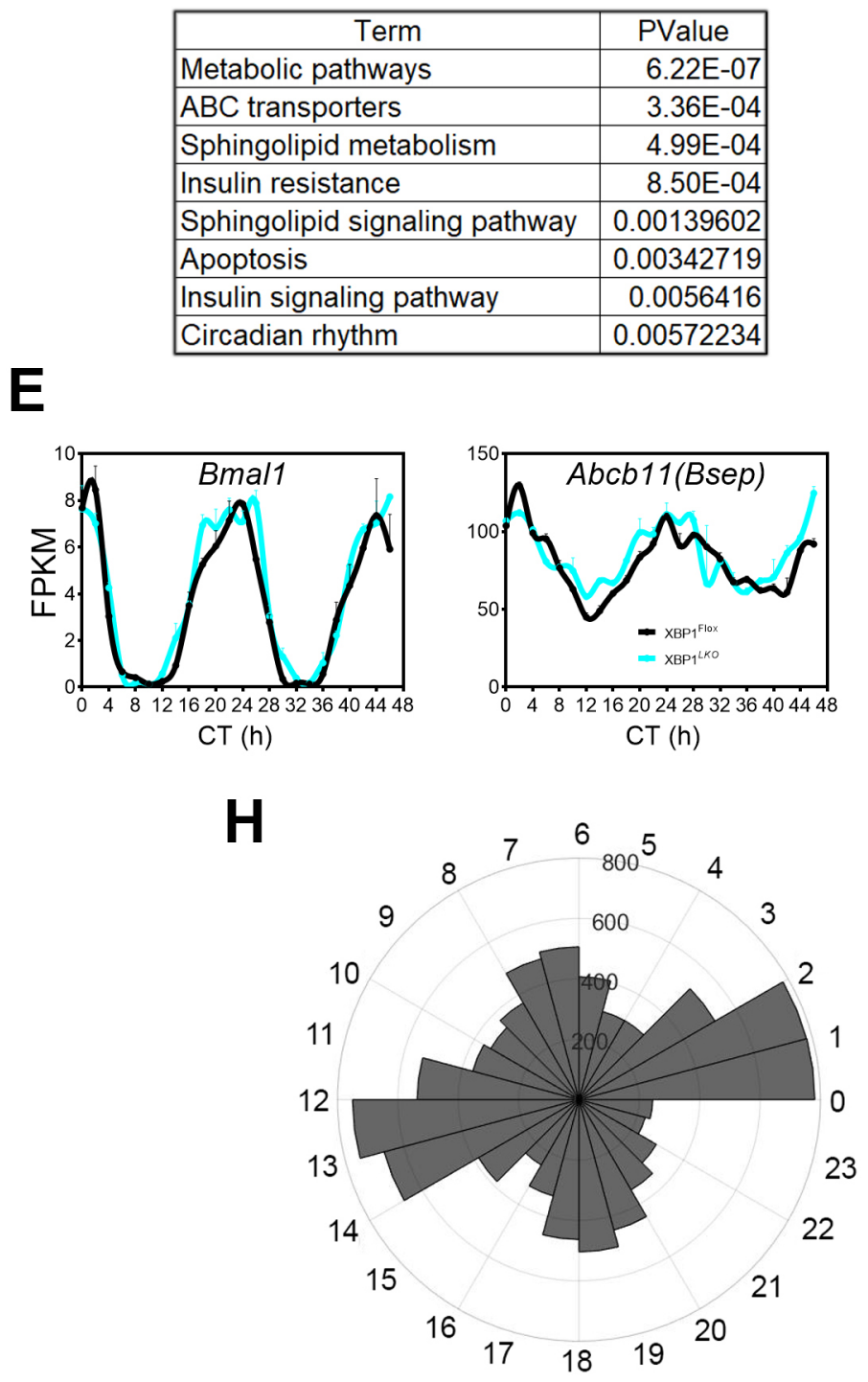

G
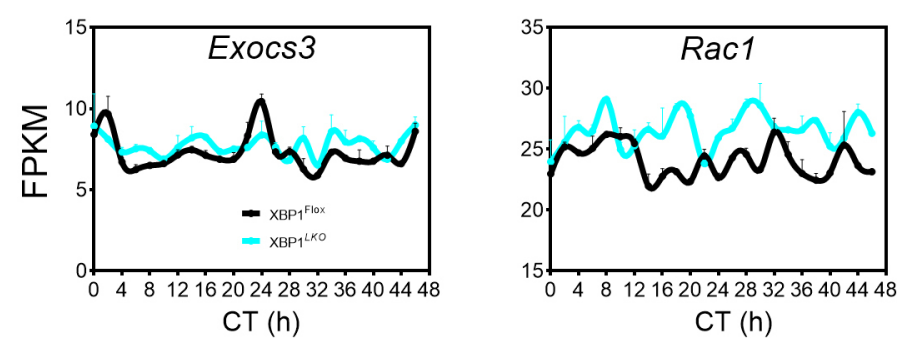

\begin{tabular}{|l|r|}
\hline \multicolumn{1}{|c|}{ Term } & \multicolumn{1}{c|}{ PValue } \\
\hline RNA degradation & $3.73 \mathrm{E}-04$ \\
\hline PI3K-Akt signaling pathway & 0.00143 \\
\hline Ras signaling pathway & 0.00147 \\
\hline Epstein-Barr virus infection & 0.00225 \\
\hline Fanconi anemia pathway & 0.00251 \\
\hline Pathways in cancer & 0.00271 \\
\hline Bladder cancer & 0.00489 \\
\hline
\end{tabular}

CT (h)

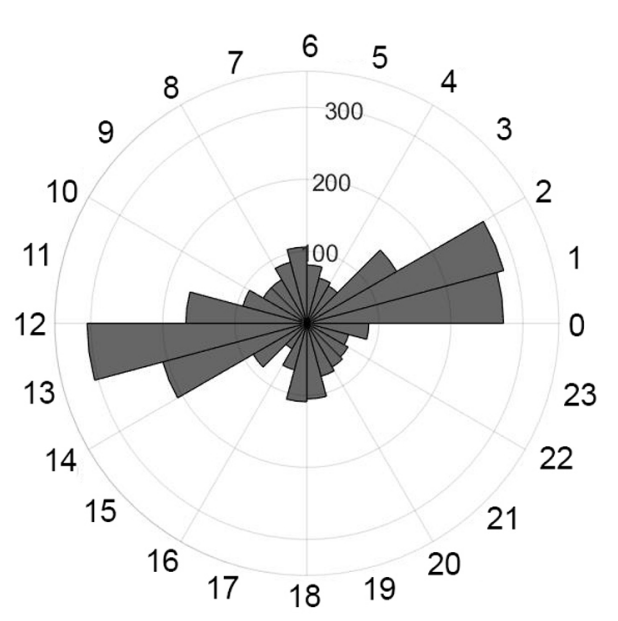


bioRxiv preprint doi: https://doi.org/10.1101/559039; this version posted March 8, 2019. The copyright holder for this preprint (which was not certified by peer review) is the author/funder. All rights reserved. No reuse allowed without permission.

\section{Figure S4.}

A

mRNA processing

Ribosome biogenesis/Translation regulation

- Protein processing in the ER/ER-Golgi transport

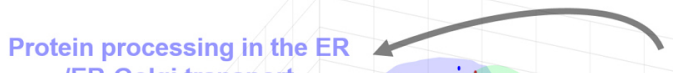

/ER-Golgi transport

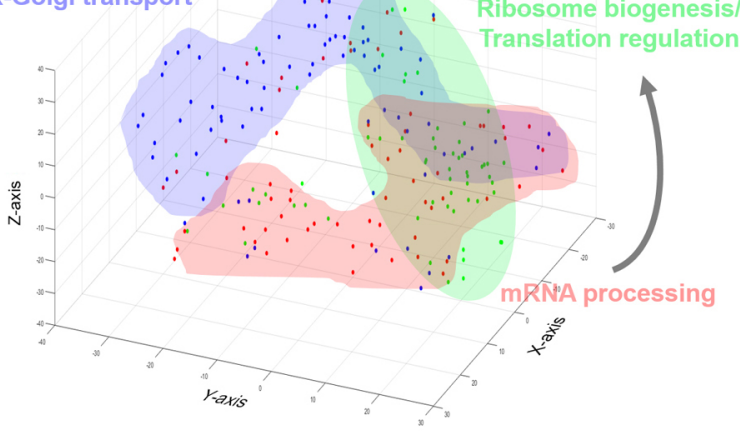

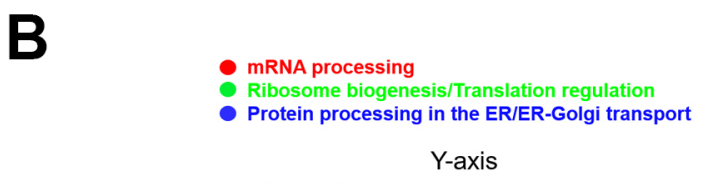

Protein processing in the ER /ER-Golgi transport

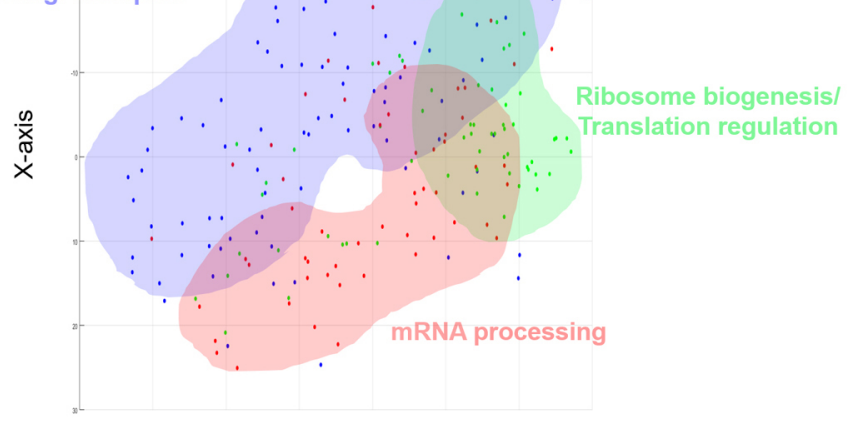

C

- Ribosome biogenesis

- Translation initiation

- Protein folding in the ER

- Protein ER-Golgi transport

- Glycosylation

Protiolys:ls/ERAD

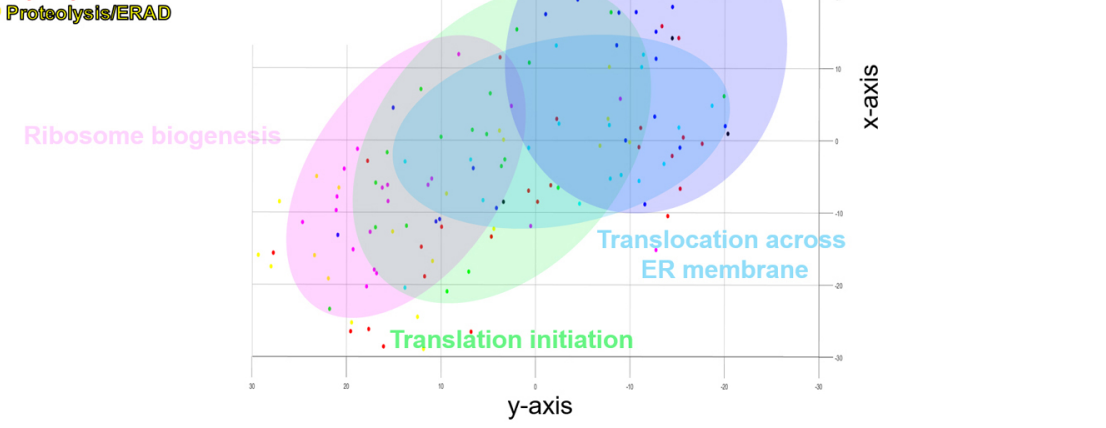

D

Amino and nucleotide sugar metabolism

/N-glycan biosynthesis

mRNA processing

Protein processing in the ER/ER-Golgi transport

- Amino and nucleotide sugar metabolism/N-glycan biosynthesis

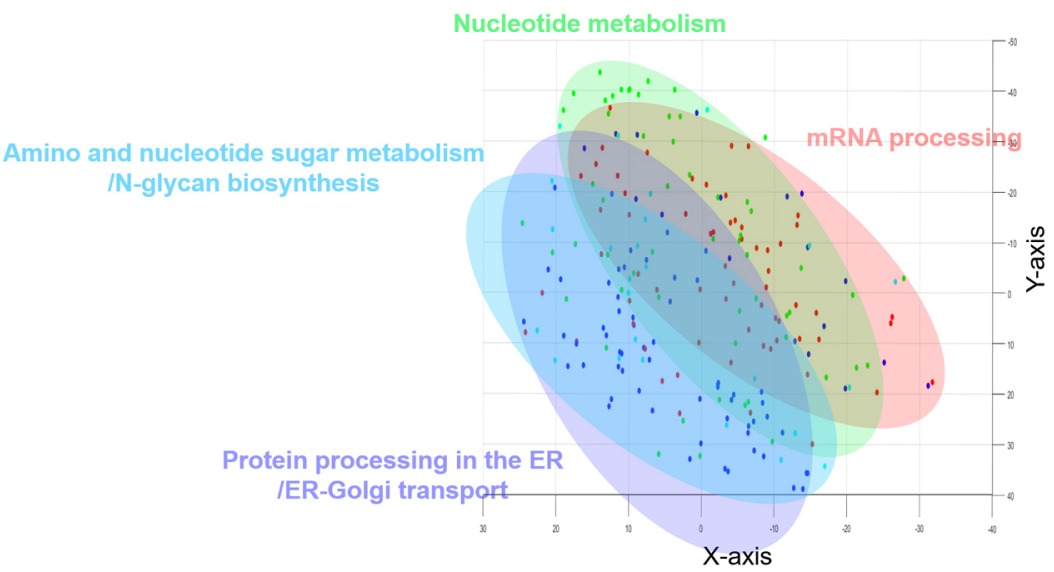


Figure S5.

A

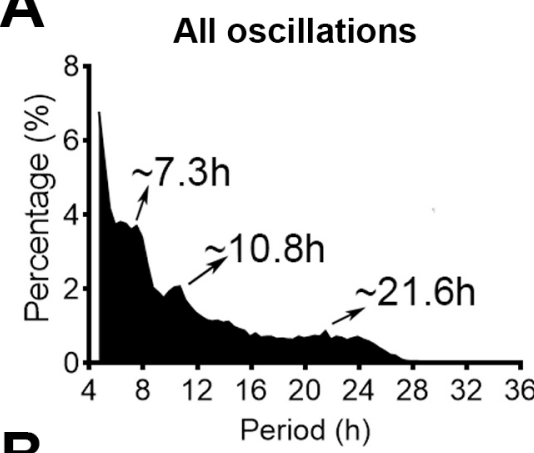

B

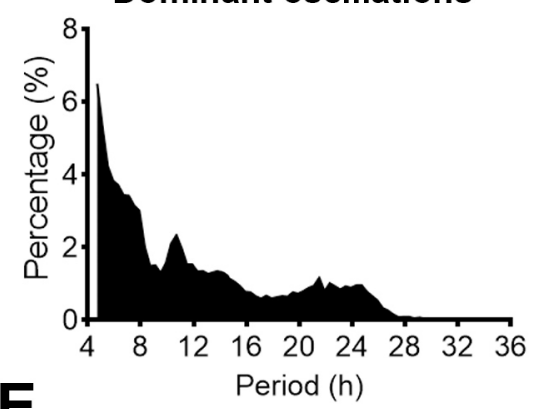

E

\begin{tabular}{|l|c|}
\hline \multicolumn{1}{|c|}{ Term } & PValue \\
\hline Circadian rhythm & $2.62 \mathrm{E}-07$ \\
\hline Renal cell carcinoma & $9.60 \mathrm{E}-06$ \\
\hline Biosynthesis of antibiotics & $2.23 \mathrm{E}-05$ \\
\hline Neurotrophin signaling pathway & $2.35 \mathrm{E}-05$ \\
\hline HIF-1 signaling pathway & $3.21 \mathrm{E}-05$ \\
\hline Protein processing in endoplasmic reticulum & $1.01 \mathrm{E}-04$ \\
\hline Epstein-Barr virus infection & $2.66 \mathrm{E}-04$ \\
\hline Pancreatic cancer & $2.99 \mathrm{E}-04$ \\
\hline Hippo signaling pathway & $4.27 \mathrm{E}-04$ \\
\hline
\end{tabular}

$\mathbf{F}$

H
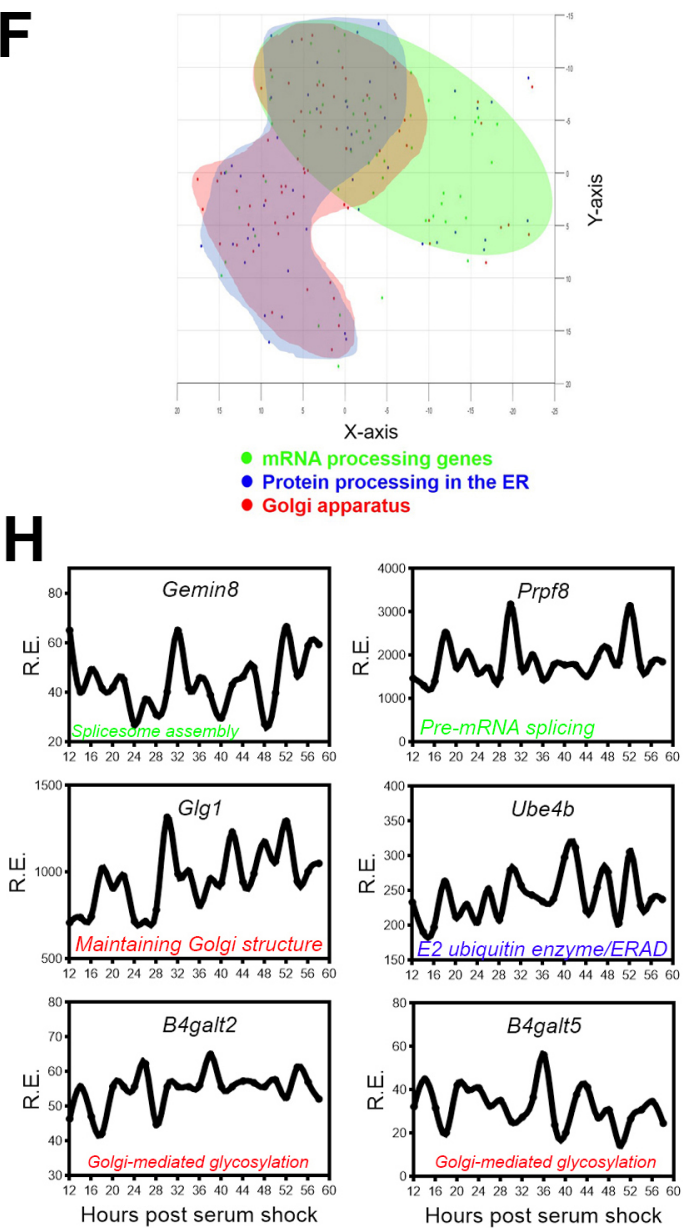

C

D
Hours post

serum shock $(h) 12$

Corresponding CT(h) 2
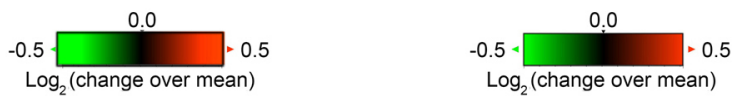

Hours post serum shock $(h) 12$

Corresponding CT(h) 2

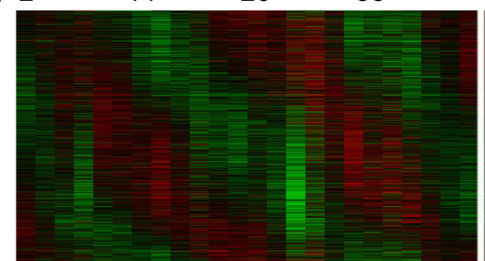

Log $_{2}$ (change over mean)

$\log _{2}$ (change over mean)

\begin{tabular}{cccc}
\multicolumn{4}{c}{ Raw data } \\
\hline h) 12 & 24 & 36 & 48 \\
2 & 14 & 26 & 38
\end{tabular}

Superimposed 24 h rhythms

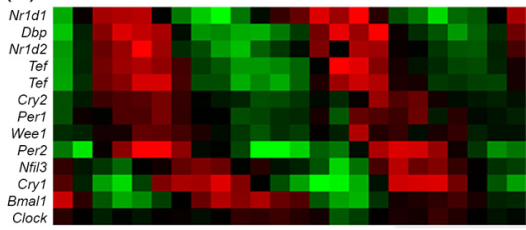

$\begin{array}{llll}12 & 24 & 36 & 48\end{array}$

$\begin{array}{llll}2 & 14 & 26 & 38\end{array}$
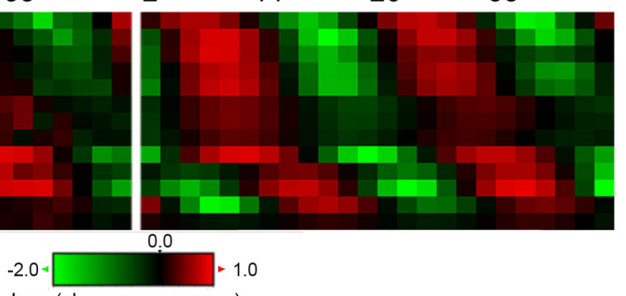

$\log _{2}$ (change over mean)

$G$
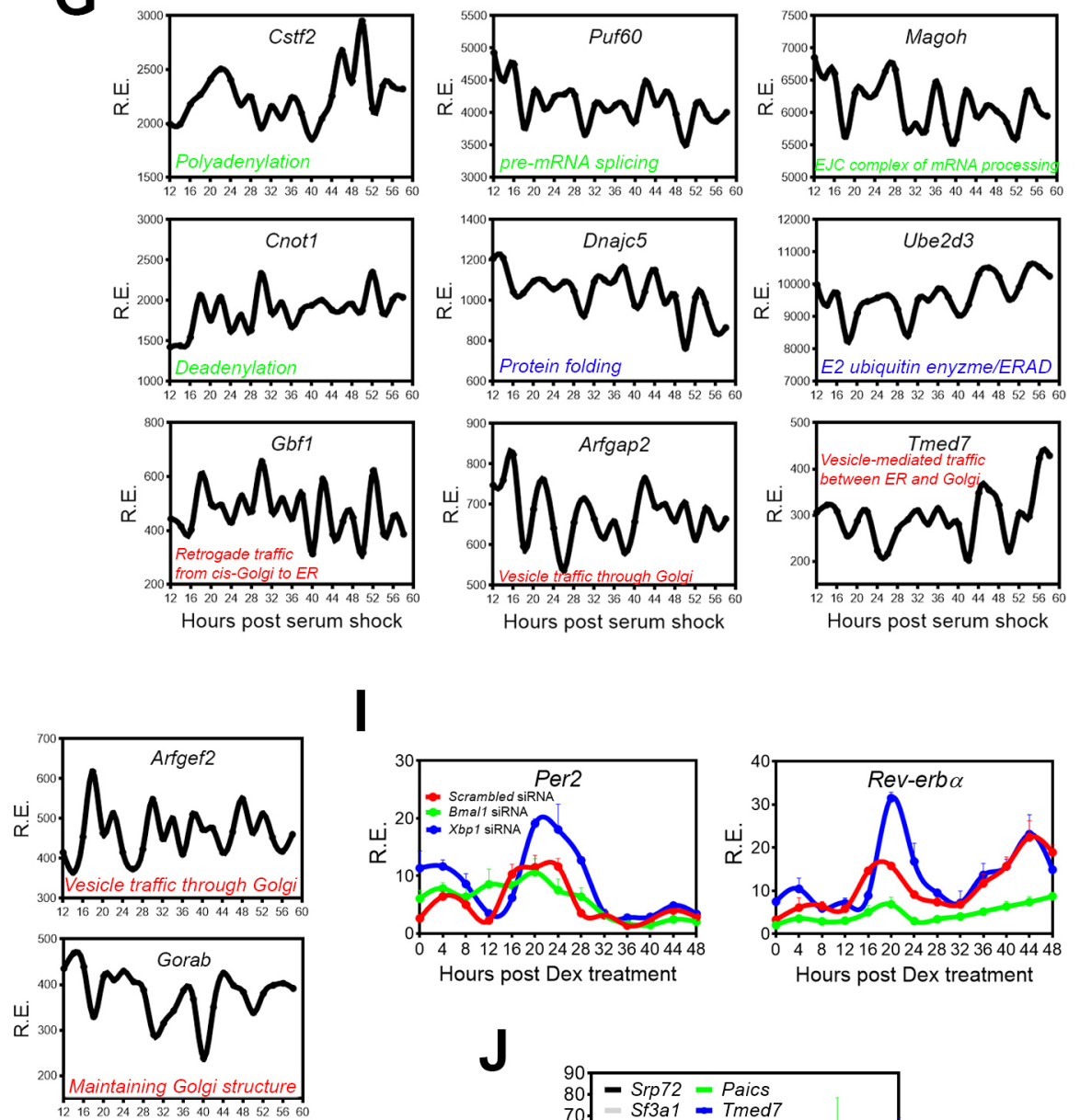

J
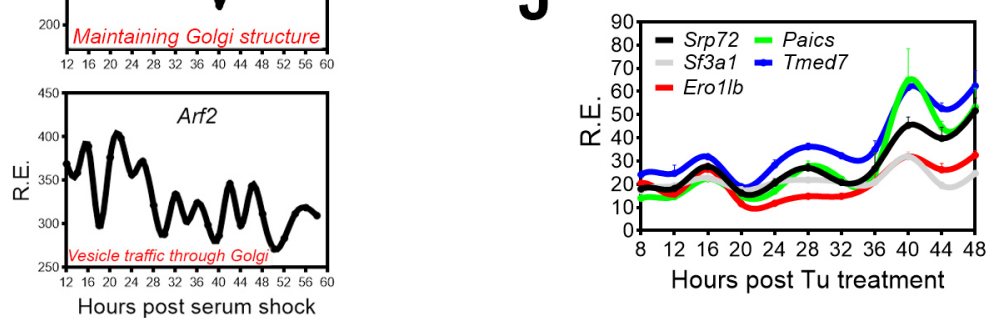
bioRxiv preprint doi: https://doi.org/10.1101/559039; this version posted March 8, 2019. The copyright holder for this preprint (which was not Figure S6. certified by peer review) is the author/funder. All rights reserved. No reuse allowed without permission.

A
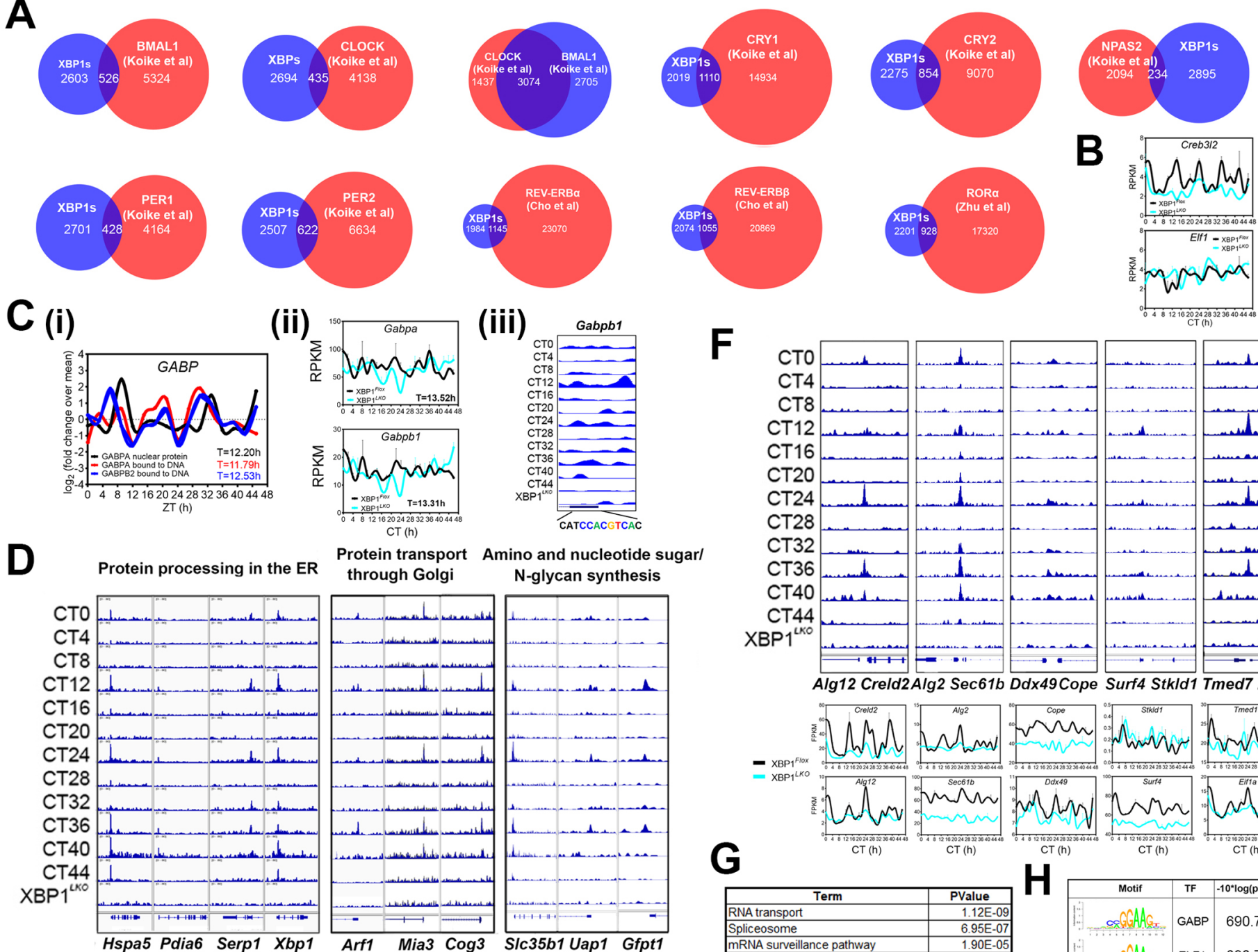

Protein transport Amino and nucleotide sugar

E
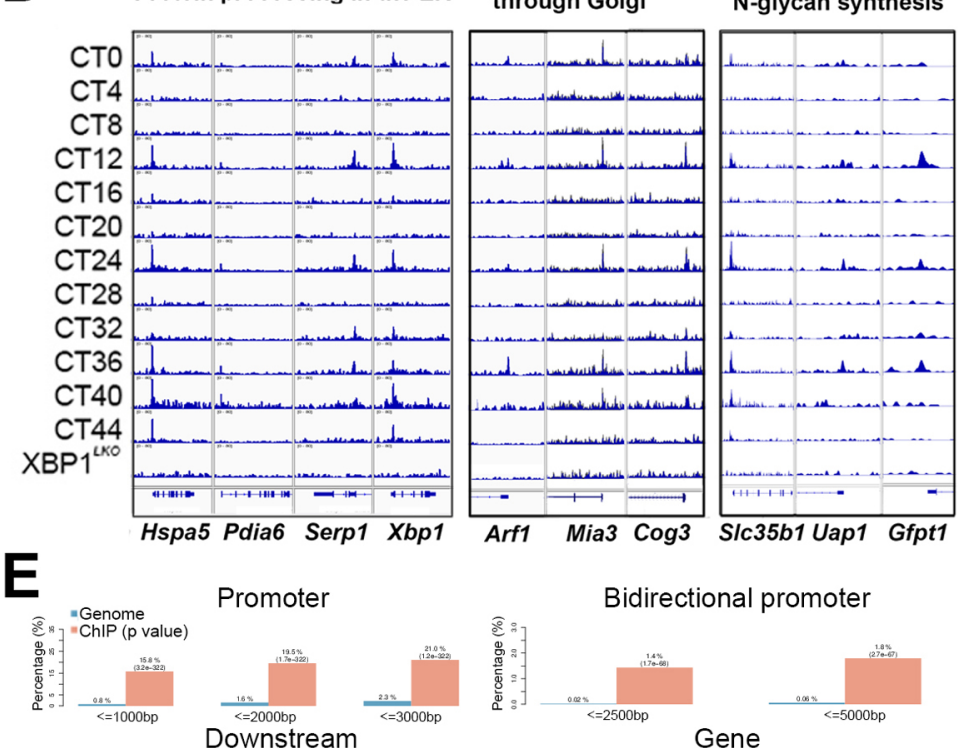

Promoter

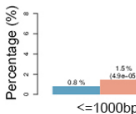
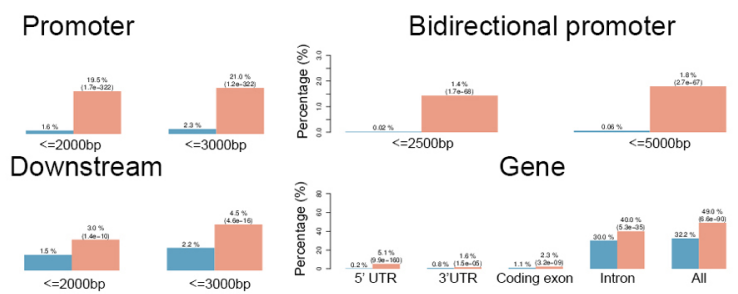

J
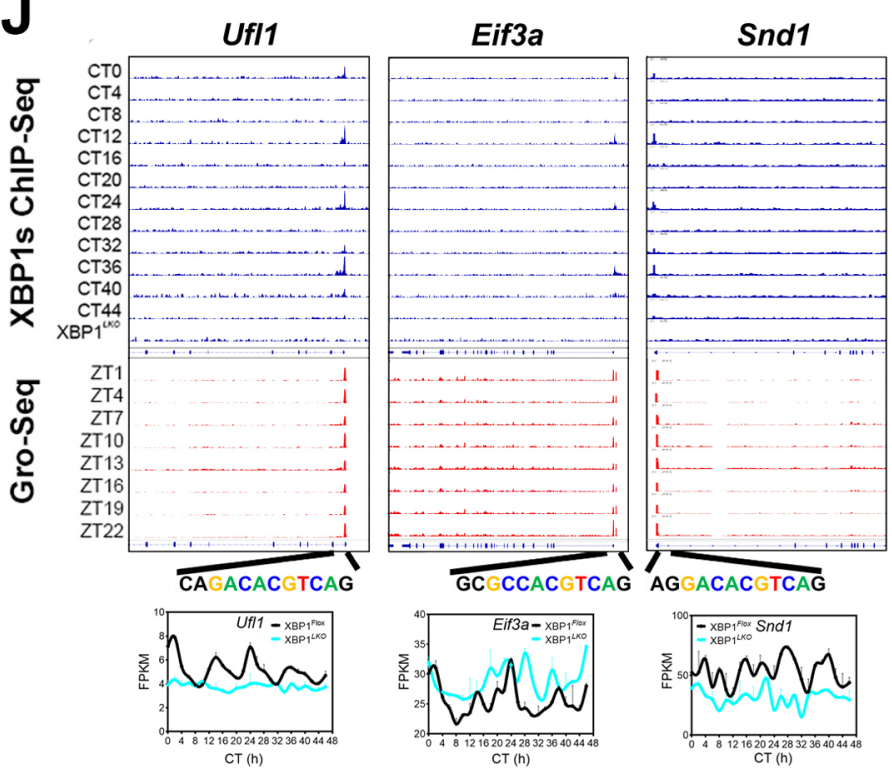

\section{,}

$F$

G
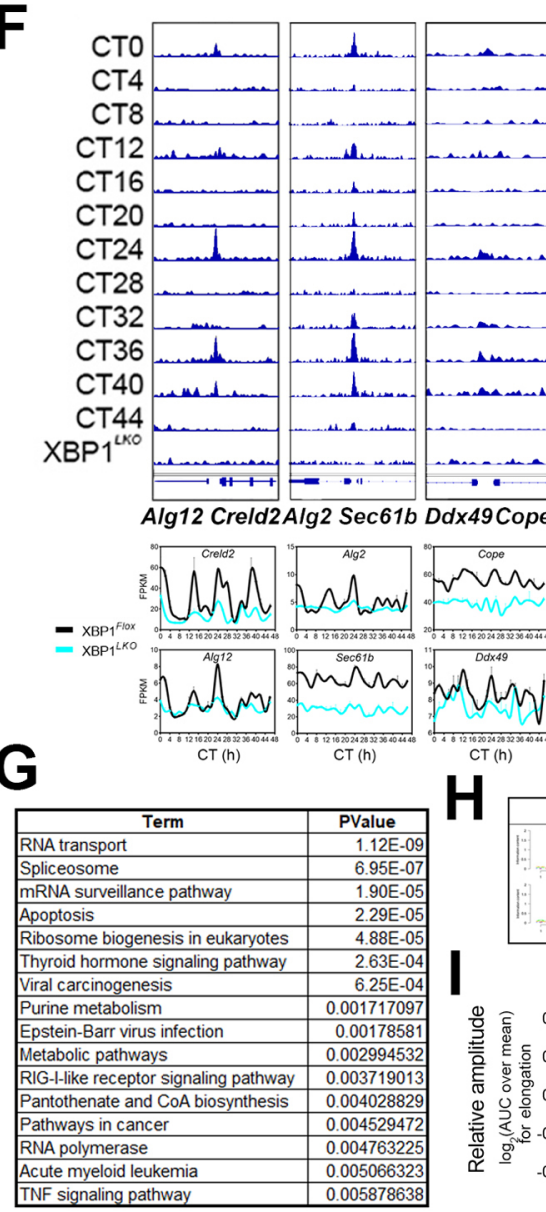

Alg12 Creld2Alg2 Sec61b Ddx49Cope Surf4 Stkld1 Tmed7 Eif1a
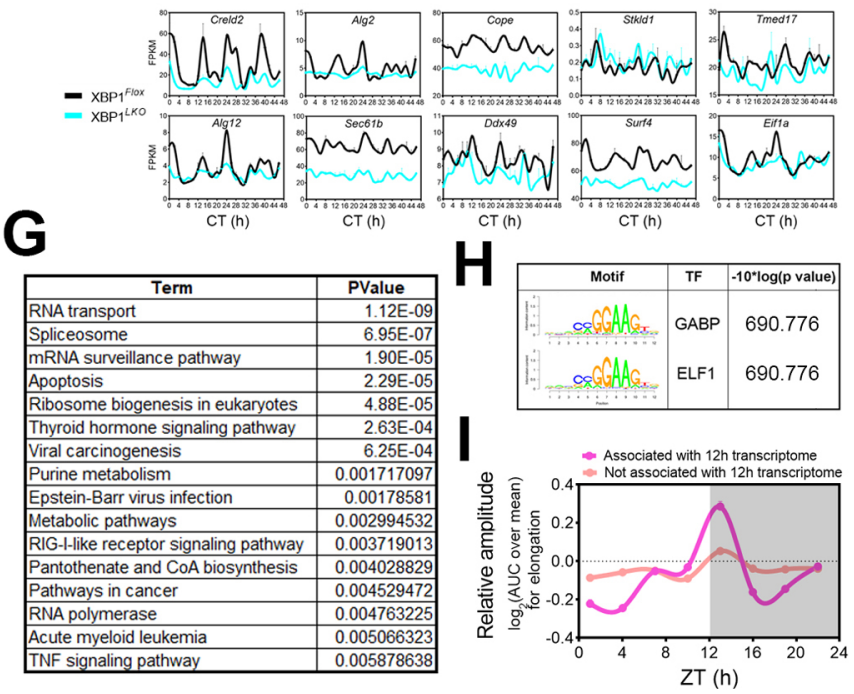

RNA-Seq
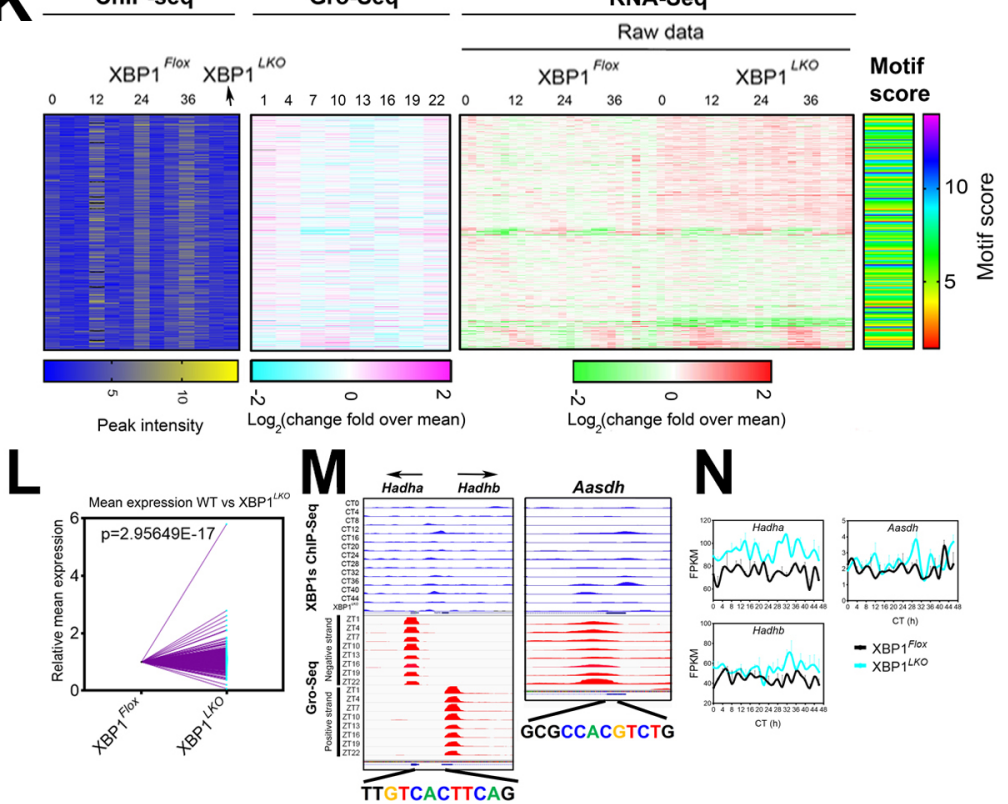

$\mathbf{N}$

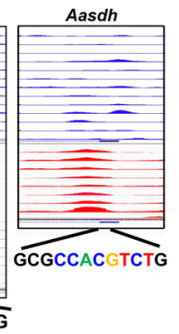

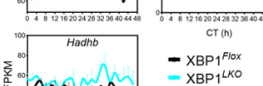

Aasdon 
bioRxiv preprint doi: https://doi.org/10.1101/559039; this version posted March 8, 2019. The copyright holder for this preprint (which was not

Figure S7.

A

C. rota (absolute time)

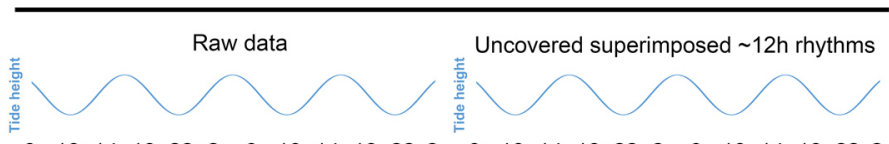

$\begin{array}{llllllllllllllllllllllll}6 & 10 & 14 & 18 & 22 & 2 & 6 & 10 & 14 & 18 & 22 & 2 & 6 & 10 & 14 & 18 & 22 & 2 & 6 & 10 & 14 & 18 & 22 & 2\end{array}$

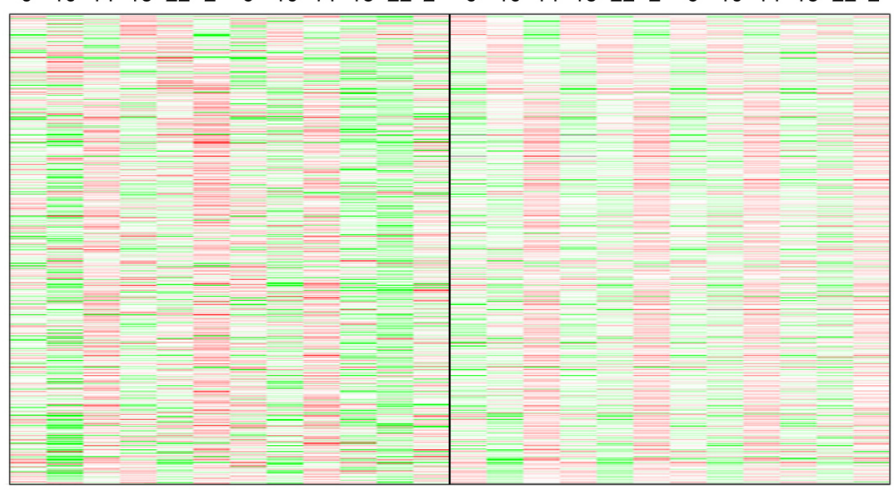

B

Ubiquitin-mediated proteolysis

Protein sorting through Golgi

Transcription regulation

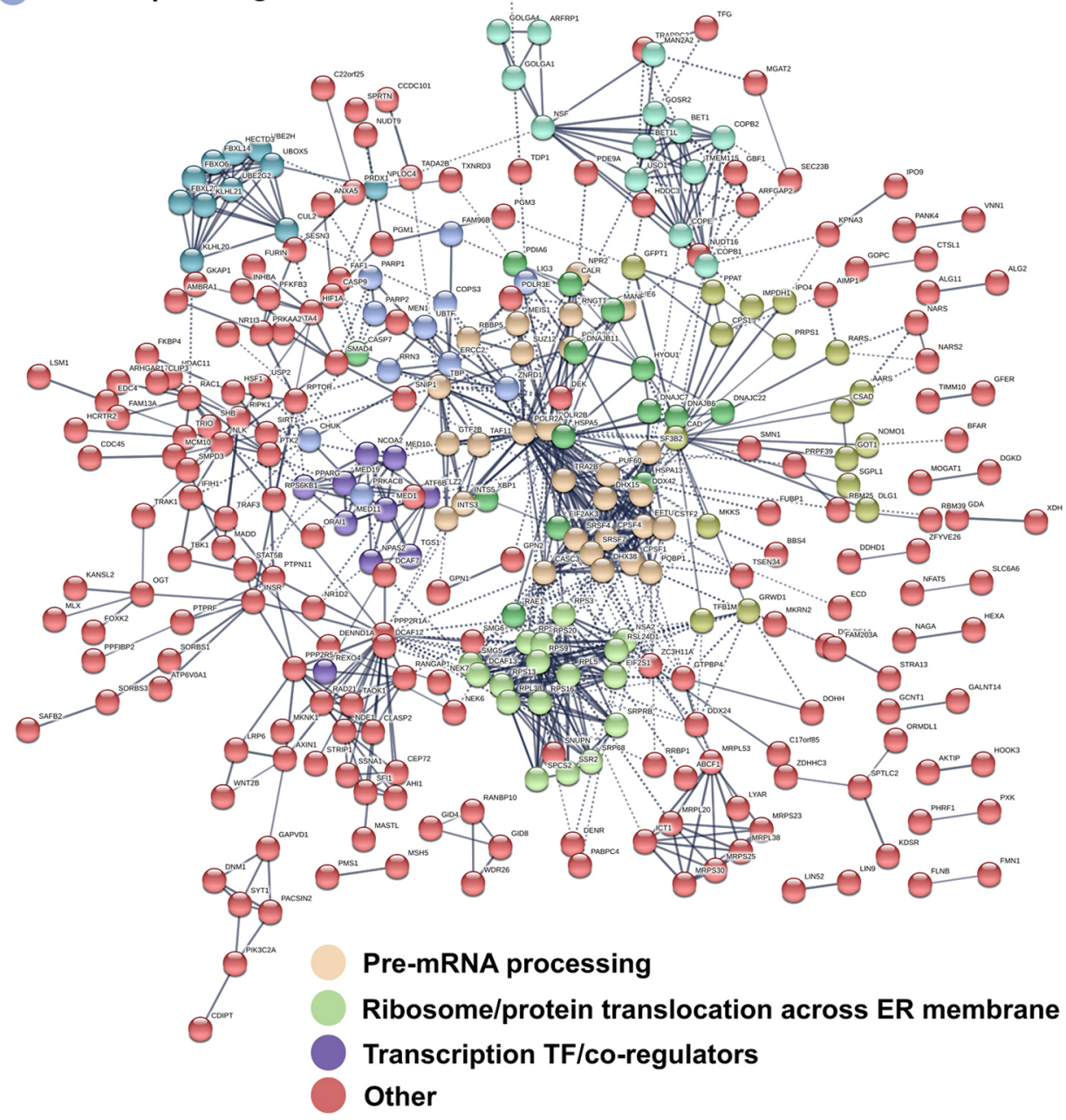

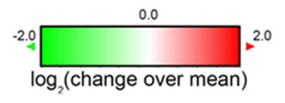

M. musculus (CT)

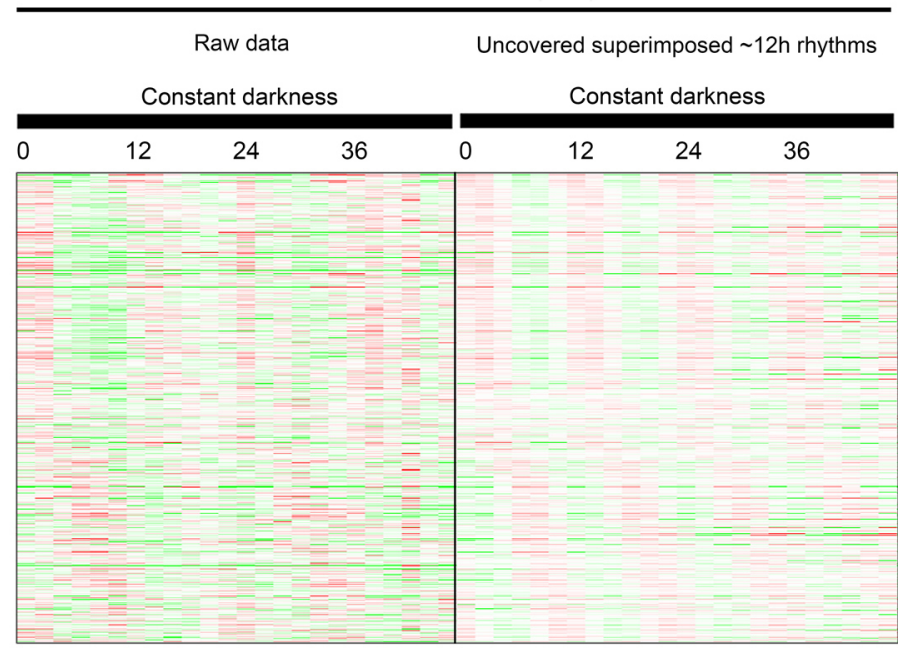

C

AA/Nucleotide metabolism

Protein folding/UPR

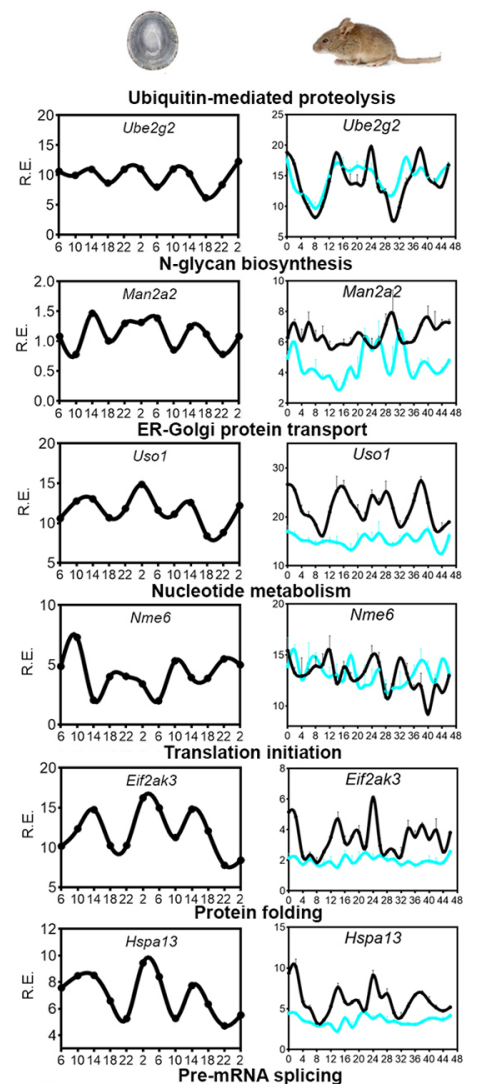

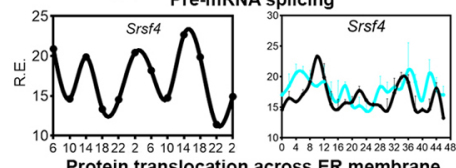
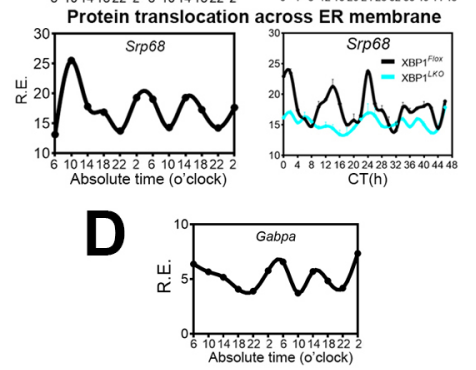